\title{
Challenges in smoking cessation for people with chronic obstructive pulmonary disease
}

Citation for published version (APA):

van Eerd, E. A. M. (2017). Challenges in smoking cessation for people with chronic obstructive pulmonary disease. [Doctoral Thesis, Maastricht University]. Maastricht University.

https://doi.org/10.26481/dis.20170614eve

Document status and date:

Published: 01/01/2017

DOI:

10.26481/dis.20170614eve

Document Version:

Publisher's PDF, also known as Version of record

\section{Please check the document version of this publication:}

- A submitted manuscript is the version of the article upon submission and before peer-review. There can be important differences between the submitted version and the official published version of record.

People interested in the research are advised to contact the author for the final version of the publication, or visit the DOI to the publisher's website.

- The final author version and the galley proof are versions of the publication after peer review.

- The final published version features the final layout of the paper including the volume, issue and page numbers.

Link to publication

\footnotetext{
General rights rights.

- You may freely distribute the URL identifying the publication in the public portal. please follow below link for the End User Agreement:

www.umlib.nl/taverne-license

Take down policy

If you believe that this document breaches copyright please contact us at:

repository@maastrichtuniversity.nl

providing details and we will investigate your claim.
}

Copyright and moral rights for the publications made accessible in the public portal are retained by the authors and/or other copyright owners and it is a condition of accessing publications that users recognise and abide by the legal requirements associated with these

- Users may download and print one copy of any publication from the public portal for the purpose of private study or research.

- You may not further distribute the material or use it for any profit-making activity or commercial gain

If the publication is distributed under the terms of Article $25 \mathrm{fa}$ of the Dutch Copyright Act, indicated by the "Taverne" license above, 


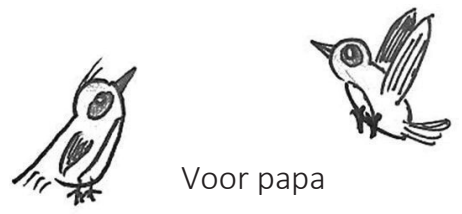


The work presented in this dissertation was supported by the SBOH, employer of GP trainees

\section{SBCHK}

voor ortsen in opleiding

From 2012-2013 the research was supported by funding from the Lung Foundation Netherlands (Longfonds).

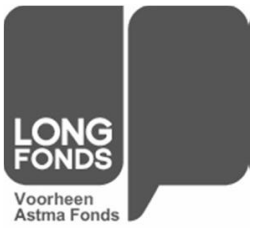

\section{Colophon}

Cover design: Godelieve Steendijk-van Eerd

Lay-out: $\quad$ Eva van Eerd

Printed by: Gildeprint

ISBN: $\quad$ 978-94-6233-628-5

(C) Eva A.M. van Eerd, Maastricht 2017

The research presented in this dissertation was conducted at the Care and Public Health Research Institute (CAPHRI), Department of Family Medicine, Maastricht University. CAPHRI participates in the Netherlands School of Primary Care Research (CaRe), acknowledged by the Royal Dutch Academy of Science (KNAW).

All rights are reserved. No part of this book may be reproduced or transmitted in any form or by any means, without the written permission from the author or, where appropriate, the publisher of the article. 


\title{
Challenges in smoking cessation for people with chronic obstructive pulmonary disease
}

\author{
PROEFSCHRIFT \\ Ter verkrijging van de graad van doctor \\ aan de Universiteit Maastricht, \\ op gezag van de Rector Magnificus, prof. dr. Rianne M. Letschert, \\ volgens het besluit van het College van Decanen, \\ in het openbaar te verdedigen op \\ woensdag 14 juni 2017 om 14.00 uur
}

door

Eva Anne Marije van Eerd 


\section{Promotores}

Prof. dr. D. Kotz, Heinrich-Heine-University Düsseldorf

Prof. dr. C.P. van Schayck

\section{Beoordelingscommissie}

Prof. dr. J.W.M. Muris (voorzitter)

Prof. dr. P.N.R. Dekhuijzen, Radboudumc Nijmegen

Dr. A. Moser

Dr. G.G.U. Rohde

Prof. dr. C. van Weel, Radboudumc Nijmegen 
$\begin{array}{lll}\text { Chapter } 1 & \text { General introduction } & 7\end{array}$

Chapter 2 Smoking cessation for people with chronic obstructive $\quad 15$ pulmonary disease: a systematic review Cochrane Database Syst Rev. 2016 Aug 20;(8):CD010744

Chapter 3 Do we need tailored smoking cessation interventions for 59 smokers with COPD? A comparative study of smokers with and without COPD regarding factors associated with tobacco smoking Respiration 2015;90(3):211-9

Chapter 4 Experiences of tobacco smoking and quitting in smokers with and without chronic obstructive pulmonary disease - a qualitative analysis

BMC Fam Pract. 2015 Nov 4;16:164

Chapter 5 Predictors of long-term smoking cessation in patients with COPD: results from a randomised controlled trial Accepted as research letter in Eur Respir J

Chapter 6 Why do physicians lack engagement with smoking cessation treatment in their COPD patients? A multinational qualitative study

Accepted for publication in npj Primary Care Respiratory Medicine

Chapter 7 General discussion

Summary

Samenvatting 169

Valorisation

Dankwoord

Curriculum vitae

Publications 195 

Chapter 1

General introduction

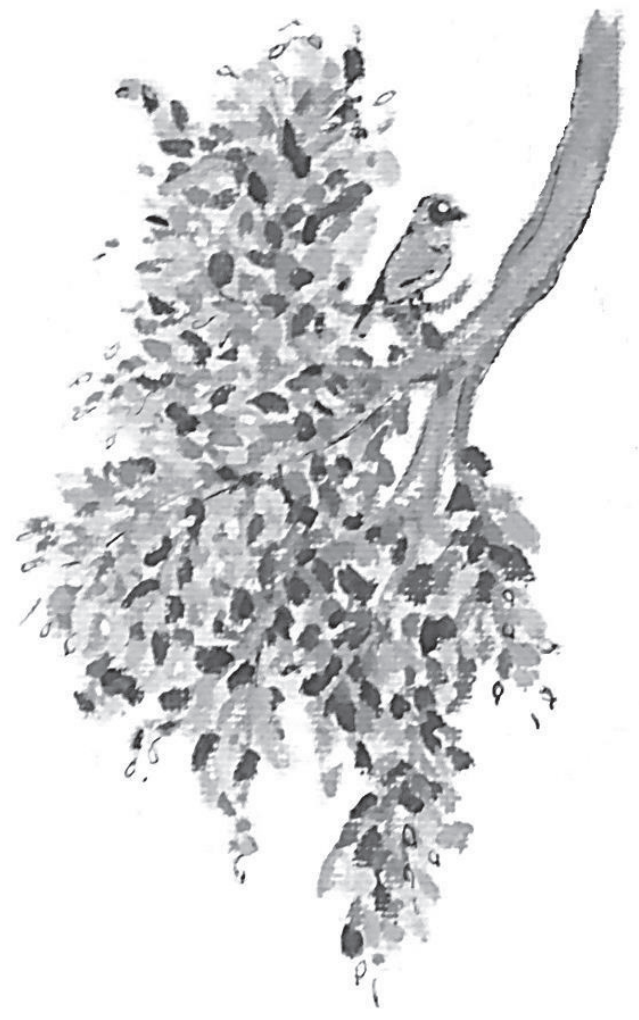





\section{General introduction}

Chronic obstructive pulmonary disease (COPD) is a common and preventable disease characterised by persistent airflow limitation and an enhanced chronic inflammatory response in the airways and the lung ${ }^{1}$. COPD holds a leading position in morbidity and mortality worldwide ${ }^{1}$. In the Netherlands, over 596,000 people have COPD ${ }^{2}$. Almost 6,000 people died in the Netherlands in 2014 with COPD as the primary cause ${ }^{2}$. Furthermore, the emotional and physical health consequences of COPD are a huge burden to the health care system. Combined with asthma, COPD accounts for more than 1.5 billion euros per year in the Netherlands ${ }^{2}$.

The risk for developing COPD results from an interaction between genetic factors and many different environmental exposures ${ }^{3}$. Tobacco smoking is the most important risk factor for developing COPD in high-income countries ${ }^{1}$. In the Netherlands, $85 \%$ of new COPD cases is attributed to smoking ${ }^{2}$. Besides, smoking has a detrimental effect on the course of this disease ${ }^{1}$. An overview of the literature showed that the forced expiratory volume in one second in male smokers with mild to moderate COPD declines within a range of 42 to $82 \mathrm{~mL} / \mathrm{y}$ compared with 0 to $49 \mathrm{~mL} / \mathrm{y}$ in males with COPD who quit smoking ${ }^{4}$. Smoking cessation is the only evidence-based intervention that reduces the risk of developing COPD and slows the accelerated decline in lung function ${ }^{1,5}$.

Several smoking cessation interventions have been developed to support smokers when quitting. To find out whether and which interventions are successful in smokers with COPD we conducted a Cochrane review on smoking cessation interventions directed at these patients ${ }^{6}$. We noticed that no COPD-specific smoking cessation interventions exist. Just as for other smokers we concluded that for smokers with COPD a combination of behavioural and pharmacological treatments is superior to any other treatment separately ${ }^{6}$. Despite the availability of these evidence-based interventions, the prevalence of smoking in patients with COPD is still high and exceeds the rate of smoking in the general population ${ }^{7}$. There is only limited evidence that patients get motivated to quit on receiving a diagnosis of $\operatorname{COPD}^{8,9}$. Many still continue smoking, and do not use evidence-based smoking cessation interventions. We think that COPD specific patient- and physician-related factors influence the use and effectiveness of smoking cessation treatments. In order to stimulate smoking cessation and the use of these interventions in this particular group of patients, we aimed in this dissertation to 
get a better understanding of these underlying patient- and physician-related factors connected to quitting.

\section{Patient-related factors associated with quitting}

We considered different reasons why smokers with COPD do not successfully quit smoking. The higher prevalence of smoking among COPD patients suggests that, compared with smokers from the general population, smokers with COPD find it more difficult to quit smoking. Their chances of quitting might partly be reduced because of a higher tobacco consumption and its concomitant higher level of nicotine dependence $^{10}$. Patients with COPD are also more susceptible to develop depressive symptoms ${ }^{11}$. Other studies did not find smokers with and without COPD to be different on smoking related characteristics ${ }^{12}$. This makes us still grope in the dark about important COPD specific characteristics regarding the use of smoking cessation interventions. We also lack qualitative data on experiences of smokers with COPD regarding smoking cessation and the use of interventions. Consequently, it remains difficult to design a smoking cessation intervention tailored to COPD patients' characteristics and needs. Therefore, we explored differences between smokers with and without COPD on factors associated with smoking and quitting and the patients' experiences herewith.

Furthermore, we wanted to identify COPD-specific predictors of successful quitting. Identifying these predictors will help us better understand reasons why smoking cessation interventions are not very successful in this group of smokers. We know from the literature that high nicotine dependence ${ }^{13-15}$ and high levels of psychological distress $^{14,16}$ predict relapse in the general smoking population. A few studies also described predictors for relapse in smokers with COPD. Demographic factors, such as being younger ${ }^{17-19}$, having a lower income ${ }^{17,18}$ and living alone ${ }^{18}$, predicted relapse in smokers with COPD. Regarding clinical symptoms, patients were less likely to quit if they had milder COPD symptoms or were less impaired due to these symptoms ${ }^{17,} 18$. Better mental health was related to high success rates for quitting ${ }^{15,}$. If . we gain further insight into these predictors we can address this information in tailored smoking cessation interventions.

\section{Physician-related factors associated with quitting}


In the end physicians decide how evidence-based smoking cessation interventions are used in daily practice. Therefore, physicians play a very important role in providing different smoking cessation treatments to patients with COPD. However, literature shows that they do not routinely deal with smoking cessation in their consultations with smokers ${ }^{20-22}$. According to a large European review several factors seem to influence physicians' engagement in smoking cessation: attitude, cessation-specific knowledge and skills, time and reimbursement ${ }^{22}$. A different review found that physicians had negative thoughts about smoking cessation interventions as they considered it time-consuming and ineffective, and they lacked confidence in their ability to discuss smoking cessation with their patients ${ }^{23}$. Studies exploring experiences with COPD care in general reported similar barriers ${ }^{24,25}$. Furthermore, they showed that patient-related factors such as being non-compliant and not taking responsibility for their condition were barriers for doctors to carry out COPD care ${ }^{26,27}$. We wanted to get more insight into physicians' experienced problems in providing smoking cessation treatment in primary care. By addressing these problems we aim at increasing engagement in evidence-based smoking cessation treatments.

In conclusion, smoking cessation interventions are currently not tailored specifically to the needs of COPD patients, and physicians do not sufficiently seem to engage in existing smoking cessation treatments for their patients with COPD. There are suggestions from the literature that COPD patients face specific problems and have different needs regarding smoking cessation. In this thesis we try to gain more clarity on these different problems and needs. If we address these in tailored smoking cessation interventions for patients with COPD, the effectiveness of these interventions will increase and more patients with COPD will successfully quit smoking.

\section{Outline of the thesis}

In Chapter 2 we systematically describe in a Cochrane review which smoking cessation interventions are currently available and effective for smokers with COPD. In Chapter 3 and 4 we show the results of two studies comparing smokers with and without COPD on factors associated with smoking and quitting. In Chapter 3 we describe the quantitative results from a cross-sectional study, showing that smokers with COPD have different smoking related characteristics. In Chapter 4 we report qualitative results obtained from interviews on COPD specific thoughts and emotions concerning smoking and smoking cessation. In Chapter 5 we show the outcomes of a secondary 
analysis which was done in order to identify baseline predictors of long-term cessation in smokers with COPD who participated in a randomised controlled trial. In Chapter 6 we describe the results of a secondary analysis on focus group discussions about exacerbation management in patients with COPD. In this analysis we assessed physicians' experienced difficulties and potential solutions regarding the smoking of their COPD patients and the effectiveness of smoking cessation treatments. In the general discussion in Chapter 7 the main results and conclusions of the studies are described, and implications for daily practice and future research are discussed. 


\section{References}

1. From the Global Strategy for the Diagnosis, Management and Prevention of COPD, Global Initiative for Chronic Obstructive Lung Disease (GOLD) 2017. http://goldcopd.org. Accessed 17 November 2015.

2. Volksgezondheidenzorg.info. www.volksgezondheidenzorg.info. RIVM: Bilthoven. Accessed 8 November 2016.

3. Mannino D.M., Buist A.S. Global burden of COPD: risk factors, prevalence, and future trends. Lancet. 370, 765-773 (2007).

4. Willemse B.W., Postma D.S., Timens W., ten Hacken N.H. The impact of smoking cessation on respiratory symptoms, lung function, airway hyperresponsiveness and inflammation. Eur Respir J. 23, 464-476 (2004).

5. Anthonisen N.R., Connett J.E., Murray R.P. Smoking and lung function of Lung Health Study participants after 11 years. Am J Respir Crit Care Med. 166, 675-679 (2002).

6. van Eerd E.A., van der Meer R.M., van Schayck O.C., Kotz D. Smoking cessation for people with chronic obstructive pulmonary disease. Cochrane Database Syst Rev. CD010744 (2016).

7. Shahab L., Jarvis M.J., Britton J., West R. Prevalence, diagnosis and relation to tobacco dependence of chronic obstructive pulmonary disease in a nationally representative population sample. Thorax. 61, 1043-1047 (2006).

8. Danielsen S.E., Lochen M.L., Medbo A., Vold M.L., Melbye H. A new diagnosis of asthma or COPD is linked to smoking cessation - the Tromso study. Int I Chron Obstruct Pulmon Dis. 11, 1453-1458 (2016).

9. Kotz D., Wesseling G., Huibers M.J., van Schayck O.C. Efficacy of confronting smokers with airflow limitation for smoking cessation. Eur Respir J. 33, 754-762 (2009).

10. Jimenez-Ruiz C.A., Masa F., Miravitlles M., Gabriel R., Viejo J.L., Villasante C., et al. Smoking characteristics: differences in attitudes and dependence between healthy smokers and smokers with COPD. Chest. 119, 1365-1370 (2001).

11. Tashkin D.P., Murray R.P. Smoking cessation in chronic obstructive pulmonary disease. Respir Med. 103, 963-974 (2009).

12. Vozoris N.T., Stanbrook M.B. Smoking prevalence, behaviours, and cessation among individuals with COPD or asthma. Respir Med. 105, 477-484 (2011).

13. Vangeli E., Stapleton J., Smit E.S., Borland R., West R. Predictors of attempts to stop smoking and their success in adult general population samples: a systematic review. Addiction. 106, 2110-2121 (2011).

14. Cosci F., Corlando A., Fornai E., Pistelli F., Paoletti P., Carrozzi L. Nicotine dependence, psychological distress and personality traits as possible predictors of smoking cessation. Results of a double-blind study with nicotine patch. Addict Behav. 34, 28-35 (2009).

15. Kupiainen H., Kinnula V.L., Lindqvist A., Postma D.S., Boezen H.M., Laitinen T., et al. Successful Smoking Cessation in COPD: Association with Comorbidities and Mortality. Pulm Med. 2012, 725024 (2012).

16. Augustson E.M., Wanke K.L., Rogers S., Bergen A.W., Chatterjee N., Synder K., et al. Predictors of sustained smoking cessation: a prospective analysis of chronic smokers from the alpha-tocopherol Beta-carotene cancer prevention study. Am J Public Health. 98, 549-555 (2008).

17. Schiller J.S., Ni H. Cigarette smoking and smoking cessation among persons with chronic obstructive pulmonary disease. Am J Health Promot. 20, 319-323 (2006). 
18. Tottenborg S.S., Thomsen R.W., Johnsen S.P., Nielsen H., Lange P. Determinants of Smoking Cessation in Patients With COPD Treated in the Outpatient Setting. Chest. 150, 554-562 (2016).

19. Adams S.G., Pugh J.A., Kazis L.E., Lee S., Anzueto A. Characteristics associated with sustained abstinence from smoking among patients with COPD. Am J Med. 119, 441447 (2006).

20. Coleman T., Wynn A., Barrett S., Wilson A. Discussion of NRT and other antismoking interventions in UK general practitioners' routine consultations. Nicotine Tob Res. 5, 163-168 (2003).

21. Ellerbeck E.F., Ahluwalia J.S., Jolicoeur D.G., Gladden J., Mosier M.C. Direct observation of smoking cessation activities in primary care practice. J Fam Pract. 50, 688-693 (2001).

22. Stead M., Angus K., Holme I., Cohen D., Tait G. Factors influencing European GPs' engagement in smoking cessation: a multi-country literature review. Br J Gen Pract. 59, 682-690 (2009).

23. Vogt F., Hall S., Marteau T.M. General practitioners' and family physicians' negative beliefs and attitudes towards discussing smoking cessation with patients: a systematic review. Addiction. 100, 1423-1431 (2005).

24. Salinas G.D., Williamson J.C., Kalhan R., Thomashow B., Scheckermann J.L., Walsh J., et al. Barriers to adherence to chronic obstructive pulmonary disease guidelines by primary care physicians. Int J Chron Obstruct Pulmon Dis. 6, 171-179 (2011).

25. Perez X., Wisnivesky J.P., Lurslurchachai L., Kleinman L.C., Kronish I.M. Barriers to adherence to COPD guidelines among primary care providers. Respir Med. 106, 374381 (2012).

26. Johnston K.N., Young M., Grimmer-Somers K.A., Antic R., Frith P.A. Why are some evidence-based care recommendations in chronic obstructive pulmonary disease better implemented than others? Perspectives of medical practitioners. Int J Chron Obstruct Pulmon Dis. 6, 659-667 (2011).

27. Risor M.B., Spigt M., Iversen R., Godycki-Cwirko M., Francis N., Altiner A., et al. The complexity of managing COPD exacerbations: a grounded theory study of European general practice. BMJ Open. 3, (2013). 
Chapter 2

\section{Smoking cessation for people with chronic obstructive pulmonary disease: a systematic review}

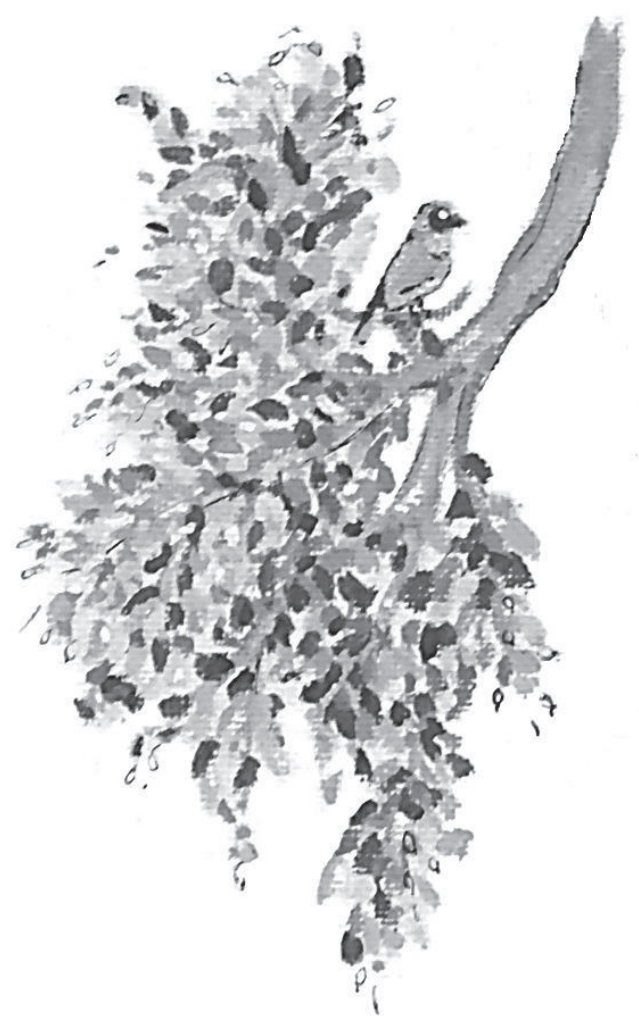

Eva van Eerd Regina van der Meer Onno van Schayck

Daniel Kotz

Published as full Cochrane review Cochrane Database of Systematic Reviews 2016 Aug 20;(8):CD010744 


\section{Abstract}

\section{Background}

Smoking cessation is the most important treatment for smokers with chronic obstructive pulmonary disease (COPD), but little is known about the effectiveness of different smoking cessation interventions for this particular group of smokers.

\section{Objectives}

To evaluate the effectiveness of behavioural or pharmacological smoking cessation interventions, or both, in smokers with COPD.

\section{Search methods}

We searched all records in the Cochrane Airways Group Specialised Register of Trials. In addition to this electronic search, we searched clinical trial registries for planned, ongoing, and unpublished trials. We searched all databases from their inception. We checked the reference lists of all included studies and of other systematic reviews in relevant topic areas. We searched for errata or retractions from eligible trials on PubMed. We conducted our most recent search in March 2016.

\section{Selection criteria}

We included randomised controlled trials assessing the effectiveness of any behavioural or pharmacological treatment, or both, in smokers with COPD reporting at least six months of follow-up abstinence rates.

\section{Data collection and analysis}

Two review authors independently extracted the data and performed the methodological quality assessment for each study. We resolved any disagreements by consensus.

\section{Main results}

We included 16 studies (involving 13,123 participants) in this systematic review, two of which were of high quality. These two studies showed that nicotine sublingual tablet and varenicline increased the quit rate over placebo (risk ratio (RR) 2.60 (95\% 
confidence interval (CI) 1.29 to 5.24) and RR 3.34 (95\% Cl 1.88 to 5.92)). Pooled results of two studies also showed a positive effect of bupropion compared with placebo (RR 2.03 (95\% Cl 1.26 to 3.28)). When pooling these four studies, we found high-quality evidence for the effectiveness of pharmacotherapy plus high-intensity behavioural treatment compared with placebo plus high-intensity behavioural treatment (RR 2.53 (95\% Cl 1.83 to 3.50)). Furthermore, we found some evidence that high-intensity behavioural treatment increased abstinence rates when compared with usual care (RR 25.38 (95\% Cl 8.03 to 80.22$)$ ) or low-intensity behavioural treatment (RR 2.18 (95\% Cl 1.05 to 4.49)). Finally, the results showed effectiveness of various combinations of psychosocial and pharmacological interventions.

\section{Authors' conclusions}

We found high-quality evidence in a meta-analysis including four (1,540 participants) of the 16 included studies that a combination of behavioural treatment and pharmacotherapy is effective in helping smokers with COPD to quit smoking. Furthermore, we conclude that there is no convincing evidence for preferring any particular form of behavioural or pharmacological treatment. 



\section{Background}

\section{Description of the condition}

Chronic obstructive pulmonary disease (COPD), a common and largely preventable disease, is characterised by persistent airflow limitation that is usually progressive and associated with an enhanced chronic inflammatory response to noxious particles in the airways and the lung ${ }^{1}$. Exacerbations and comorbidities contribute to the overall severity in individual patients. The diagnosis must be confirmed by spirometry, the most widely available reproducible test of lung function ${ }^{1}$.

COPD prevalence, morbidity, and mortality vary across countries and across different groups within countries ${ }^{1}$. For example, a worldwide study showed that the prevalence of moderate COPD (that is Global Initiative for Chronic Obstructive Lung Disease (GOLD) stage II) in women 40 years of age or older ranged from $3.1 \%$ to $12.6 \%$, and in men from $6.7 \%$ to $13.1 \%^{2}$. This variation in prevalence is partly due to differences in pack-years of smoking history. The odds ratio of COPD per 10-year interval of packyears of smoking is 1.28 (95\% confidence interval $(\mathrm{Cl}) 1.15$ to 1.42 ) among women and 1.16 (95\% Cl 1.12 to 1.21 ) among men ${ }^{2}$. Except for differences in exposure to risk factors, COPD prevalence variation is due to differences in diagnostic criteria, survey methods, and analytical approaches. Under-recognition and underdiagnosis of COPD also affects the accuracy of prevalence and mortality data. In a large-scale English study, the prevalence of COPD was highest among current smokers (19.3\%), followed by ex-smokers (15.2\%) and never smokers $(8.2 \%)^{3}$. Furthermore, the prevalence of undetected COPD was high among asymptomatic smokers. The prevalence of previously undiagnosed COPD in male smokers 40 years of age or older ranged from $12 \%$ in a Greek research population ${ }^{4}$, to $30 \%$ in a Dutch research population ${ }^{5}$. The Global Burden of Disease Study projected that COPD will become the third-leading cause of death worldwide by $2020^{1}$. This increased mortality is driven mainly by the expanding epidemic of tobacco smoking, reduced mortality from other common causes of death, and aging of the world population ${ }^{1}$.

The risk for developing COPD results from an interaction between genetic factors and many different environmental exposures ${ }^{6}$. Cigarette smoking is the most commonly encountered risk factor for COPD in high-income countries ${ }^{1,7,8}$. Furthermore, a higher prevalence of respiratory symptoms and lung function abnormalities and a higher 
COPD mortality rate are seen among cigarette smokers with COPD than non-smokers with COPD ${ }^{1}$. For example, an overview of the literature showed the effect of smoking on forced expiratory volume in one second (FEV1) in males with mild to moderate COPD $^{9}$. The FEV1 of participants who continued to smoke declined within a range of 42 to $82 \mathrm{~mL}$ per year compared with 0 to $49 \mathrm{~mL}$ per year in participants who quit smoking at the start of the study ${ }^{9}$. The latter decline is comparable with the physiological lung function decline that occurs naturally with increasing age ${ }^{10}$.

Smoking cessation is the only evidence-based intervention that reduces the risk of developing COPD and slows the accelerated decline in lung function in people with COPD $^{11}$. To date, none of the existing medications for COPD have been conclusively shown to modify the long-term decline in lung function ${ }^{1}$. Furthermore, smoking cessation is the single most cost-effective way to reduce the risk of development of COPD and worsening of the disease ${ }^{1}$.

\section{Description of the intervention}

For the current review, we included randomised controlled trials that assessed the effectiveness of any form of behavioural or pharmacological treatment, or combinations of both, as an aid to smoking cessation in people with COPD. Behavioural treatment refers to any psychotherapeutic approach aimed at identifying and modifying the behaviours associated with smoking ${ }^{12}$. Pharmacological treatments included nicotine replacement therapy (NRT), antidepressants for smoking cessation, nicotine receptor partial agonists, and nicotine vaccines. The following NRT delivery systems are currently available: nicotine chewing gum, nicotine inhaler, nicotine lozenge, nicotine patch, and nicotine sprays. Bupropion is the most commonly used antidepressant, as nortriptyline is not registered as a smoking cessation aid and is rarely used now. Varenicline is the most commonly used nicotine receptor partial agonist. Vaccines are not currently licensed for public use, although several vaccines are under development. A smoking cessation intervention is often a combination of a pharmacological and a behavioural treatment.

\section{How the intervention might work}

Smoking is an addictive behaviour. The chances of successful smoking cessation are therefore reduced without the use of behavioural or pharmacological treatments, or both. In the general smoking population, several behavioural and pharmacological 
treatments have demonstrated efficacy in helping to achieve abstinence. For example, the antidepressants nortriptyline and bupropion aid long-term smoking cessation, and evidence suggests that the mode of action is independent of their antidepressant effects ${ }^{13}$. Their efficacy is similar to that of $\mathrm{NRT}^{14}$. A review of nicotine receptor partial agonists showed that varenicline increased the chances of successful long-term smoking cessation compared with bupropion ${ }^{15}$. Comparison of NRT and varenicline suggested a minor benefit of varenicline tending towards equivalency ${ }^{15}$. Furthermore, a recent review showed the nicotine receptor partial agonist cytisine to be an effective treatment for smoking cessation ${ }^{16}$. Interventions that combine behavioural and pharmacological treatments are even more successful in achieving abstinence ${ }^{17}$. Providing behavioural treatment in person or via telephone for people using pharmacotherapy to stop smoking showed a small but important effect ${ }^{17}$. However, these studies did not make a distinction between different kinds of smokers, even though there is some evidence that smokers with COPD are different from smokers without COPD. Jimenez-Ruiz et al. ${ }^{18}$ showed that smokers with COPD have more packyears of smoking history, stronger dependence on cigarettes, and use particular inhalation patterns while smoking. Furthermore, findings of a recent study endorsed the higher cigarette dependence in smokers with COPD and suggested that smokers with COPD have higher levels of depression and lower self-efficacy to refrain from smoking $^{19}$. This suggests that smokers are not a homogeneous group. It is therefore important to make the intervention fit best for each specific group, such as people with $\operatorname{COPD}^{20}$, for example by giving valuable and clear information on how smoking is related to COPD and to respiratory symptoms. It might also be useful to specifically address the increased comorbidities and cigarette dependence levels reported in people with COPD.

\section{Why it is important to do this review}

Smoking cessation is the most important intervention to reduce the risk of developing COPD and to improve the prognosis of people with the disease. People with COPD have a more urgent need to stop smoking than the average smoker; moreover, many often find it more difficult to do so $^{21}$. It is therefore important to provide an overview of the evidence base for different smoking cessation interventions directed at these patients.

Compared with smokers from the general population, smokers with COPD might have more difficulty quitting smoking because of their higher number of pack-years of 
smoking history, stronger dependence on nicotine, higher levels of depression, and a lower self-efficacy to refrain from smoking ${ }^{3,18,19}$. A Dutch study showed that smokers with mild to severe COPD were less likely to achieve abstinence than smokers without COPD; the prolonged abstinence rate after six months with nortriptyline therapy was $21 \%$ in smokers with COPD compared with $32 \%$ in smokers without COPD ${ }^{22}$. However, that study did not control for baseline differences. Interventions aimed at smokers with COPD therefore might need to be tailored more specifically to the needs of people with COPD to increase their desire to stop and to address their increased levels of nicotine dependence and depression and their lower self-efficacy ${ }^{3,19}$. However, evidence for the effectiveness of tailored versus general smoking cessation interventions in this patient group is scarce.

The scope of this updated review was the same as the original Cochrane review: to review the evidence 'whether and which treatments are effective in smokers with $\mathrm{COPD}^{\prime 23}$. However, results may have changed because new trials on this subject have been published since 2003.

\section{Objectives}

To evaluate the effectiveness of behavioural or pharmacological smoking cessation interventions, or both, in smokers with COPD.

\section{Methods}

\section{Criteria for considering studies for this review}

\section{Types of studies}

We examined randomised controlled trials.

\section{Types of participants}

We included smokers with a diagnosis of COPD, according to criteria from the guidelines of the American Thoracic Society (ATS) ${ }^{24}$, the British Thoracic Society (BTS) ${ }^{25}$, or GOLD ${ }^{1}$, or as confirmed by the treating physician.

\section{Types of interventions}

We included randomised controlled trials that assessed the effectiveness of any behavioural or pharmacological treatment, or both, as an aid to smoking cessation in 
participants with COPD. We categorised behavioural treatment as 'high' if more than one pre-scheduled counselling session of greater than 10 minutes was offered with at least one face-to-face counselling session ${ }^{12}$. Otherwise we categorised the behavioural treatment as 'low'.

We included the following comparisons.

- Behavioural treatment versus no treatment or usual care.

- One form of behavioural treatment versus a different form of behavioural treatment.

- Pharmacological treatment versus placebo.

- Pharmacological treatment versus a different pharmacological treatment.

- Comparison of different combinations of behavioural and pharmacological treatments.

\section{Types of outcome measures}

As the primary outcome, we were interested in the percentage of participants who met the criteria for 'continuous or prolonged abstinence' over a period of six months or longer. 'Continuous abstinence' refers to abstinence periods that begin on the quit date. 'Prolonged abstinence' refers to continuous abstinence after an initial 'grace period $^{\prime 26}$. The preferred outcome was biochemically validated continuous or prolonged abstinence at the longest-reported time point. However, as biochemically validated abstinence might be lacking, we examined both self-reported abstinence and biochemically validated abstinence. Unfortunately, lack of clarity is evident in the literature about the reliability of self-reported abstinence ${ }^{27,28}$. When it was unclear whether the given quit rate was a point prevalence or a continuous or prolonged abstinence rate, we defined the quit rate as point prevalence. 'Point prevalence abstinence rate' refers to the proportion of participants who were non-smokers at a specific point in time during follow-up. It is a considerably less valid estimate of smoking abstinence than continuous/prolonged abstinence because participants could be classified as non-smokers even if they had smoked a week before the reference date ${ }^{29,30}$. We therefore used continuous or prolonged abstinence as the primary outcome measure, and point prevalence as the secondary outcome measure. 


\section{Primary outcomes}

Percentage of participants with continuous or prolonged abstinence over a period of six months or longer.

\section{Secondary outcomes}

Percentage of participants with point prevalence abstinence over a period of six months or longer.

\section{Search methods for identification of studies}

\section{Electronic searches}

We identified trials from the Cochrane Airways Group Specialised Register of Trials (CAGR), which is derived from systematic searches of bibliographic databases, including the Cochrane Central Register of Controlled Trials (CENTRAL), MEDLINE, EMBASE, CINAHL, AMED, and PsycINFO (please see Appendix 1 in full text for further details). We searched all records in the CAGR using the search strategy described in Appendix 2 (see full text). In addition to the electronic search, we searched clinical trial registries for planned, ongoing, and unpublished trials (for example ClinicalTrials.gov and World Health Organization International Clinical Trials Registry Platform). We searched all databases from their inception to March 2016, and applied no restriction on language of publication.

\section{Searching other resources}

We checked the reference lists of all included studies and other systematic reviews in relevant topic areas. We searched for errata or retractions from eligible trials in PubMed on 22 March 2016.

\section{Data collection and analysis}

\section{Selection of studies}

Two review authors (EVE and RVDM) independently selected studies for inclusion by applying the selection criteria. We resolved any disagreements through discussion, consulting a third review author (DK) if required. We identified and excluded duplicates and collated multiple reports on the same study so that each study, rather than each report, was the unit of interest in the review. We recorded the selection process in sufficient detail to complete a Preferred Reporting Items for Systematic Reviews and 
Meta-Analysis (PRISMA) flow diagram (Figure 2.1) and a Characteristics of excluded studies table (see full text) ${ }^{31}$.

\section{Data extraction and management}

Two review authors (EVE and RVDM) independently extracted study characteristics from included studies. We adapted the standard data collection form for study characteristics and outcome data to the inclusion criteria. We noted in the Characteristics of included studies table (see full text) whether outcome data were reported in an unusable way. One review author (EVE) copied the data from the data collection form into the RevMan 2014 file. We double-checked that the data had been entered correctly by comparing the study reports with the presentation of data in the systematic review. We extracted the following study characteristics.

- Methods: study setting, study design, method of recruitment of participants, number of participants randomly assigned and followed up.

- Participants: age, sex, cigarettes smoked per day, mean score on Fagerström Test for Nicotine Dependence (FTND) ${ }^{32}$, severity of COPD baseline lung function (FEV1 and forced vital capacity (FVC)).

- Interventions: description of the experimental and control group(s), type and intensity of the behavioural treatment, therapist providing the treatment, dose of the pharmacological treatment.

- Outcomes: primary and secondary outcomes, respectively, percentage of participants with prolonged or continuous abstinence, or both; percentage of participants with point prevalence abstinence; biochemical validation of abstinence.

- Statistical analyses: complete-case analyses or imputation of outcome data.

- Notes: funding for trial, notable conflicts of interest of trial authors.

\section{Assessment of risk of bias in included studies}

Two review authors (EVE and RVDM) independently assessed the risk of bias for each study using the criteria outlined in the Cochrane Handbook for Systematic Reviews of Interventions ${ }^{33}$. We resolved any disagreements by discussion or by involving a third review author (DK). We assessed the risk of bias according to the following domains.

- Random sequence generation. 
- Allocation concealment.

- Blinding of participants and personnel.

- Blinding of the outcome assessment.

- Incomplete outcome data.

- Selective outcome reporting.

- Other bias.

We graded each potential source of bias as high, low, or unclear and provided a quote from the study report, together with a justification for our judgement, in the 'Risk of bias' table. We summarised the 'Risk of bias' judgements across different studies for each of the domains listed (Figure 2.2 and 2.3). When information on risk of bias related to unpublished data or correspondence with a trialist, we noted this in the 'Risk of bias' table.

\section{Assessment of bias in conducting the systematic review}

We conducted the review according to the published protocol and reported any deviations from it in the Differences between protocol and review section (see full text) ${ }^{34}$.

\section{Measures of treatment effect}

We expressed results for dichotomous outcomes as risk ratios (RRs) and risk difference (RD). We calculated RRs as follows: (number of participants who quit smoking in the intervention group/number of participants randomly assigned to the intervention group)/(number of participants who quit smoking in the control group/number of participants randomly assigned to the control group). An RR greater than one favours the intervention group. RDs were the differences between the observed risks of abstinence in the intervention groups and the observed risks of abstinence in the control groups. We furthermore calculated $95 \%$ confidence interval for every study.

We undertook meta-analyses only when this was meaningful, for example if interventions, participants, and the underlying clinical question were similar enough for pooling to make sense.

When multiple trial arms were reported in a single trial, we included only the relevant arms. If two comparisons (for example drug $A$ versus placebo and drug $B$ versus 
placebo) had to be entered into the same meta-analysis, we combined the intervention groups into one comparison to avoid double counting.

\section{Unit of analysis issues}

The unit of analysis was the participant.

\section{Dealing with missing data}

We contacted investigators to verify key study characteristics and to obtain missing numerical outcome data when possible (for example when a study is identified as abstract only).

Furthermore, regarding smoking cessation, we considered participants with missing outcome data as smokers (intention to treat).

\section{Assessment of heterogeneity}

We used the $\mathrm{I}^{2}$ statistic to measure heterogeneity among the trials in each analysis. The $1^{2}$ statistic describes the percentage of variability in the summary estimate due to systematic heterogeneity rather than random chance stemming from sample error alone ${ }^{33}$. Values greater than $50 \%$ suggest moderate heterogeneity, and values greater than $75 \%$ suggest substantial heterogeneity. When we identified substantial heterogeneity, we explored this through prespecified subgroup analysis.

\section{Assessment of reporting biases}

When we suspected reporting bias, we attempted to contact study authors to ask them to provide missing outcome data. When this was not possible, and the missing data were thought to introduce serious bias, we explored the impact of including such studies in the overall assessment of results by a sensitivity analysis.

When we were able to pool more than 10 trials, we created and examined a funnel plot to explore possible publication biases.

\section{Data synthesis}

\section{'Summary of findings' table}

We created a 'Summary of findings' table by using the following outcomes: the primary outcome percentage of participants with prolonged or continuous abstinence, or both, 
and the secondary outcome percentage of participants with point prevalence abstinence. We used the five Grades of Recommendation, Assessment, Development and Evaluation (GRADE) considerations (study limitations, consistency of effect, imprecision, indirectness, and publication bias) to assess the quality of a body of evidence as it relates to the studies that contribute data to the meta-analyses for the prespecified outcomes ${ }^{35}$. We used methods and recommendations as described in Section 8.5 and Chapter 12 of the Cochrane Handbook for Systematic Reviews of Interventions ${ }^{33}$, and as used in GRADEpro GDT software. We justified all decisions to downgrade or upgrade the quality of studies by using footnotes and making comments to aid the reader's understanding of the review when necessary.

\section{Subgroup analysis and investigation of heterogeneity}

To examine whether the intervention effect varies in different subgroups, we planned to carry out the following subgroup analyses, when applicable.

- Severity of COPD: mild-moderate versus severe-very severe.

- Level of behavioural treatment: low versus high.

- Type of pharmacotherapy: nicotine replacement therapy, nicotine receptor partial agonists, antidepressants, nicotine vaccines.

- Definition of abstinence: percentage of participants with continuous or prolonged abstinence over a period of 12 months or longer versus less than 12 months versus percentage of participants with point prevalence.

We used the following outcomes in the subgroup analysis.

- Smoking status (\% of group) at a minimum of six months from the quit date.

\section{Sensitivity analysis}

We undertook sensitivity analyses to assess the effect of removing studies with a high risk of bias.

\section{Results}

\section{Description of studies}

See: Characteristics of included studies tables in full text. 


\section{Results of the search}

We completed a PRISMA flow diagram ${ }^{31}$ (Figure 2.1). We identified 390 records by searching the Cochrane Airways Group Specialised Register of Trials, and additional sources added 20 records. Based on title and abstract, we excluded 287 records and assessed 119 full-text articles for eligibility. We included a total of 16 studies in the review $^{22,36-50}$. Five of these were also included in the previous version of this Cochrane review $^{23}$. Of the 16 studies, four reported their data in two publications: Brandt et al. ${ }^{39}$ and Kallan et al. ${ }^{51}$, Christenhusz et al. ${ }^{41}$ and Christenhusz et al. ${ }^{52}$, Hilberink et al. ${ }^{43}$ and Hilberink et al. ${ }^{53}$, and Wagena et al. ${ }^{22}$ and Van Schayck et al. ${ }^{54}$. Two studies reported their data in three publications: Tashkin et al. ${ }^{49}$, Tashkin et al. ${ }^{55}$, and Lock et al. ${ }^{56}$; and Wilson et al. ${ }^{50}$, Wilson et al. ${ }^{57}$, and Wilson et al. ${ }^{28}$. One study reported results in four publications: Kotz et al. ${ }^{44}$, Kotz et al. ${ }^{58}$, Kotz et al. ${ }^{59}$, and Kotz et al. ${ }^{60}$. One study reported the results in several different articles, of which we used five: Anthonisen et al. $^{38}$, Connett et al. ${ }^{61}$, O'Hara et al. ${ }^{62}$, Buist et al. ${ }^{63}$, and Scanlon et al. ${ }^{64}$.

\section{Included studies}

We included 16 studies in this review update involving a total of 13,123 participants. An overview of the included studies is described in Table 2.1, and the key characteristics of the studies are described in detail in the Characteristics of included studies table (see full text).

\section{Study participants}

All participants were smokers with a diagnosis of COPD. All studies carried out spirometry to confirm the diagnosis of COPD, except for three studies that did not confirm the COPD diagnosis by spirometry ${ }^{39,43,47}$. Half of the studies included an equal distribution of men and women $22,36,37,39,41,43,45,50$; in the other half of the studies the percentage of men exceeded the percentage of women. The age of the participants in the different studies ranged from 48 to 66 years. Four studies included participants visiting inpatient clinics $38,39,42,47$, whereas the remaining studies included participants visiting outpatient clinics or practices. Eight of the studies described severity of COPD according to Global Initiative for Chronic Obstructive Lung Disease/National Institute for Health and Care Excellence/European Respiratory Society/American Thoracic Society guidelines. One study ${ }^{42}$, described severity of COPD according to their own definitions: early COPD (FEV1 70\% to 90\%) and late COPD (FEV1 less than 70\%). Kotz et al. $^{44}$ and Tashkin et al. ${ }^{48}$ included only participants classified with mild-moderate COPD; 
the other six studies included a mix of mild-moderate and severe-very severe COPD participants. Four studies included mostly participants with mild-moderate COPD, and two, Chen et al. ${ }^{40}$ and Tønnesen et al. ${ }^{36}$, included a large group of

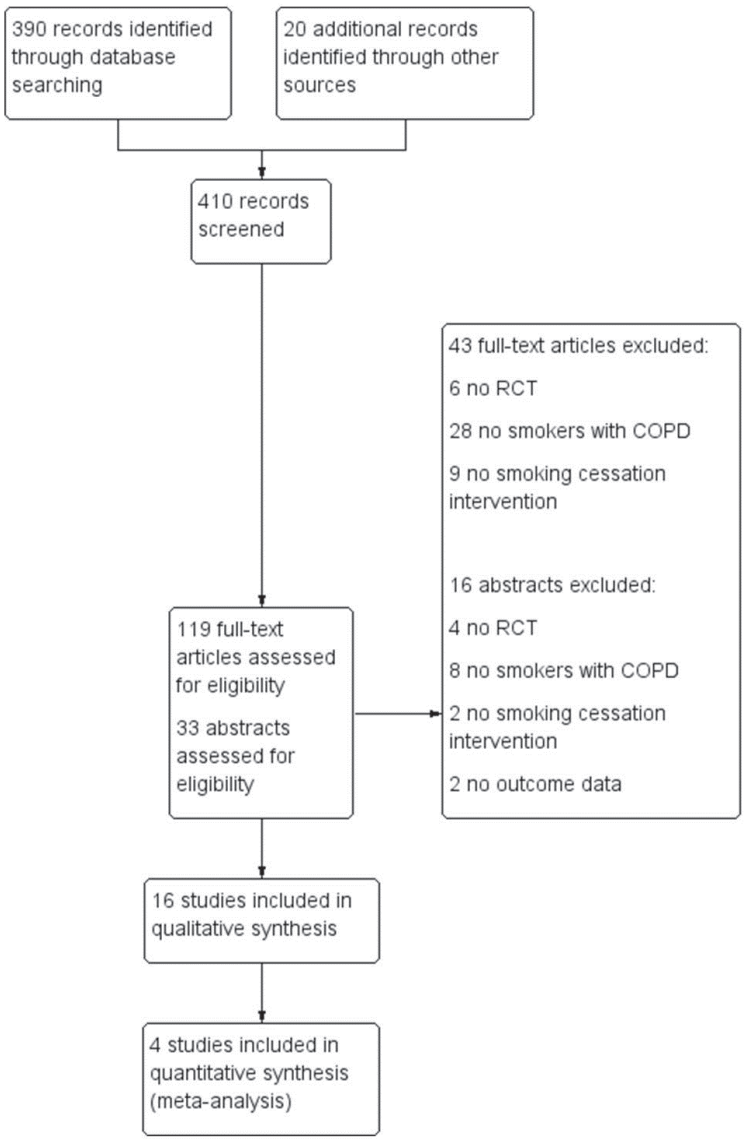

Figure 2.1 PRISMA study flow diagram

severe-very severe COPD participants. In Chen et al. ${ }^{40}, 57 \%$ of COPD participants had mild-moderate COPD, and 43\% had severe-very severe COPD. In Tønnesen et al. ${ }^{36}, 62 \%$ had mild-moderate COPD, and 38\% had severe-very severe COPD.

\section{Interventions}

Eight studies evaluated behavioural treatments, in some of which pharmacotherapy was recommended or obligatory. Six studies evaluated pharmacotherapy, all of which 
included mandatory behavioural treatment. Five studies evaluated different combinations of behavioural and pharmacological treatment.

\section{Behavioural treatments}

The content of the behavioural treatments varied widely. All behavioural treatments contained some form of individual counselling, often combined with some form of group counselling, telephone counselling, and/or self-help/written material. All of the behavioural treatments except for one ${ }^{39}$, were high-intensity treatments because they offered more than one pre-scheduled counselling session of greater than 10 minutes with at least one face-to-face counselling session ${ }^{12}$.

\section{Pharmacological treatments}

Placebo-controlled trials included the investigation of nicotine replacement therapy (NRT) sublingual tablet ${ }^{36}$, bupropion ${ }^{22,48}$, nortriptyline ${ }^{22}$, and varenicline ${ }^{49}$. Three trials compared different pharmacotherapies: bupropion versus NRT patch ${ }^{46}$, NRT versus NRT with bupropion ${ }^{43}$, and bupropion versus nortriptyline ${ }^{22}$. This last study was the only study using a double-dummy design when investigating bupropion and nortriptyline against placebo $^{22}$. In ontrast with the other studies, the use of pharmacotherapy in Hilberink et al.43 was not mandatory and not provided for free, which resulted in only a few people using NRT or bupropion. All pharmacological

Table 2.1 Characteristics of included studies

\begin{tabular}{|c|c|c|c|c|c|c|c|c|}
\hline Study & Country & Setting (in-/outpatients) & $\mathrm{N}$ randomised & $\mathrm{N}$ completed & Intervention 1 & Intervention 2 & Control 1 & Control 2 \\
\hline Anthonisen 1994 & CA \& US & In & 5887 & Not reported & BH \& PH-NRT & NA & UC & NA \\
\hline Brandt 1997 & DK & In & 56 & 45 & $\mathrm{BH}$ & NA & UC & NA \\
\hline Chen 2014 & $\mathrm{CN}$ & Out & 85 & 80 & $\mathrm{BH}$ & NA & $\mathrm{BH}$ & NA \\
\hline Christenhusz 2007 & NL & Out & 234 & 225 & BH \& PH-BUP & NA & $\mathrm{BH}$ & NA \\
\hline Crowley 1995 & US & $\ln \&$ out & 53 & 36 & BH \& PH-NRT & NA & BH \& PH-NRT & BH \& PH-NRT \\
\hline Gorecka 2003 & PL & Out & 70 & 69 & BH \& PH-BUP & NA & BH \& PH-NRT & NA \\
\hline Hilberink 2011 & NL & Out & 697 & Not reported & $\mathrm{BH}$ & NA & UC & NA \\
\hline Kotz 2009 & NL & Out & 296 & 248 & BH \& PH-NOR & NA & BH \& PH-NOR & UC \\
\hline Lou 2013 & $\mathrm{CN}$ & Out & 3562 & 2607 & $\mathrm{BH}$ & NA & UC & NA \\
\hline Pederson 1991 & CA & In & 74 & 64 & $\mathrm{BH}$ & NA & $\mathrm{BH}$ & NA \\
\hline Sundblad 2008 & SE & Out & 478 & 391 & $\mathrm{BH}$ & NA & UC & NA \\
\hline Tashkin 2001 & us & Out & 411 & 278 & BH \& PH-BUP & NA & $\mathrm{BH}$ & NA \\
\hline Tashkin 2011 & US & Out & 504 & 499 & BH \& PH-VAR & NA & $\mathrm{BH}$ & NA \\
\hline Tonnesen 2006 & DK & Out & 370 & 288 & BH \& PH-NRT & BH \& PH-NRT & $\mathrm{BH}$ & $\mathrm{BH}$ \\
\hline Wagena 2005 & NL & Out & 255 & 220 & BH \& PH-BUP & BH \& PH-NOR & $\mathrm{BH}$ & NA \\
\hline Wilson 2008 & IE & Out & 91 & 68 & BH \& PH-NRT & BH \& PH-NRT & UC & NA \\
\hline
\end{tabular}

CA: Canada; CN: China; DK: Denmark; IE: Ireland; NL: Netherlands; PL: Poland; SE: Sweden; US: United States $\mathrm{BH}$ : behavioural; BUP: bupropion; NA: not applicable; NOR: nortriptyline; NRT: nicotine replacement therapy; $\mathrm{PH}$ : pharmacological; UC: usual care; VAR: varenicline 
treatments were accompanied by high-intensity behavioural treatment. Tønnesen et al. ${ }^{36}$ was the only study with a factorial design, as a result of which the behavioural component in the pharmacological comparison was a mix of high- and low-intensity behavioural treatment.

\section{Outcomes}

Our primary outcome was continuous or prolonged abstinence over a period of six months or longer. Ten studies reported continuous, sustained, or prolonged abstinence. However, the definitions of abstinence used by the studies were diverse and sometimes vague, and did not always match our definition. Furthermore, most of these studies reported abstinence data after an initial grace period. We therefore clustered continuous, sustained, and prolonged abstinence data, which we categorised under the outcome 'prolonged abstinence'. Of the 10 studies reporting prolonged abstinence data, six studies reported six months' and seven studies reported 12 months' prolonged abstinence data. Few studies reported both six and 12 months' abstinence data. Furthermore, Wilson et al. ${ }^{50}$ reported nine months' and Anthonisen et al. ${ }^{38}$ reported two- to five-year prolonged abstinence data of the Lung Health Study (LHS). In addition, Anthonisen et al. ${ }^{11}$ reported prolonged abstinence 11 years after the start of the LHS.

Our secondary outcome was point prevalence abstinence over a period of six months or longer. Eleven of the 16 included studies reported this outcome. Nine studies reported six months' and eight studies reported 12 months' point prevalence abstinence data. A few studies reported both six and 12 months' abstinence data. Furthermore, Wilson et al. ${ }^{50}$ reported nine months' and Sundblad et al. ${ }^{37}$ reported three-year point prevalence abstinence data. Lou et al. ${ }^{45}$ described abstinence data as being continuous, however their definition of continuous abstinence was vague and corresponded with a mix of prolonged and point prevalence abstinence. In addition, all data except from the six months' follow-up data were more consistent with point prevalence abstinence data, as the number of abstinent participants increased over time. We therefore categorised the six months' follow-up data as prolonged abstinence data and the outcome data from six months onwards as point prevalence abstinence data. 
All abstinence data were biochemically validated, however Brandt et al. ${ }^{39}$ only measured exhaled carbon monoxide (CO) levels in self-reported non-smokers, and Sundblad et al. ${ }^{37}$ only measured $\mathrm{CO}$ in a random sample of self-reported non-smokers. Brandt et al. ${ }^{39}$ reported that the CO levels of the self-reported non-smokers confirmed their abstinence, and Sundblad et al. ${ }^{37}$ reported that of the 35 tested, 33 had a CO level of less than 8 ppm, confirming that most of them were indeed abstinent. Eleven studies used exhaled CO measurement techniques, three studies measured cotinine levels in saliva, and three studies measured cotinine in urine. Pederson et al. ${ }^{47}$ was an exception, as this study measured the CO level in blood samples. Cutoff levels varied: $\leq$ 8 to $\leq 10 \mathrm{ppm}$ of $\mathrm{CO}$ in exhaled air, $\leq 10$ to $\leq 20 \mathrm{ng} / \mathrm{mL}$ cotinine in saliva, and $\leq 50$ to $\leq$ $60 \mathrm{ng} / \mathrm{mL}$ cotinine in urine.

\section{Excluded studies}

We excluded 59 of the potentially eligible studies: 10 studies were not randomised controlled trials, 36 studies did not include smokers with COPD, 11 studies were not studying smoking cessation interventions, and two did not report outcome data. These studies are listed with their reasons for exclusion in the Characteristics of excluded studies table (see full text).

\section{Ongoing studies}

We searched the clinical trial registers for ongoing studies and identified two potentially interesting studies that complied with the inclusion criteria for this review (www.ClinicalTrials.gov ${ }^{65}$ ). One of the studies compares varenicline plus behavioural treatment with placebo plus behavioural treatment (NCT01694732). The estimated completion date of this study is November 2016. The other study compares behavioural treatment plus NRT with a different behavioural treatment plus NRT (NCT02148445). The estimated completion date of this study is September 2016. More information about these studies is summarised in the Characteristics of ongoing studies table (see full text).

\section{Risk of bias in included studies}

The risk of bias of each item for all included studies is summarised in Figure 2.2, and Figure 2.3 shows the percentages of the different items across all included studies. 
In conclusion, we recommend interpreting the results of six studies with caution, as we expect the risk of bias to have a significant influence on the results $22,37,39,42,43,50$. In these studies, there was bias on several important components or bias on one crucial component; contamination bias; or poor adherence to the study protocol. In three studies, four or more components of risk of bias remained unclear and resulted in an overall unclear risk of bias ${ }^{45-47}$.

\section{Allocation}

In four of the 16 studies, the random sequence generation method and allocation concealment were not described clearly enough for us to judge possible occurrence of selection bias $^{42,45-47}$.

\section{Blinding}

As almost all of the included studies evaluated different behavioural components, it was not possible to blind the participants and personnel for that part of the intervention, resulting in high 'Risk of bias' scores in almost all studies. Tashkin et al. ${ }^{48}$ and Wagena et al. ${ }^{22}$ were the only two pharmacological studies including identical behavioural treatment in all groups and describing the blinding of participants and personnel in detail. Blinding of outcome assessment referred to blinding of selfreported or validated abstinence, or both. Only four studies reported any information about blinding. Christenhusz et al. ${ }^{41}$ and Kotz et al. ${ }^{44}$ were the only studies to report on how blinding was performed. Sundblad et al. ${ }^{37}$ and Wilson et al. ${ }^{50}$ explicitly reported that they did not blind participants and personnel for the outcome measurement.

\section{Incomplete outcome data}

Ten studies scored at high risk of bias for incomplete outcome data, due mostly to a high percentage of missing values or the presence of attrition bias, or both.

\section{Selective reporting}

We detected selective reporting of data in three studies: Christenhusz et al. ${ }^{41}$ reported different outcome data in different papers and abstracts, Crowley et al. ${ }^{42}$ did not report all prespecified outcomes, and Hilberink et al. ${ }^{43}$ did not mention their randomised controlled trial (RCT) being a three-armed RCT and only reported data from two arms in one of the publications. 


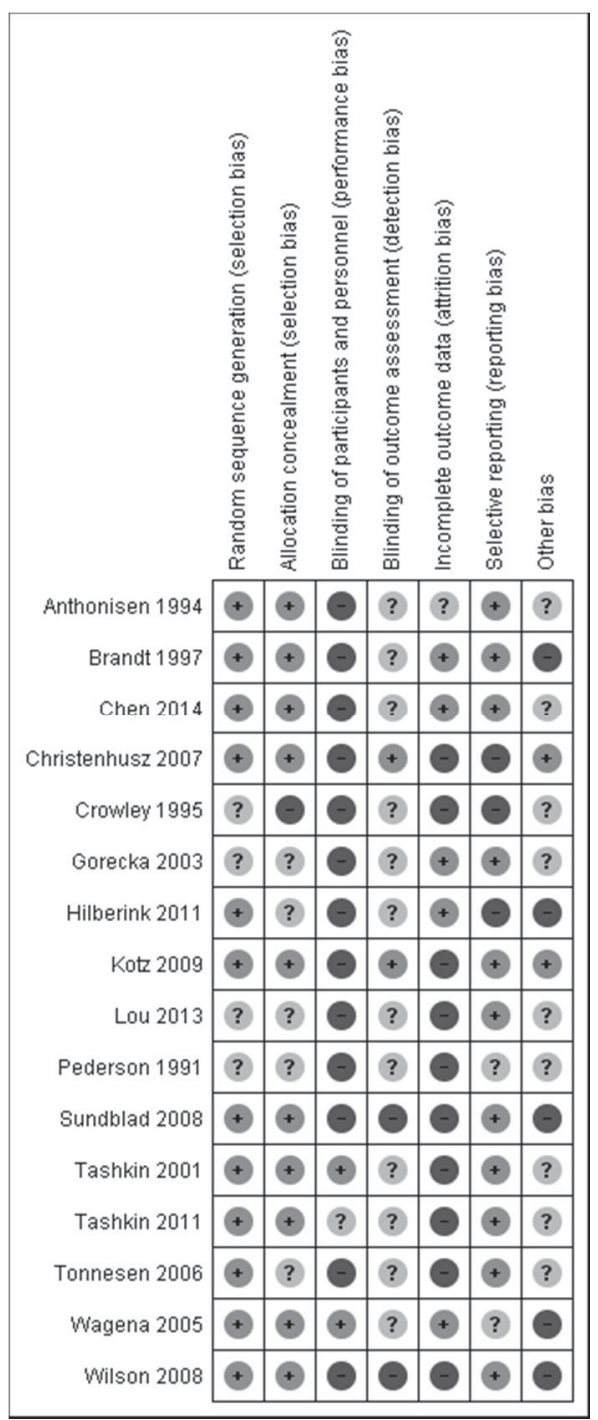

Figure 2.2 Risk of bias summary: review authors' judgements about each risk of bias item for each included study

\section{Other potential sources of bias}

Finally, we observed other potentially important forms of bias: adherence to study protocols for participants and personnel was not described in 11 of the studies; was found poor in three studies $22,43,50$; and was reported to be satisfactory in only two studies $^{41,44}$. Furthermore, contamination bias might have occurred in two studies ${ }^{39,43}$. 
In Figure 2.2 the final column shows the combined score for these sources of bias, per study.

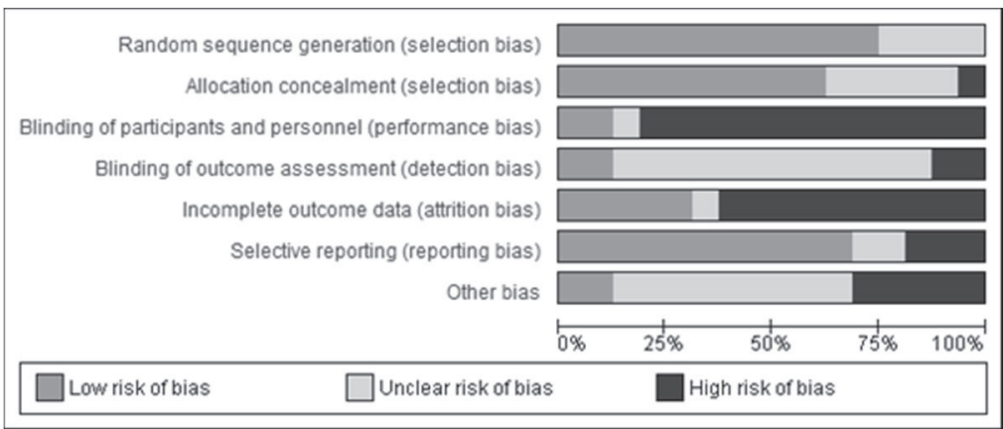

Figure 2.3 Risk of bias graph: review authors' judgements about each risk of bias item presented as percentages across all included studies

\section{Effects of interventions}

See: Summary of findings for the main comparison Behavioural treatment compared to no treatment or usual care in smokers with COPD (see Addendum 2.1); Summary of findings 2 One form of behavioural treatment compared to a different form of behavioural treatment in smokers with COPD (see Addendum 2.2); Summary of findings 3 Pharmacological treatment compared to placebo in smokers with COPD (see Addendum 2.3); Summary of findings 4 Pharmacological treatment compared to a different pharmacological treatment for smokers with COPD (see Addendum 2.4); Summary of findings 5 Combination interventions compared to different (combination) interventions or usual care for smokers with COPD (see Addendum 2.5)

Outcome data from the included studies was based on complete-case, intention-totreat (ITT), and modified ITT principles. To increase consistency across study outcome data, we performed an ITT analysis on outcome data from all studies. In the following comparisons we only described subgroup analyses when a meta-analysis was performed.

\section{Comparison 1: Behavioural treatment versus no treatment or usual care}

Two studies compared a behavioural treatment with usual care ${ }^{39,45}$. The content of the behavioural treatments varied widely, and the studies showed too much statistical heterogeneity for pooling to make sense. Brandt et al. ${ }^{39}$ compared an intervention 
group in which the doctors used the term 'smoker's lung' with a group receiving usual care by using the concept 'chronic bronchitis'. Only 12 months' point prevalence data were available for this study. In the 'smoker's lung' group, 32\% (8/25) quit smoking, and in the 'chronic bronchitis' group, 16\% (5/31) quit smoking (risk ratio (RR) 1.98, 95\% confidence interval $(\mathrm{Cl}) 0.74$ to 5.31 ; risk difference (RD) $0.16,95 \% \mathrm{Cl}-0.07$ to 0.38 ) (see analysis 1.2 in full text). In Lou et al. $^{45}$, a cluster design was used, and the behavioural-treatment group received a high-intensity treatment: the participants were provided written material and individual counselling in the practice and during home visits, and they participated in group meetings. The content and number of usual-care services were not standardised. Outcome data of this study were difficult to classify according to our definitions. As previously described, we included follow-up data at six months' follow-up as prolonged abstinence data and data from six months onwards as point prevalence abstinence data. The prolonged abstinence rate at six months was $4.4 \%(79 / 1814)$ in the behavioural-treatment group, versus $0.2 \%(3 / 1748)$ in the usual-care group. The RR was $25.38(95 \% \mathrm{Cl} 8.03$ to 80.22$)$ and the RD was 0.04 (95\% $\mathrm{Cl} 0.03$ to 0.05$)$ (see analysis 1.1 in full text). All point prevalence abstinence rates at follow-up from 12 to 48 months showed a positive effect of the behaviouraltreatment group on abstinence rates. At 48 months, the point prevalence abstinence rate was 33.6\% (610/1814) in the behavioural-treatment group compared with 3.6\% $(63 / 1748)$ in the usual-care group, with a RR of 9.33 (95\% Cl 7.26 to 11.99$)$ and a RD of 0.30 (95\% Cl 0.28 to 0.32 ) (see analysis 1.2 in full text). However, these effects may be overestimated, as the authors did not control for the cluster design of the RCT in their analysis.

Comparison 2: One form of behavioural treatment versus a different form of behavioural treatment

Six studies compared two different behavioural treatments ${ }^{36,40,42,44,47,50}$. The content of the behavioural treatments varied widely, and the studies showed too much statistical heterogeneity for pooling to make sense.

Chen et al. ${ }^{40}$ and Pederson et al. ${ }^{47}$ compared a high-intensity behavioural treatment with a low-intensity behavioural treatment. In Chen et al. ${ }^{40}$, participants received individual counselling, self-help material, and telephone follow-up calls. This behavioural-treatment group was compared with a low-intensity behavioural treatment that only provided simple advice to the participants. The six month' 
prolonged abstinence in the group with high-intensity counselling was 40\% (17/42) compared with 19\% (8/43) in the group receiving simple advice. The RR was 2.18 (95\% $\mathrm{Cl} 1.05$ to 4.49 ) and the RD was 0.22 ( $95 \% \mathrm{Cl} 0.03$ to 0.41 ) (see analysis 2.1 in full text). Point prevalence data of this study were not reported. Pederson et al. ${ }^{47}$ only examined point prevalence abstinence at six months' follow-up. Rates for abstinence were $27 \%$ (10/37) in the group receiving high-intensity counselling compared with 16.2\% (6/37) in the group receiving simple advice ( $\mathrm{RR} 1.67,95 \% \mathrm{Cl} 0.68$ to $4.11 ; \mathrm{RD} 0.11,95 \% \mathrm{Cl}-0.08$ to 0.29 ) (see analysis 2.2 in full text).

Crowley et al. ${ }^{42}$, Tønnesen et al. ${ }^{36}$, Kotz et al. ${ }^{44}$, and Wilson et al. ${ }^{50}$ compared a highintensity behavioural treatment with a different high-intensity behavioural treatment. Crowley et al. ${ }^{42}$ compared three different behavioural-treatment groups. All groups received individual counselling and written material. They differed in the way the participants received lottery tickets for abstinence. Payment of lottery tickets according to abstinence occurred in two groups: one group received payment for self-reported abstinence, the other group for CO-validated abstinence. The third group received lottery tickets when their 'buddy' in the other group also received lottery tickets; this was not linked with their smoking status. The authors stated that the three groups did not differ in six months' point prevalence abstinence rates, but there were no data available per group. Kotz et al. ${ }^{44}$ compared individual and telephone counselling with confrontation with spirometry, with individual and telephone counselling without confrontation with spirometry. The prolonged abstinence at 12 months' follow-up in the group with confrontation with spirometry was 11\% (13/116) compared with $12 \%$ $(13 / 112)$ in the group without confrontation with spirometry. The RR was $0.97(95 \% \mathrm{Cl}$ 0.47 to 1.99$)$ and the RD was -0.00 ( $95 \% \mathrm{Cl}-0.09$ to 0.08$)$ (see analysis 2.1 in full text). This study reported no point prevalence data. In Tønnesen et al. ${ }^{36}$, the participants in one behavioural-treatment group received high-intensity individual counselling and proactive telephone counselling. This group was compared with less intensive - but still high-intensity according to our definition - individual counselling and proactive telephone counselling. As Tønnesen et al. ${ }^{36}$ was a study with factorial design, the same number of participants in both groups also received either NRT (sublingual tablet) or placebo. The prolonged abstinence rate at 12 months' follow-up in the group with high-intensity counselling was 10\% (19/187) compared with 9\% (17/183) in the group receiving less high-intensive counselling. The RR was 1.09 (95\% $\mathrm{Cl} 0.59$ to 2.04) and the RD was 0.01 ( $95 \% \mathrm{Cl}-0.05$ to 0.07 ) (see analysis 2.1 in full text). The 12 months' point 
prevalence abstinence rate was 16\% (29/187) in the high-intensity counselling group and $11 \%(21 / 183)$ in the less high-intensive counselling group (RR 1.35, 95\% Cl 0.80 to 2.28; and $\mathrm{RD} 0.04,95 \% \mathrm{Cl}-0.86$ to 0.94 ) (see analysis 2.2 in full text). Wilson et al. ${ }^{50}$ compared individual counselling and group counselling. Both groups were also offered the opportunity to use NRT patches. In both groups none of the participants became prolonged abstinent at 12 months (see analysis 2.1 in full text). Point prevalence abstinences rates were $0 \%(0 / 27)$ in the individual-counselling group and $10 \%(3 / 29)$ in the group-counselling group (RR $0.15,95 \% \mathrm{Cl} 0.01$ to 2.83 ; and $\mathrm{RD}-0.10,95 \% \mathrm{Cl}-0.23$ to 0.02 ) (see analysis 2.2 in full text).

\section{Comparison 3: Pharmacological treatment versus placebo}

Four studies compared the following pharmacotherapy with placebo: NRT sublingual tablet $^{22,36,48}$, nortriptyline ${ }^{22}$, and varenicline ${ }^{49}$. All studies except Wagena et al. ${ }^{22}$ reported both prolonged and point prevalence abstinence data. Primary and secondary outcome data of the individual studies are presented in data and analyses table 3 (see Analysis 3.1; Analysis 3.2; Analysis 3.3; Analysis 3.4; Analysis 3.5; Analysis 3.6 in full text). All pharmacotherapy groups, except for the nortriptyline group from Wagena et al. $^{22}$, showed an increase in the chance of quitting compared with placebo. The prolonged abstinence rates in the pharmacotherapy groups ranged from $14 \%$ to $27 \%$. The placebo group quit rates ranged from $5 \%$ to $9 \%$. The pooled RR was $2.53(95 \% \mathrm{Cl}$ 1.83 to 3.50$)$ and the RD 0.10 ( $95 \% \mathrm{Cl} 0.07$ to 0.14 ), with no evidence of heterogeneity $\left(\mathrm{I}^{2}=0 \%\right)$ (see analysis $3.1 \mathrm{in}$ full text). The point prevalence abstinence rates in the pharmacotherapy groups ranged from $17 \%$ to $26 \%$. The placebo group quit rates ranged from $10 \%$ to $16 \%$. The pooled RR was $1.68(95 \% \mathrm{Cl} 1.32$ to 2.15$)$ and the RD 0.09 (95\% Cl 0.05 to 0.13 ), with no evidence of heterogeneity $\left(\mathrm{I}^{2}=0 \%\right.$ ) (see analysis 3.4 in full text). In all studies, pharmacotherapy was combined with high-intensity counselling.

All studies except Tønnesen et al. ${ }^{36}$ included participants with mostly mild to moderate COPD. Tashkin et al. ${ }^{48}$ included only participants with mild to moderate COPD. In Tashkin et al. ${ }^{49}, 89 \%$ had mild to moderate and $11 \%$ had severe to very severe COPD, and Wagena et al. ${ }^{22}$ included $94 \%$ of mild to moderate severity and $6 \%$ of severe to very severe COPD patients. In a subgroup analysis, we distinguished between trials with mostly mild-moderate COPD, Tashkin et al. ${ }^{48}$, Tashkin et al. ${ }^{49}$, and Wagena et al. ${ }^{22}$, and a trial with a substantial number of people with severe-very severe $\operatorname{COPD}^{36}$. Both 
subgroups showed almost similar prolonged abstinence rates, with a RR of $2.51(95 \% \mathrm{Cl}$ 1.74 to 3.62$)$ and a $\mathrm{RD}$ of $0.11(95 \% \mathrm{Cl} 0.07$ to 0.15$)$ in the group with mild-moderate COPD, and a RR of $2.60(95 \% \mathrm{Cl} 1.29$ to 5.24) and a RD of 0.09 (95\% Cl 0.03 to 0.15$)$ in the study with a substantial number of people with severe-very severe COPD (see analysis 3.1 in full text). Point prevalence abstinence rates were also comparable between the group with mild-moderate COPD patients (RR 1.66, 95\% Cl 1.26 to 2.18; $\mathrm{RD} 0.10,95 \% \mathrm{Cl} 0.05$ to 0.15 ) and the study with a substantial amount of people with severe-very severe COPD (RR 1.78, 95\% Cl 1.04 to 3.05; RD 0.08, 95\% Cl 0.01 to 0.14 ) (see analysis 3.4 in full text).

The four studies in this comparison used different kinds of pharmacotherapy. Tønnesen et al. ${ }^{36}$ used NRT (sublingual), Tashkin et al. ${ }^{48}$ and Wagena et al. ${ }^{22}$ used bupropion, Wagena et al. ${ }^{22}$ also used nortriptyline, and Tashkin et al. ${ }^{49}$ used varenicline. As previously mentioned, all pharmacotherapy, except for nortriptyline in the Wagena et al. $^{22}$ study, had a positive effect on prolonged abstinence compared with placebo (see analysis 3.2 in full text); the study using NRT had a RR of 2.60 (95\% Cl 1.29 to 5.24) and a RD of 0.09 ( $95 \% \mathrm{Cl} 0.03$ to 0.15 ), the two studies using bupropion had a pooled RR of 2.03 (95\% Cl 1.26 to 3.28) and a RD of 0.09 (95\% Cl 0.03 to 0.15 ), the study of nortriptyline had a RR of $2.54(95 \% \mathrm{Cl} 0.87$ to 7.44$)$ and a RD of $0.13(95 \% \mathrm{Cl}-0.01$ to $0.26)$, and varenicline had a RR of 3.34 (95\% Cl 1.88 to 5.92$)$ and a RD of $0.13(95 \% \mathrm{Cl}$ 0.07 to 0.18 ). The chances of point prevalence abstinence were also higher in the groups receiving pharmacotherapy compared with placebo (see analysis 3.5 in full text); the study using NRT had a RR of 1.78 (95\% Cl 1.04 to 3.05$)$ and a RD of 0.08 (95\% $\mathrm{Cl} 0.01$ to 0.14 ), the study using bupropion had a RR of 1.46 ( $95 \% \mathrm{Cl} 0.97$ to 2.19 ) and a $\mathrm{RD}$ of 0.07 ( $95 \% \mathrm{Cl}-0.00$ to 0.15 ), and the study using varenicline had a RR of 1.83 (95\% Cl 1.27 to 2.65$)$ and a RD of $0.12(95 \% \mathrm{Cl} 0.05$ to 0.19$)$.

We carried out a sensitivity analysis excluding the study by Wagena et al. ${ }^{22}$, as this study showed a high risk of bias due to poor adherence to the treatment protocols. This did not result in a significant change to the prolonged abstinence rate (RR 2.49, 95\% Cl 1.77 to 3.50; and RD 0.10, 95\% Cl 0.06 to 0.13 ).

Comparison 4: Pharmacological treatment versus a different pharmacological treatment Three studies compared pharmacotherapy with a different kind of pharmacotherapy ${ }^{22,}$ 43, 46. The comparisons the studies made between pharmacotherapies were too diverse for pooling to make sense. In Gorecka et al. ${ }^{46}$ and Wagena et al. ${ }^{22}$, the 
pharmacotherapy was combined with high-intensity behavioural treatment. In Hilberink et al. ${ }^{43}$, the intensity of the behavioural treatment was dependent on the level of motivation for quitting and varied between low and high.

Gorecka et al. ${ }^{46}$ compared bupropion with NRT patch. Prolonged abstinence rates at 12 months were $16 \%(5 / 32)$ in the bupropion group and $21 \%(8 / 38)$ in the NRT patch group with a RR of 0.74 ( $95 \% \mathrm{Cl} 0.27$ to 2.05$)$ and a RD of -0.05 ( $95 \% \mathrm{Cl}-0.23$ to 0.13 ) (see analysis 4.1 in full text). No point prevalence data were available for this study. Hilberink et al. ${ }^{43}$ compared a group in which they recommended NRT with a group in which they recommended NRT and bupropion. Prolonged abstinence data were not available, and 12 months' point prevalence rates were 15\% (39/252) in the NRT group and 6\% (18/291) in the NRT plus bupropion group (RR 2.50, 95\% Cl 1.47 to 4.26; RD $0.09,95 \% \mathrm{Cl} 0.04$ to 0.15 ) (see analysis 4.2 in full text). However, this is likely to be a misrepresentation, as contamination bias occurred in both groups. Wagena et al. ${ }^{22}$ compared bupropion with nortriptyline in a study with double-dummy design. In the group using bupropion, 27\% (12/44) were prolonged abstinent at six months versus $21 \%(11 / 52)$ in the group using nortriptyline. The RR was 1.29 (95\% Cl 0.63 to 2.63 ) and the RD was 0.06 ( $95 \% \mathrm{Cl}-0.11$ to 0.23 ) (see analysis 4.1 in full text). This study reported no other abstinence data.

\section{Comparison 5: Comparison of different combinations of behavioural and pharmacological} treatments

Six studies made comparisons between different kinds of pharmacological and behavioural treatments ${ }^{37,38,41,43,44,50}$ ). The content of the treatments in the different studies was too diverse for pooling to make sense. The studies had in common that they all used high-intensity behavioural treatments in their experimental group, except for the behavioural treatment in Hilberink et al. ${ }^{43}$, which could be low or high intensive, depending on the motivational stage of the participant.

Five studies compared an experimental group with usual care. Anthonisen et al. ${ }^{38}$ compared two different experimental groups with usual care. As receiving a bronchodilator or a placebo was the only difference between the two experimental groups, we combined them into one experimental group. The participants in this group all received counselling in combination with NRT gum. The participants in the control group received usual care. The prolonged abstinence rate at 12 months' follow-up in the joined experimental group was 34\% (1345/3923) and in the usual-care group 9\% 
(177/1964) (RR 3.80, 95\% Cl 3.28 to 4.41 ; and RD $0.25,95 \% \mathrm{Cl} 0.23$ to 0.27 ). The prolonged abstinence at five years' follow-up in the joined experimental group was $21 \%(835 / 3923)$ and in the usual-care group 5\% (102/1964) (RR 4.10, 95\% Cl 3.36 to 5.00; and $\mathrm{RD} 0.16,95 \% \mathrm{Cl} 0.14$ to 0.18 ) (see analysis 5.1 in full text). At 11 years' followup $16 \%(637 / 3923)$ in the joined experimental group and $4 \%(85 / 1964)$ in the usualcare group had been prolonged abstinent (RR 3.75, 95\% Cl 3.01 to 4.67; and RD 0.12, $95 \% \mathrm{Cl} 0.10$ to 0.13$)$. We also combined the two experimental groups in Hilberink et al. $^{43}$ into one experimental group, as in both intervention groups contamination bias occurred, and the advice to use NRT and/or bupropion was given to all participants in both groups. This joined experimental group with a combination of participants using no pharmacotherapy, NRT, and/or bupropion in addition to a behavioural treatment was compared with a usual-care group. The basis of the behavioural treatment was the minimal intervention strategy and in addition, dependent on the motivational stage, face-to-face and/or telephone counselling and written information. Only point prevalence abstinence rates were reported, and at 12 months' follow-up 7\% (39/543) in the joined experimental group and 3\% (5/154) in the usual-care group were abstinent (RR 2.21, 95\% Cl 0.89 to 5.52; RD 0.04, 95\% Cl 0.00 to 0.07 ) (see analysis 5.2 in full text). Kotz et al. ${ }^{44}$ compared counselling and nortriptyline with usual care. Prolonged abstinence rates at 12 months were 11\% (13/116) in the experimental group and $6 \%(4 / 68)$ in the usual-care group (RR 1.91, 95\% Cl 0.65 to 5.61; RD 0.05, 95\% Cl0.03 to 0.13 ) (see analysis 5.1 in full text). This study did not report point prevalence abstinence rates. In Sundblad et al. $^{37}$, the experimental group consisted of a highintensity behavioural treatment with hospitalisation in addition to the recommendation of NRT, which was compared with usual care. No prolonged abstinence rates were reported. The one-year point prevalence rates were $43 \%$ $(106 / 247)$ in the experimental group and 6\% (15/231) in the usual-care group (RR 6.61, $95 \% \mathrm{Cl} 3.97$ to $11.01 ; \mathrm{RD} 0.36,95 \% \mathrm{Cl} 0.29$ to 0.43$)$. The three-year point prevalence rates were $30 \%(73 / 247)$ and $7 \%(20 / 231)$, respectively (RR $3.41,95 \% \mathrm{Cl} 2.15$ to 5.41 ; RD $0.21,95 \% \mathrm{Cl} 0.14$ to 0.28 ) (see analysis 5.2 in full text). Finally, Wilson et al. ${ }^{50}$ had two experimental groups, one with group and one with individual counselling, both plus optional NRT patches, in comparison to brief advice from the doctor. No participants in any of the groups became prolonged abstinent (Analysis 5.1). Point prevalence abstinence rates at 12 months were $0 \%(0 / 27)$ in the individual-counselling group, $10 \%(3 / 29)$ in the group-counselling group, and 3\% (3/35) in the brief-advice group (individual counselling plus optional NRT compared with brief advice (RR 0.43 , 
95\% $\mathrm{Cl} 0.02$ to $10.12 ; \mathrm{RD}-0.03,95 \% \mathrm{Cl}-0.11$ to 0.05$)$, group counselling plus optional NRT compared with brief advice (RR 3.62, 95\% Cl 0.40 to 32.97 ; RD $0.07,95 \% \mathrm{Cl}-0.05$ to 0.20$)$ ) (see analysis 5.2 in full text).

One study compared high-intensity counselling plus bupropion with low- or highintensity counselling, depending on motivational stage, without pharmacotherapy ${ }^{41}$. At 12 months 17\% (20/117) of the participants in the counselling plus bupropion group were prolonged abstinent versus $8 \%(9 / 117)$ in the control group (RR 2.22, 95\% Cl 1.06 to 4.68; RD 0.09, $95 \% \mathrm{Cl} 0.01$ to 0.18 ) (see analysis 5.1 in full text). Point prevalence abstinence rates at 12 months were 21\% (24/117) in the counselling plus bupropion group and 13\% (15/117) in the control group (RR 1.60, 95\% Cl 0.89 to 2.89; RD 0.08, $95 \% \mathrm{Cl}-0.05$ to 0.20 ) (see analysis 5.2 in full text).

\section{Discussion}

\section{Summary of main results}

We reviewed the results of 16 RCTs (including a total of 13123 participants) evaluating the effectiveness of behavioural or pharmacological smoking cessation interventions, or both, in smokers with COPD. We found 11 additional studies in this update of the review $^{23}$. The 'Summary of findings' tables 1 to 5 show the results of the main outcomes (see Addendum 2.1-2.5).

There was evidence from one study that high-intensity behavioural treatment increased abstinence rates when compared with usual care ${ }^{45}$. However, we rated the quality of this study as moderate as we were unclear of the risk of bias due to lack of information (see Addendum 2.1; Summary of findings table 1).

One study at low risk of bias showed higher abstinence rates for high-intensity behavioural treatment over low-intensity behavioural treatment ${ }^{40}$. Other studies that compared high-intensity behavioural treatment with another high-intensity behavioural treatment were too diverse to formulate univocal results (see Addendum 2.2; Summary of findings table 2).

We pooled studies comparing pharmacotherapy with placebo and found high-quality evidence that, in smokers with COPD, pharmacotherapy plus high-intensity behavioural 
treatment was effective in increasing quit rates ( $R R 2.53,95 \% \mathrm{Cl} 1.83$ to 3.50 ) compared with placebo plus high-intensity behavioural treatment ${ }^{22,36,48,49}$. Among individual studies of pharmacotherapy, nortriptyline did not significantly increase the quit rate ${ }^{22}$, whereas nicotine sublingual tablet, in Tønnesen et al. ${ }^{36}$, and varenicline, in Tashkin et al. ${ }^{49}$, did. Pooled results of two studies on bupropion, Tashkin et al. ${ }^{48}$ and Wagena et al. ${ }^{22}$, also showed a positive effect of bupropion compared with placebo (see Addendum 2.3; Summary of findings table 3).

When comparing different kinds of pharmacological treatments, bupropion did not seem to be more effective than nortriptyline, in Wagena et al. $^{22}$, or nicotine patch, in Gorecka et al. ${ }^{46}$. However, these studies were not pooled and therefore not rated for quality, but had an overall high and unclear risk of bias, respectively (see Addendum 2.4; Summary of findings table 4).

Finally, we compared different combinations of behavioural and pharmacological treatments. These studies were not pooled and therefore not rated for quality. In a study at low risk of bias, high-intensity behavioural treatment plus nicotine gum increased abstinence rates when compared with usual care ${ }^{38}$. Furthermore, in a study at low risk of bias, high-intensity behavioural treatment plus bupropion was superior to low- or high-intensity behavioural treatment, depending on motivational stage, without pharmacotherapy ${ }^{37,41}$. Also, high-intensity behavioural treatment with hospitalisation plus recommendation of any NRT increased the chance of quitting compared with usual care ${ }^{37}$. However, this last study had a high risk of bias (see Addendum 2.5; Summary of findings table 5).

The included studies reported a wide variety of outcome measures, and different studies used different definitions for the same outcome measure. Some studies used point prevalence as the outcome measure, while other studies used continuous abstinence, and some used both. According to Velicer et al. ${ }^{66}$, the use of a combination of outcome measurements is often most appropriate in studies assessing the effects of a smoking cessation intervention.

Moreover, in different studies time points to assess the main outcome varied between six months and five years. The 'gold standard' for long-term follow-up is six or 12 months ${ }^{67}$. Most relapses occur early in a quit attempt, and then persist. A measure 
taken at six months would certainly capture the majority of those relapse events, and 12 months' follow-up would be even better ${ }^{30}$.

Also, six out of 16 studies had an overall high risk of bias, and three studies had an unclear risk of bias. This interfered with a clear and concise interpretation of the results. The most striking form of bias was the high proportion of missing data in 10 of the studies. Moreover, blinding was not possible in the behavioural interventions, resulting in a high risk of bias score in almost all of the included studies.

Finally, neither the exact content of the behavioural interventions nor that of usual care was always clearly described. This hampered the interpretation and implication of the results.

\section{Overall completeness and applicability of evidence}

We are confident that our rigorous search strategy ensured that we have identified the key research to inform this review. The studies in this review were conducted in different countries, which resulted in an international perspective of the results by comparing countries with cultural and economic differences. However, the trials on the same pharmacological intervention in smokers with COPD are limited to single studies only, except for two studies on bupropion. Also, the trials on behavioural interventions are very heterogeneous, and even though we categorised them into high- and lowintensity interventions according to the literature, this still hampers drawing univocal conclusions. Furthermore, the completeness of the evidence was restricted to smoking cessation outcomes and did not include clinical outcomes, such as FEV1.

\section{Quality of the evidence}

In the 'Summary of findings' tables the quality of the evidence in the different comparisons is illustrated using the GRADE approach. One study was of low quality, two studies and one pool of studies were of moderate quality, and two studies and one pool of studies were of high quality. In the meta-analysis, four studies, with a total of 1,429 participants, measured the effect of a pharmacological treatment plus behavioural treatment versus a placebo treatment plus behavioural treatment and showed strong and high-quality evidence in favour of pharmacological treatment plus behavioural treatment for smoking cessation in smokers with COPD. 


\section{Potential biases in the review process}

We undertook actions in order to decrease the chance of bias; to ensure that we included all relevant studies, we searched all relevant databases without major restrictions; in addition to the electronic search, we searched for planned, ongoing, and unpublished trials; we checked the reference lists of all included studies and of other systematic reviews in relevant topic areas and searched for errata or retractions from eligible trials; to decrease inter-rater variability, two review authors independently selected studies for inclusion; these review authors also independently extracted study characteristics from included studies and independently assessed the risk of bias for each study; and any disagreement was resolved by involving a third review author.

We used an intensity classification system for the different behavioural interventions. We distinguished high- from low-intensity behavioural treatment. This classification was based on existing criteria from the literature ${ }^{12}$. However, not all included studies used these criteria, and we had to reclassify some behavioural treatments, which might have introduced bias. Two review authors independently reclassified the behavioural interventions, resolving any disagreements by involving a third review author.

\section{Agreements and disagreements with other studies or reviews}

There is evidence that in the general smoking population NRT, bupropion, nortriptyline, varenicline, and cytisine are effective pharmacotherapies for smoking cessation. Varenicline has been shown to be superior to single forms of NRT and bupropion, but not to combination $\mathrm{NRT}^{15}$. Also, adding behavioural treatment to the use of pharmacological treatment shows a small but important effect in increasing the chances of quitting ${ }^{17}$.

In smokers with COPD, international guidelines recommend smoking cessation interventions that are similar to interventions for smokers without COPD ${ }^{25,68}$. However, the literature suggests that smokers with COPD have specific characteristics that reduce their chance of successful quitting compared with other smokers 3 , 18, 69-71. Currently, systematic reviews on smoking cessation interventions for smokers with COPD do not show differences compared to the general smoking population. Most of the existing reviews, including the previous version of this review ${ }^{23}$, included studies which showed that pharmacological treatment plus behavioural treatment is more effective than each strategy separately $y^{29,72-74}$. This conclusion is endorsed by the 
results of this review. There is little evidence on the intensity of behavioural treatments and the type of pharmacotherapy used ${ }^{29,73-75}$. This review adds that high-intensity behavioural treatment, according to our classification, seemed to result in higher abstinence rates when compared with low-intensity behavioural treatment. Furthermore, this review did not add conclusive information on the efficacy of the different pharmacological treatments, as the evidence from these studies had a high and unclear risk of bias.

\section{Authors' conclusions}

\section{Implications for practice}

Based on four studies involving 1,540 participants, we found high-quality evidence that a combination of behavioural treatment and pharmacotherapy is effective in helping smokers with COPD quit. Furthermore, we conclude that there is no convincing evidence for preferring any particular form of behavioural or pharmacological treatment.

\section{Implications for research}

There is no evidence to change the present international smoking cessation guidelines for smokers with COPD. The question still remains of whether smokers with COPD require a different smoking cessation treatment than smokers without COPD. Although some evidence suggests that smokers with COPD have specific features that make it harder for them to quit ${ }^{69,71}$, more research in this field is needed. Future research on smoking cessation interventions for smokers with COPD could then focus on investigating which behavioural-change techniques specifically motivate people with COPD to quit, and which could be added to existing interventions, such as symptom diaries or exercise capacity testing.

\section{Acknowledgements}

We would very much like to thank the editorial team of the Cochrane Airways Group (CAG), in particular Dr Emma Welsh and Emma Jackson, for their help in conducting and writing this systematic review. Furthermore, we would like to thank the CAG Information Specialist, Liz Stovold, for her advice. 
We thank Ayalu Reda for his constructive comments on the review text.

We thank Carl Brandt, Juan Chen, Lieke Christenhusz, Sander Hilberink, Daniel Kotz, Britt-Marie Sundblad, and Julie Wilson for providing additional information regarding their original studies.

We thank the following contributors for their respective translations in Farsi, Chinese, French, German, Polish, and Danish: Farhad Shokraneh, Ali Khamesipour, Zhi Hui Chang, Ben Shaw, Frederica Cassis, Samantha Lowry, Uwe Wollina, Filip Mejza, Marcin Stankiewicz, Jane Dennis, and Mia Schmidt-Hansen.

Julia Walters was the Editor for this review and commented critically on the review.

The background and methods sections of this review are based on a standard template used by the CAG.

This project was supported by the National Institute for Health Research (NIHR), via Cochrane Infrastructure funding to the Cochrane Airways Group. The views and opinions expressed therein are those of the authors and do not necessarily reflect those of the Systematic Reviews Programme, NIHR, NHS, or the Department of Health. 


\section{References}

1. From the Global Strategy for the Diagnosis, Management and Prevention of COPD, Global Initiative for Chronic Obstructive Lung Disease (GOLD) 2017. http://goldcopd.org. Accessed 17 November 2015.

2. Buist A.S., McBurnie M.A., Vollmer W.M., Gillespie S., Burney P., Mannino D.M., et al. International variation in the prevalence of COPD (the BOLD Study): a populationbased prevalence study. Lancet. 370, 741-750 (2007).

3. Shahab L., Jarvis M.J., Britton J., West R. Prevalence, diagnosis and relation to tobacco dependence of chronic obstructive pulmonary disease in a nationally representative population sample. Thorax. 61, 1043-1047 (2006).

4. Tzanakis N., Anagnostopoulou U., Filaditaki V., Christaki P., Siafakas N. Prevalence of COPD in Greece. Chest. 125, 892-900 (2004).

5. Geijer R.M., Sachs A.P., Hoes A.W., Salome P.L., Lammers J.W., Verheij T.J. Prevalence of undetected persistent airflow obstruction in male smokers $40-65$ years old. Fam Pract. 22, 485-489 (2005).

6. Mannino D.M., Buist A.S. Global burden of COPD: risk factors, prevalence, and future trends. Lancet. 370, 765-773 (2007).

7. Celli B.R., MacNee W. Standards for the diagnosis and treatment of patients with COPD: a summary of the ATS/ERS position paper. Eur Respir J. 23, 932-946 (2004).

8. Kohansal R., Martinez-Camblor P., Agusti A., Buist A.S., Mannino D.M., Soriano J.B. The natural history of chronic airflow obstruction revisited: an analysis of the Framingham offspring cohort. Am J Respir Crit Care Med. 180, 3-10 (2009).

9. Willemse B.W., Postma D.S., Timens W., ten Hacken N.H. The impact of smoking cessation on respiratory symptoms, lung function, airway hyperresponsiveness and inflammation. Eur Respir J. 23, 464-476 (2004).

10. Kerstjens H.A., Rijcken B., Schouten J.P., Postma D.S. Decline of FEV1 by age and smoking status: facts, figures, and fallacies. Thorax. 52, 820-827 (1997).

11. Anthonisen N.R., Connett J.E., Murray R.P. Smoking and lung function of Lung Health Study participants after 11 years. Am J Respir Crit Care Med. 166, 675-679 (2002).

12. US Department of Health and Human Services. Public Health Service. Clinical practice guideline. Treating tobacco use and dependence: 2008 update. www.ncbi.nlm.nih.gov/books/NBK63952/. Accessed 17 November 2015.

13. Hughes J.R. Use of nicotine replacement after a smoking lapse. Nicotine Tob Res. 14, 751-754 (2012).

14. Hughes J.R., Stead L.F., Hartmann-Boyce J., Cahill K., Lancaster T. Antidepressants for smoking cessation. Cochrane Database Syst Rev. CD000031 (2014).

15. Cahill K., Stevens S., Perera R., Lancaster T. Pharmacological interventions for smoking cessation: an overview and network meta-analysis. Cochrane Database Syst Rev. CD009329 (2013).

16. Hajek P., McRobbie H., Myers K. Efficacy of cytisine in helping smokers quit: systematic review and meta-analysis. Thorax. 1-6 (2013).

17. Stead L.F., Koilpillai P., Lancaster T. Additional behavioural support as an adjunct to pharmacotherapy for smoking cessation. Cochrane Database Syst Rev. CD009670 (2015).

18. Jimenez-Ruiz C.A., Masa F., Miravitlles M., Gabriel R., Viejo J.L., Villasante C., et al. Smoking characteristics: differences in attitudes and dependence between healthy smokers and smokers with COPD. Chest. 119, 1365-1370 (2001). 
19. van Eerd E.A., Risor M.B., van Rossem C.R., van Schayck O.C., Kotz D. Experiences of tobacco smoking and quitting in smokers with and without chronic obstructive pulmonary disease-a qualitative analysis. BMC Fam Pract. 16, (2015).

20. Borrelli B., Hayes R.B., Dunsiger S., Fava J.L. Risk perception and smoking behavior in medically ill smokers: a prospective study. Addiction. 105, 1100-1108 (2010).

21. Tønnesen P., Carrozzi L., Fagerstrom K.O., Gratziou C., Jimenez-Ruiz C., Nardini S., et al. Smoking cessation in patients with respiratory diseases: a high priority, integral component of therapy. Eur Respir J. 29, 390-417 (2007).

22. Wagena E.J., Knipschild P.G., Huibers M.J., Wouters E.F., van Schayck C.P. Efficacy of bupropion and nortriptyline for smoking cessation among people at risk for or with chronic obstructive pulmonary disease. Arch Intern Med. 165, 2286-2292 (2005).

23. van der Meer R.M., Wagena E.J., Ostelo R.W., Jacobs J.E., van Schayck C.P. Smoking cessation for chronic obstructive pulmonary disease. Cochrane Database Syst Rev. CD002999 (2003).

24. Qaseem A., Wilt T.J., Weinberger S.E., Hanania N.A., Criner G., van der Molen T., et al. Diagnosis and management of stable chronic obstructive pulmonary disease: a clinical practice guideline update from the American College of Physicians, American College of Chest Physicians, American Thoracic Society, and European Respiratory Society. Ann Intern Med. 155, 179-191 (2011).

25. National Institute for Health and Clinical Excellence. NICE guidelines: Stop smoking service. NICE guidelines [PH10]. www.nice.org.uk/guidance/ph10/chapter/introduction. Accessed 17 November 2015.

26. Hughes J.R., Keely J.P., Niaura R.S., Ossip-Klein D.J., Richmond R.L., Swan G.E. Measures of abstinence in clinical trials: issues and recommendations. Nicotine Tob Res. 5, 13-25 (2003).

27. Hilberink S.R., Jacobs J.E., van Opstal S., van der Weijden T., Keegstra J., Kempers P., et al. Validation of smoking cessation self-reported by patients with chronic obstructive pulmonary disease. Int J Gen Med. 4, 85-90 (2011).

28. Wilson J.S., Elborn J.S., Fitzsimons D., McCrum-Gardner E. Do smokers with chronic obstructive pulmonary disease report their smoking status reliably? A comparison of self-report and bio-chemical validation. Int J Nurs Stud. 48, 856-862 (2011).

29. Strassmann R., Bausch B., Spaar A., Kleijnen J., Braendli O., Puhan M.A. Smoking cessation interventions in COPD: a network meta-analysis of randomised trials. Eur Respir J. 34, 634-640 (2009).

30. West R., Hajek P., Stead L., Stapleton J. Outcome criteria in smoking cessation trials: proposal for a common standard. Addiction. 100, 299-303 (2005).

31. Liberati A., Altman D.G., Tetzlaff J., Mulrow C., Gotzsche P.C., loannidis J.P., et al. The PRISMA statement for reporting systematic reviews and meta-analyses of studies that evaluate health care interventions: explanation and elaboration. J Clin Epidemiol. 62, e1-34 (2009).

32. Heatherton T.F., Kozlowski L.T., Frecker R.C., Fagerstrom K.O. The Fagerstrom Test for Nicotine Dependence: a revision of the Fagerstrom Tolerance Questionnaire. $\mathrm{Br} J$ Addict. 86, 1119-1127 (1991).

33. Higgins JPT, Green S. Cochrane Handbook for Systematic Reviews of Interventions. Chichester, John Wiley \& Sons; 2008.

34. van Eerd EAM, van der Meer RM, Reda AA, van Schayck CP, Kotz D. Smoking cessation in smokers with chronic obstructive pulmonary disease. Cochrane Database Syst Rev. (2013) 
35. Guyatt G.H., Oxman A.D., Vist G.E., Kunz R., Falck-Ytter Y., Alonso-Coello P., et al. GRADE: an emerging consensus on rating quality of evidence and strength of recommendations. BMJ. 336, 924-926 (2008).

36. Tønnesen P., Mikkelsen K., Bremann L. Nurse-conducted smoking cessation in patients with COPD using nicotine sublingual tablets and behavioral support. Chest. 130, 334342 (2006).

37. Sundblad B.M., Larsson K., Nathell L. High rate of smoking abstinence in COPD patients: Smoking cessation by hospitalization. Nicotine Tob Res. 10, 883-890 (2008).

38. Anthonisen N.R., Connett J.E., Kiley J.P., Altose M.D., Bailey W.C., Buist A.S., et al. Effects of smoking intervention and the use of an inhaled anticholinergic bronchodilator on the rate of decline of FEV1. The Lung Health Study. JAMA. 272, 1497-1505 (1994).

39. Brandt C.J., Ellegaard H., Joensen M., Kallan F.V., Sorknaes A.D., Tougaard L. Effect of diagnosis of 'smoker's lung'. RYLUNG Group. Lancet. 349, 253 (1997).

40. Chen J., Chen Y., Chen P., Liu Z., Luo H., Cai S. Effectiveness of individual counseling for smoking cessation in smokers with chronic obstructive pulmonary disease and asymptomatic smokers. Exp Ther Med. 7, 716-720 (2014).

41. Christenhusz L., Pieterse M., Seydel E., van der Palen J. Prospective determinants of smoking cessation in COPD patients within a high intensity or a brief counseling intervention. Patient Educ Couns. 66, 162-166 (2007).

42. Crowley T.J., Macdonald M.J., Walter M.I. Behavioral anti-smoking trial in chronic obstructive pulmonary disease patients. Psychopharmacol Bull. 119, 193-204 (1995).

43. Hilberink S.R., Jacobs J.E., Breteler M.H.M., de Vries H., Grol R.P.T.M. General practice counseling for patients with chronic obstructive pulmonary disease to quit smoking: impact after 1 year of two complex interventions. Patient Educ Couns. 83, 120-124 (2011).

44. Kotz D., Wesseling G., Huibers M.J., van Schayck O.C. Efficacy of confronting smokers with airflow limitation for smoking cessation. Eur Respir J. 33, 754-762 (2009).

45. Lou P., Zhu Y., Chen P., Zhang P., Yu J., Zhang N., et al. Supporting smoking cessation in chronic obstructive pulmonary disease with behavioral intervention: a randomized controlled trial. BMC Fam Pract. 14, 91 (2013).

46. Gorecka D., Bednarek M., Nowinski A., Puscinska E., Goljan-Geremek A., Zielinski J. [Effect of treatment for nicotine dependence in patients with COPD]. Pneumonol Alergol Pol. 71, 411-417 (2003).

47. Pederson L.L., Wanklin J.M., Lefcoe N.M. The effects of counseling on smoking cessation among patients hospitalized with chronic obstructive pulmonary disease: a randomized clinical trial. Int J Addict. 26, 107-119 (1991).

48. Tashkin D., Kanner R., Bailey W., Buist S., Anderson P., Nides M., et al. Smoking cessation in patients with chronic obstructive pulmonary disease: a double-blind, placebo-controlled, randomised trial. Lancet. 357, 1571-1575 (2001).

49. Tashkin D.P., Rennard S., Hays J.T., Ma W., Lawrence D., Lee T.C. Effects of varenicline on smoking cessation in patients with mild to moderate COPD: a randomized controlled trial. Chest. 139, 591-599 (2011).

50. Wilson J.S., Fitzsimons D., Bradbury I., Stuart Elborn J. Does additional support by nurses enhance the effect of a brief smoking cessation intervention in people with moderate to severe chronic obstructive pulmonary disease? A randomised controlled trial. Int J Nurs Stud. 45, 508-517 (2008). 
51. Kallan F.V., Brandt C.J., Ellegaard H., Joensen M.B., Sorknaes A.D., Tougaard L. [The diagnosis of 'smoker's lung' encourages smoking cessation]. Ugeskr Laeger. 159, 65286530 (1997).

52. Christenhusz L.C., Prenger R., Pieterse M.E., Seydel E.R., van der Palen J. Costeffectiveness of an intensive smoking cessation intervention for COPD outpatients. Nicotine Tob Res. 14, 657-663 (2012).

53. Hilberink S.R., Jacobs J.E., Bottema B.J., de Vries H., Grol R.P. Smoking cessation in patients with COPD in daily general practice (SMOCC): six months' results. Prev Med. 41, 822-827 (2005).

54. Van Schayck C.P., Kaper J., Wagena E.J., Wouters E.F., Severens J.L. The costeffectiveness of antidepressants for smoking cessation in chronic obstructive pulmonary disease (COPD) patients. Addiction. 104, 2110-2117 (2009).

55. Tashkin D.P., Rennard S., Taylor Hays J., Lawrence D., Marton J.P., Lee T.C. Lung function and respiratory symptoms in a 1-year randomized smoking cessation trial of varenicline in COPD patients. Respir Med. 105, 1682-1690 (2011).

56. Lock K., Wilson K., Murphy D., Riesco J.A. A cost-effectiveness model of smoking cessation based on a randomised controlled trial of varenicline versus placebo in patients with chronic obstructive pulmonary disease. Expert Opin Pharmacother. 12, 2613-2626 (2011).

57. Wilson J.S., Elborn J.S., Fitzsimons D. 'It's not worth stopping now': why do smokers with chronic obstructive pulmonary disease continue to smoke? A qualitative study. $J$ Clin Nurs. 20, 819-827 (2011).

58. Kotz D., Wesseling G., Huibers M.J., van Schayck O.C. Efficacy of confrontational counselling for smoking cessation in smokers with previously undiagnosed mild to moderate airflow limitation: study protocol of a randomized controlled trial. BMC Public Health. 7, 332 (2007).

59. Kotz D., Huibers M.J., West R.J., Wesseling G., van Schayck O.C. What mediates the effect of confrontational counselling on smoking cessation in smokers with COPD? Patient Educ Couns. 76, 16-24 (2009).

60. Kotz D., Vos R., Huibers M.J. Ethical analysis of the justifiability of labelling with COPD for smoking cessation. J Med Ethics. 35, 534-540 (2009).

61. Connett J.E., Bjornson-Benson W.M., Daniels K. Recruitment of participants in the Lung Health Study, II: Assessment of recruiting strategies. Control Clin Trials. 14, 38S-51S (1993).

62. O'Hara P., Grill J., Rigdon M.A., Connett J.E., Lauger G.A., Johnston J.J. Design and results of the initial intervention program for the Lung Health Study. The Lung Health Study Research Group. Prev Med. 22, 304-315 (1993).

63. Buist A.S. The US Lung Health Study. Respirology. 2, 303-307 (1997).

64. Scanlon P.D., Connett J.E., Waller L.A., Altose M.D., Bailey W.C., Buist A.S., et al. Smoking cessation and lung function in mild-to-moderate chronic obstructive pulmonary disease. The Lung Health Study. Am J Respir Crit Care Med. 161, 381-390 (2000).

65. Clinical trial registers. www.ClinicalTrials.gov. Accessed 22 March 2016.

66. Velicer W.F., Prochaska J.O., Rossi J.S., Snow M.G. Assessing outcome in smoking cessation studies. Psychol Bull. 111, 23-41 (1992).

67. Hatsukami D.K., Mooney M.E. Pharmacological and Behavioral Strategies for Smoking Cessation. J Clin Psychol Med Settings. 6, 11-38 (1999).

68. West R., McNeill A., Raw M. Smoking cessation guidelines for health professionals: an update. Health Education Authority. Thorax. 55, 987-999 (2000). 
69. Jimenez-Ruiz C.A., Andreas S., Lewis K.E., Tønnesen P., van Schayck C.P., Hajek P., et al. Statement on smoking cessation in COPD and other pulmonary diseases and in smokers with comorbidities who find it difficult to quit. Eur Respir J. 46, 61-79 (2015).

70. Tashkin D.P., Murray R.P. Smoking cessation in chronic obstructive pulmonary disease. Respir Med. 103, 963-974 (2009).

71. van Eerd E.A., van Rossem C.R., Spigt M.G., Wesseling G., van Schayck O.C., Kotz D. Do we need tailored smoking cessation interventions for smokers with COPD? A comparative study of smokers with and without COPD regarding factors associated with tobacco smoking. Respiration. 90, 211-219 (2015).

72. Piresyfantouda R., Absalom G., Clemens F. Smoking Cessation Interventions for Chronic Obstructive Pulmonary Disease - A Review of the literature. Respir Care. (2013).

73. Thabane M. Smoking cessation for patients with chronic obstructive pulmonary disease (COPD): an evidence-based analysis. Ont Health Technol Assess Ser. 12, 1-50 (2012).

74. Warnier M.J., Riet E.E., Rutten F.H., Bruin M.L., Sachs A.P. Smoking cessation strategies in patients with chronic obstructive pulmonary disease. Eur Respir J. (2013).

75. Coronini-Cronberg S., Heffernan C., Robinson M. Effective smoking cessation interventions for COPD patients: a review of the evidence. JRSM Short Rep. 2, 78 (2011). 


\section{Addendum 2.1 - Summary of findings table 1}

Behavioural treatment compared to no treatment or usual care in smokers with COPD

\begin{tabular}{|c|c|c|c|c|c|c|}
\hline \multicolumn{7}{|c|}{$\begin{array}{l}\text { Patient or population: smokers with COPD } \\
\text { Setting: in- and outpatients } \\
\text { Intervention: behavioural treatment } \\
\text { Comparison: no treatment or usual care }\end{array}$} \\
\hline \multirow[t]{3}{*}{ Outcomes } & $\begin{array}{l}\text { Illustrative c } \\
(95 \% \mathrm{Cl})\end{array}$ & pparative risks* & \multirow{3}{*}{$\begin{array}{l}\text { Relative } \\
\text { effect } \\
(95 \% \mathrm{Cl})\end{array}$} & \multirow{3}{*}{$\begin{array}{l}\text { No of } \\
\text { participants } \\
\text { (studies) }\end{array}$} & \multirow{3}{*}{$\begin{array}{l}\text { Quality of } \\
\text { the } \\
\text { evidence } \\
\text { (GRADE) }\end{array}$} & \multirow[t]{3}{*}{ Comments } \\
\hline & Assumed risk & $\begin{array}{l}\text { Corresponding } \\
\text { risk }\end{array}$ & & & & \\
\hline & $\begin{array}{l}\text { No treatment } \\
\text { or usual care }\end{array}$ & $\begin{array}{l}\text { Behavioural } \\
\text { treatment }\end{array}$ & & & & \\
\hline $\begin{array}{l}\text { Prolonged } \\
\text { abstinence at } \\
\text { longest } \\
\text { follow-up } \\
\text { Follow up: } 6 \\
\text { months }\end{array}$ & 2 per 1,000 & $\begin{array}{l}44 \text { per } 1,000 \\
\text { (14 to } 138)\end{array}$ & $\begin{array}{l}\text { RR } 25.38 \\
(8.03 \text { to } \\
80.22)\end{array}$ & $\begin{array}{l}3562 \\
\text { (1 study) }\end{array}$ & $\begin{array}{l}\oplus \oplus \oplus \ominus \\
\text { moderate }\end{array}$ & \\
\hline $\begin{array}{l}\text { Point } \\
\text { prevalence } \\
\text { abstinence at } \\
\text { longest } \\
\text { follow-up } \\
\text { Follow up: } \\
12-48 \\
\text { months }\end{array}$ & $\begin{array}{l}\text { See } \\
\text { comment }\end{array}$ & See comment & $\begin{array}{l}\text { Not } \\
\text { estimable }\end{array}$ & $\begin{array}{l}3618 \\
\text { (2 studies) }\end{array}$ & $\begin{array}{l}\text { See } \\
\text { comment }\end{array}$ & $\begin{array}{l}\text { Due to clinical and } \\
\text { statistical } \\
\text { heterogeneity, } \\
\text { studies were not } \\
\text { pooled. Individual RR } \\
\text { were } 1.98 \text { ( } 95 \% \mathrm{Cl} \\
0.74,5.31) \text { and RR } \\
9.33(95 \% \mathrm{Cl} 7.26 \text {, } \\
11.99) .1 \text { study had a } \\
\text { high risk of bias due } \\
\text { to a serious risk of } \\
\text { contamination bias }\end{array}$ \\
\hline
\end{tabular}

*The basis for the assumed risk (e.g. the median control group risk across studies) is provided in footnotes. The corresponding risk (and its 95\% confidence interval) is based on the assumed risk in the comparison group and the relative effect of the intervention (and its 95\% Cl). Cl: confidence interval; COPD: chronic obstructive pulmonary disease; RR: risk ratio

GRADE Working Group grades of evidence

High quality: Further research is very unlikely to change our confidence in the estimate of effect.

Moderate quality: Further research is likely to have an important impact on our confidence in the estimate of effect and may change the estimate.

Low quality: Further research is very likely to have an important impact on our confidence in the estimate of effect and is likely to change the estimate.

Very low quality: We are very uncertain about the estimate.

${ }^{1}$ This study had an unclear risk of bias as several important items were scored unclear, for example random sequence generation and allocation concealment. Downgrade once 


\section{Addendum 2.2 - Summary of findings table 2}

One form of behavioural treatment compared to a different form of behavioural treatment in

\begin{tabular}{|c|c|c|c|c|c|c|}
\hline \multicolumn{7}{|c|}{$\begin{array}{l}\text { Patient or population: smokers with COPD } \\
\text { Setting: in- and outpatients } \\
\text { Intervention: one form of behavioural treatment } \\
\text { Comparison: a different form of behavioural treatment }\end{array}$} \\
\hline \multirow[t]{3}{*}{ Outcomes } & \multicolumn{2}{|c|}{$\begin{array}{l}\text { Illustrative comparative risks* } \\
(95 \% \mathrm{Cl})\end{array}$} & \multirow{3}{*}{$\begin{array}{l}\text { Relative } \\
\text { effect } \\
(95 \% \mathrm{Cl})\end{array}$} & \multirow{3}{*}{$\begin{array}{l}\text { No of } \\
\text { participants } \\
\text { (studies) }\end{array}$} & \multirow{3}{*}{$\begin{array}{l}\text { Quality of } \\
\text { the } \\
\text { evidence } \\
\text { (GRADE) }\end{array}$} & \multirow[t]{3}{*}{ Comments } \\
\hline & Assumed risk & $\begin{array}{l}\text { Corresponding } \\
\text { risk }\end{array}$ & & & & \\
\hline & $\begin{array}{l}\text { A different } \\
\text { form of } \\
\text { behavioural } \\
\text { treatment }\end{array}$ & $\begin{array}{l}\text { One form of } \\
\text { behavioural } \\
\text { treatment }\end{array}$ & & & & \\
\hline $\begin{array}{l}\text { Prolonged } \\
\text { abstinence } \\
\text { at longest } \\
\text { follow-up } \\
\text { Follow up: } \\
6-12 \\
\text { months }\end{array}$ & $\begin{array}{l}\text { See } \\
\text { comment }\end{array}$ & See comment & $\begin{array}{l}\text { Not } \\
\text { estimable }\end{array}$ & $\begin{array}{l}739 \\
\text { (4 studies) }\end{array}$ & $\begin{array}{l}\text { See } \\
\text { comment }\end{array}$ & $\begin{array}{l}\text { No pooling due to clinical } \\
\text { and statistical } \\
\text { heterogeneity. Individual RR } \\
\text { were } 2.18(1.05,4.49), \text { RR } \\
0.97(0.47,1.99), R R 1.09 \\
(0.59,2.04) \text {, and RR not } \\
\text { estimable. } 3 \text { of the } 4 \text { studies } \\
\text { had a low risk of bias. } 1 \\
\text { study had a high risk of bias } \\
\text { due to poor adherence to } \\
\text { the study protocol }\end{array}$ \\
\hline $\begin{array}{l}\text { Point } \\
\text { prevalence } \\
\text { abstinence } \\
\text { at longest } \\
\text { follow-up } \\
\text { Follow up: } \\
6 \text {-12 } \\
\text { months }\end{array}$ & $\begin{array}{l}\text { See } \\
\text { comment }\end{array}$ & See comment & $\begin{array}{l}\text { Not } \\
\text { estimable }\end{array}$ & $\begin{array}{l}500 \\
\text { (3 studies) }\end{array}$ & $\begin{array}{l}\text { See } \\
\text { comment }\end{array}$ & $\begin{array}{l}\text { No pooling due to clinical } \\
\text { and statistical } \\
\text { heterogeneity. Individual RR } \\
\text { were } 1.67(0.68,4.11), \text { RR } \\
1.35(0.80,2.28) \text {, and RR } \\
0.15(0.01,2.83) .1 \text { study } \\
\text { had a low risk of bias, } 1 \\
\text { study had a high risk of bias } \\
\text { due to participants' poor } \\
\text { adherence to the study } \\
\text { protocol, and the remaining } \\
\text { study had an unclear risk of } \\
\text { bias }\end{array}$ \\
\hline
\end{tabular}

smokers with COPD

*The basis for the assumed risk (e.g. the median control group risk across studies) is provided in footnotes. The corresponding risk (and its $95 \%$ confidence interval) is based on the assumed risk in the comparison group and the relative effect of the intervention (and its 95\% Cl). Cl: confidence interval; COPD: chronic obstructive pulmonary disease; RR: risk ratio

GRADE Working Group grades of evidence

High quality: Further research is very unlikely to change our confidence in the estimate of effect.

Moderate quality: Further research is likely to have an important impact on our confidence in the estimate of effect and may change the estimate.

Low quality: Further research is very likely to have an important impact on our confidence in the estimate of effect and is likely to change the estimate.

Very low quality: We are very uncertain about the estimate. 


\section{Addendum 2.3 - Summary of findings table 3}

Pharmacological treatment compared to placebo in smokers with COPD

\begin{tabular}{|c|c|c|c|c|c|c|}
\hline \multicolumn{7}{|c|}{$\begin{array}{l}\text { Patient or population: smokers with COPD } \\
\text { Setting: in- and outpatients } \\
\text { Intervention: pharmacological treatment } \\
\text { Comparison: placebo }\end{array}$} \\
\hline \multirow[t]{3}{*}{ Outcomes } & \multicolumn{2}{|c|}{$\begin{array}{l}\text { Illustrative comparative risks* } \\
(95 \% \mathrm{Cl})\end{array}$} & \multirow{3}{*}{$\begin{array}{l}\text { Relative } \\
\text { effect } \\
(95 \% \mathrm{Cl})\end{array}$} & \multirow{3}{*}{$\begin{array}{l}\text { No of } \\
\text { participants } \\
\text { (studies) }\end{array}$} & \multirow{3}{*}{$\begin{array}{l}\text { Quality of } \\
\text { the } \\
\text { evidence } \\
\text { (GRADE) }\end{array}$} & \multirow[t]{3}{*}{ Comments } \\
\hline & $\begin{array}{l}\text { Assumed } \\
\text { risk }\end{array}$ & $\begin{array}{l}\text { Corresponding } \\
\text { risk }\end{array}$ & & & & \\
\hline & Placebo & $\begin{array}{l}\text { Pharmacological } \\
\text { treatment }\end{array}$ & & & & \\
\hline $\begin{array}{l}\text { Prolonged } \\
\text { abstinence at } \\
\text { longest follow- } \\
\text { up } \\
\text { Follow up: 6-12 } \\
\text { months }\end{array}$ & $\begin{array}{l}66 \text { per } \\
1000\end{array}$ & $\begin{array}{l}168 \text { per } 1000 \\
\text { (136 to } 207)\end{array}$ & $\begin{array}{l}\text { RR } 2.53 \\
(95 \% \mathrm{Cl} \\
1.83,3.50)\end{array}$ & $\begin{array}{l}1429 \\
\text { (4 studies) }\end{array}$ & $\underset{\text { high }^{1,2}}{\bigoplus} \oplus$ & $\begin{array}{l}\text { Point prevalence } \\
\text { abstinence at longest } \\
\text { follow-up } \\
\text { Follow-up: } 6 \text { to } 12 \\
\text { months RR } 2.54(95 \% \mathrm{Cl} \\
0.87,7.44)\end{array}$ \\
\hline $\begin{array}{l}\text { Prolonged } \\
\text { abstinence at } \\
\text { longest follow- } \\
\text { up; nicotine } \\
\text { replacement } \\
\text { therapy } \\
\text { Follow up: } 12 \\
\text { months }\end{array}$ & $\begin{array}{l}54 \text { per } \\
1000\end{array}$ & $\begin{array}{l}141 \text { per } 1000 \\
\text { (70 to } 283 \text { ) }\end{array}$ & $\begin{array}{l}\text { RR } 2.60 \\
(1.29 \text { to } \\
5.24)\end{array}$ & $\begin{array}{l}370 \\
\text { (1 study) }\end{array}$ & $\begin{array}{l}\oplus \oplus \oplus \oplus \\
\text { high }\end{array}$ & $\begin{array}{l}\text { Point prevalence } \\
\text { abstinence at longest } \\
\text { follow-up; nicotine } \\
\text { replacement therapy } \\
\text { Follow up: } 12 \text { months } \\
\text { RR 1.78 ( } 95 \% \text { Cl 1.04, } \\
\text { 3.05) }\end{array}$ \\
\hline $\begin{array}{l}\text { Prolonged } \\
\text { abstinence at } \\
\text { longest follow- } \\
\text { up; bupropion } \\
\text { Follow up: } 6 \\
\text { months }\end{array}$ & $\begin{array}{l}87 \text { per } \\
1000\end{array}$ & $\begin{array}{l}177 \text { per } 1000 \\
(110 \text { to } 285)\end{array}$ & $\begin{array}{l}\text { RR } 2.03 \\
(1.26 \text { to } \\
3.28)\end{array}$ & $\begin{array}{l}503 \\
\text { (2 studies) }\end{array}$ & $\begin{array}{l}\oplus \oplus \oplus \ominus \\
\text { moderate }^{3}\end{array}$ & $\begin{array}{l}\text { Point prevalence } \\
\text { abstinence at longest } \\
\text { follow-up; bupropion } \\
\text { Follow up: } 6 \text { months } \\
\text { RR 1.46 ( } 95 \% \text { Cl 0.97, } \\
\text { 2.19) }\end{array}$ \\
\hline $\begin{array}{l}\text { Prolonged } \\
\text { abstinence at } \\
\text { longest follow- } \\
\text { up; varenicline } \\
\text { Follow up: } 12 \\
\text { months }\end{array}$ & $\begin{array}{l}55 \text { per } \\
1000\end{array}$ & $\begin{array}{l}184 \text { per } 1000 \\
\text { (104 to } 326)\end{array}$ & $\begin{array}{l}\text { RR } 3.34 \\
(1.88 \text { to } \\
5.92)\end{array}$ & $\begin{array}{l}504 \\
\text { (1 study) }\end{array}$ & $\begin{array}{l}\oplus \oplus \oplus \oplus \\
\text { high }\end{array}$ & $\begin{array}{l}\text { Point prevalence } \\
\text { abstinence at longest } \\
\text { follow-up; varenicline } \\
\text { Follow up: } 12 \text { months } \\
\text { RR } 1.83 \text { ( } 95 \% \text { Cl } 1.27 \text {, } \\
2.65 \text { ) }\end{array}$ \\
\hline $\begin{array}{l}\text { Prolonged } \\
\text { abstinence at } \\
\text { longest follow- } \\
\text { up; } \\
\text { nortriptyline } \\
\text { Follow up: } 6 \\
\text { months }\end{array}$ & $\begin{array}{l}83 \text { per } \\
1000\end{array}$ & $\begin{array}{l}212 \text { per } 1000 \\
\text { ( } 73 \text { to } 620)\end{array}$ & $\begin{array}{l}\text { RR } 2.54 \\
(0.87 \text { to } \\
7.44)\end{array}$ & $\begin{array}{l}100 \\
\text { (1 study) }\end{array}$ & $\underset{\text { low }_{4,5}}{\oplus \bigoplus \ominus}$ & $\begin{array}{l}\text { No point prevalence } \\
\text { data available }\end{array}$ \\
\hline
\end{tabular}

*The basis for the assumed risk (e.g. the median control group risk across studies) is provided in footnotes. The corresponding risk (and its 95\% confidence interval) is based on the assumed risk in the comparison group and the relative effect of the intervention (and its $95 \% \mathrm{CI}$ ). $\mathrm{Cl}$ : confidence interval; COPD: chronic obstructive pulmonary disease; RR: risk ratio

GRADE Working Group grades of evidence High quality: Further research is very unlikely to change our confidence in the estimate of effect. Moderate quality: Further research is likely to have an important impact on our confidence in the estimate of effect and may change the estimate. Low quality: Further research is very likely to have an important impact on our confidence in the estimate of effect and is likely to change the estimate. Very low quality: We are very uncertain about the estimate.

${ }^{1}$ Three studies had a low risk of bias. One study had a high risk of bias due to poor adherence to the study protocol. No downgrade. ${ }^{2}$ Sensitivity analyses including only those studies judged to be at low risk of bias did not impact the pooled results. No downgrade. ${ }^{3}$ One study had a low risk of bias. One study had a high risk of bias due to poor adherence to the study protocol. Downgrade once. ${ }^{4}$ This study had a high risk of bias due to poor adherence to the study protocol. Downgrade once. ${ }^{5}$ Point estimate for prolonged abstinence includes no difference. Downgrade once for imprecision. 


\section{Addendum 2.4 - Summary of findings table 4}

Pharmacological treatment compared to a different pharmacological treatment in smokers with

\begin{tabular}{|c|c|c|c|c|c|c|}
\hline \multicolumn{7}{|c|}{$\begin{array}{l}\text { Patient or population: smokers with COPD } \\
\text { Setting: in- and outpatients } \\
\text { Intervention: pharmacological treatment } \\
\text { Comparison: a different pharmacological treatment }\end{array}$} \\
\hline \multirow[t]{3}{*}{ Outcomes } & \multicolumn{2}{|c|}{$\begin{array}{l}\text { Illustrative comparative risks* }(95 \% \\
\mathrm{Cl})\end{array}$} & \multirow{3}{*}{$\begin{array}{l}\text { Relative } \\
\text { effect } \\
(95 \% \mathrm{Cl})\end{array}$} & \multirow{3}{*}{$\begin{array}{l}\text { No of } \\
\text { participants } \\
\text { (studies) }\end{array}$} & \multirow{3}{*}{$\begin{array}{l}\text { Quality of } \\
\text { the } \\
\text { evidence } \\
\text { (GRADE) }\end{array}$} & \multirow[t]{3}{*}{ Comments } \\
\hline & Assumed risk & $\begin{array}{l}\text { Corresponding } \\
\text { risk }\end{array}$ & & & & \\
\hline & $\begin{array}{l}\text { A different } \\
\text { pharmacological } \\
\text { treatment }\end{array}$ & $\begin{array}{l}\text { Pharmacological } \\
\text { treatment }\end{array}$ & & & & \\
\hline $\begin{array}{l}\text { Prolonged } \\
\text { abstinence } \\
\text { at longest } \\
\text { follow-up } \\
\text { Follow up: } \\
6-12 \\
\text { months }\end{array}$ & See comment & See comment & $\begin{array}{l}\text { Not } \\
\text { estimable }\end{array}$ & $\begin{array}{l}166 \\
\text { (2 studies) }\end{array}$ & $\begin{array}{l}\text { See } \\
\text { comment }\end{array}$ & $\begin{array}{l}\text { No pooling due to } \\
\text { clinical and statistical } \\
\text { heterogeneity. NRT vs } \\
\text { bupropion RR } 0.74 \text { [ } 95 \% \\
\text { Cl } 0.27,2.05] \text {, } \\
\text { bupropion vs } \\
\text { nortriptyline RR } 1.29 \\
{[95 \% \mathrm{Cl} 0.63,2.63] .1} \\
\text { study had a high risk of } \\
\text { bias due to poor } \\
\text { adherence to the study } \\
\text { protocol. } 1 \text { study had an } \\
\text { unclear risk of bias }\end{array}$ \\
\hline $\begin{array}{l}\text { Point } \\
\text { prevalence } \\
\text { abstinence } \\
\text { at longest } \\
\text { follow-up } \\
\text { Follow up: } \\
12 \text { months }\end{array}$ & 62 per 1000 & $\begin{array}{l}155 \text { per } 1000 \\
\text { (91 to } 264)\end{array}$ & $\begin{array}{l}\text { RR } 2.50 \\
(1.47 \text { to } \\
4.26)\end{array}$ & $\begin{array}{l}543 \\
\text { (1 study) }\end{array}$ & $\begin{array}{l}\oplus \oplus \oplus \ominus^{1} \\
\text { moderate }\end{array}$ & $\begin{array}{l}\text { NRT vs NRT plus } \\
\text { bupropion }\end{array}$ \\
\hline
\end{tabular}

*The basis for the assumed risk (e.g. the median control group risk across studies) is provided in footnotes. The corresponding risk (and its 95\% confidence interval) is based on the assumed risk in the comparison group and the relative effect of the intervention (and its 95\% Cl). Cl: confidence interval; COPD: chronic obstructive pulmonary disease; RR: risk ratio

GRADE Working Group grades of evidence

High quality: Further research is very unlikely to change our confidence in the estimate of effect.

Moderate quality: Further research is likely to have an important impact on our confidence in the estimate of effect and may change the estimate.

Low quality: Further research is very likely to have an important impact on our confidence in the estimate of effect and is likely to change the estimate.

Very low quality: We are very uncertain about the estimate.

${ }^{1}$ This study had a high risk of bias due to contamination bias. Downgrade once. 


\section{Addendum 2.5 - Summary of findings table 5}

Combination interventions compared to different (combination) interventions or usual care in smokers with COPD

\begin{tabular}{|c|c|c|c|c|c|c|}
\hline \multicolumn{7}{|c|}{$\begin{array}{l}\text { Patient or population: smokers with COPD } \\
\text { Setting: in- and outpatients } \\
\text { Intervention: combination interventions } \\
\text { Comparison: different (combination) interventions or usual care }\end{array}$} \\
\hline \multirow[t]{3}{*}{ Outcomes } & \multicolumn{2}{|c|}{$\begin{array}{l}\text { Illustrative comparative risks* } \\
(95 \% \mathrm{Cl})\end{array}$} & \multirow{3}{*}{$\begin{array}{l}\text { Relative } \\
\text { effect } \\
(95 \% \mathrm{Cl})\end{array}$} & \multirow{3}{*}{$\begin{array}{l}\text { No of } \\
\text { participants } \\
\text { (studies) }\end{array}$} & \multirow{3}{*}{$\begin{array}{l}\text { Quality of } \\
\text { the } \\
\text { evidence } \\
\text { (GRADE) }\end{array}$} & \multirow[t]{3}{*}{ Comments } \\
\hline & Assumed risk & $\begin{array}{l}\text { Corresponding } \\
\text { risk }\end{array}$ & & & & \\
\hline & $\begin{array}{l}\text { Different } \\
\text { (combination) } \\
\text { interventions } \\
\text { or usual care }\end{array}$ & $\begin{array}{l}\text { Combination } \\
\text { interventions }\end{array}$ & & & & \\
\hline $\begin{array}{l}\text { Prolonged } \\
\text { abstinence } \\
\text { at longest } \\
\text { follow-up } \\
\text { Follow up: } \\
6-60 \\
\text { months }\end{array}$ & See comment & See comment & $\begin{array}{l}\text { Not } \\
\text { estimable }\end{array}$ & $\begin{array}{l}6431 \\
\text { (4 studies) }\end{array}$ & $\begin{array}{l}\text { See } \\
\text { comment }\end{array}$ & $\begin{array}{l}\text { No pooling due to clinical } \\
\text { and statistical } \\
\text { heterogeneity. Individual } \\
\text { RR } 4.10(3.36,5.00), \text { RR } \\
2.22(1.06,4.68), \text { RR } 1.91 \\
(0.65,5.61) \text {, and RR not } \\
\text { estimable. } 3 \text { studies had a } \\
\text { low risk of bias, } 1 \text { study } \\
\text { had a high risk of bias due } \\
\text { to poor adherence to the } \\
\text { study protocol }\end{array}$ \\
\hline $\begin{array}{l}\text { Point } \\
\text { prevalence } \\
\text { abstinence } \\
\text { at longest } \\
\text { follow-up } \\
\text { Follow up: } \\
\text { 6-12 } \\
\text { months }\end{array}$ & See comment & See comment & $\begin{array}{l}\text { Not } \\
\text { estimable }\end{array}$ & $\begin{array}{l}1535 \\
\text { (4 studies) }\end{array}$ & $\begin{array}{l}\text { See } \\
\text { comment }\end{array}$ & $\begin{array}{l}\text { No pooling. Individual RR } \\
\text { were } 1.60(0.89,2.89), \text { RR } \\
2.21(0.89,5.52), \text { RR } 3.41 \\
(2.15,5.41), \text { RR } 0.43(0.02 \text {, } \\
10.12) \text {, and RR } 3.62(0.40 \text {, } \\
32.97) .3 \text { studies had a } \\
\text { high risk of bias due to } \\
\text { contamination bias, poor } \\
\text { adherence to the study } \\
\text { protocol, or poor } \\
\text { validation of outcome. } 1 \\
\text { study had a low risk of } \\
\text { bias }\end{array}$ \\
\hline
\end{tabular}

*The basis for the assumed risk (e.g. the median control group risk across studies) is provided in footnotes. The corresponding risk (and its $95 \%$ confidence interval) is based on the assumed risk in the comparison group and the relative effect of the intervention (and its 95\% CI). Cl: confidence interval; COPD: chronic obstructive pulmonary disease; RR: risk ratio

GRADE Working Group grades of evidence

High quality: Further research is very unlikely to change our confidence in the estimate of effect.

Moderate quality: Further research is likely to have an important impact on our confidence in the estimate of effect and may change the estimate.

Low quality: Further research is very likely to have an important impact on our confidence in the estimate of effect and is likely to change the estimate.

Very low quality: We are very uncertain about the estimate. 
Do we need tailored smoking cessation interventions for smokers with COPD? A comparative study of smokers with and without COPD regarding factors associated with tobacco smoking

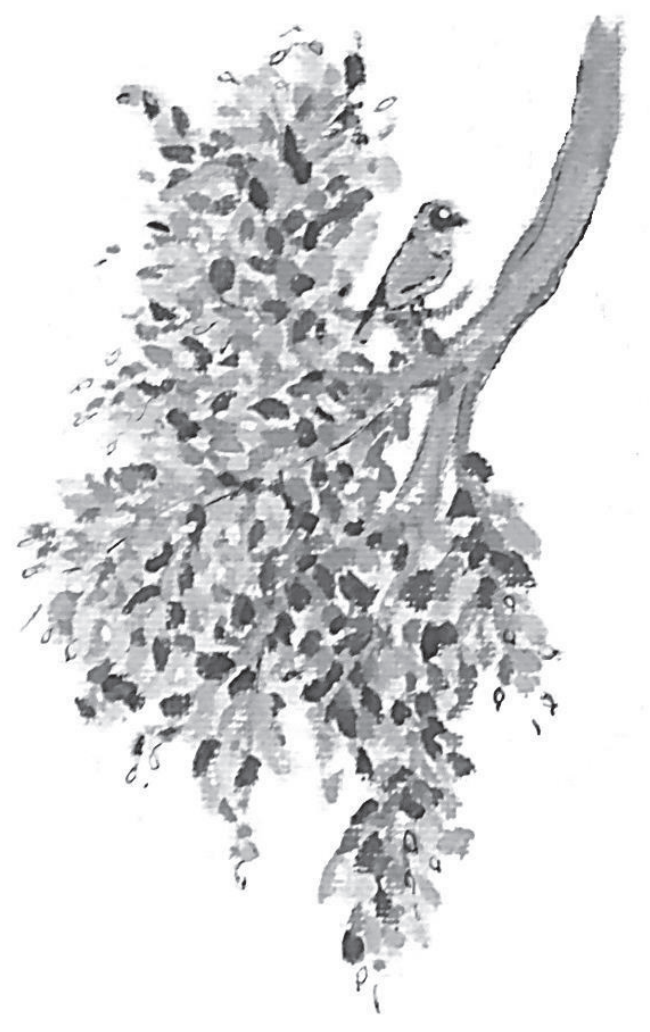

Eva van Eerd Carolien van Rossem Mark Spigt Geertjan Wesseling Onno van Schayck Daniel Kotz

Published as Respiration 2015;90(3):211-9 


\section{Abstract \\ Background}

The prevalence of tobacco smoking in patients with chronic obstructive pulmonary disease (COPD) is high. It is assumed that this group of smokers has more difficulties quitting than smokers without COPD. In order to increase the effectiveness of smoking cessation treatments in smokers with COPD it is important to identify any smokingrelated factors which are specific in this group of smokers.

\section{Objective}

To compare smokers with COPD with smokers without COPD regarding factors associated with tobacco smoking and quitting.

\section{Methods}

We conducted a questionnaire survey in all smoking patients with a recorded diagnosis of COPD from a large Dutch primary health care network. We compared this group with twice as many age-, sex-, and health care centre-matched smokers without COPD.

\section{Results}

Respondents were 107 smokers with COPD and 86 smokers without COPD. The number of attempts to quit was similar in both groups but more smokers with COPD had ever used pharmacological, behavioural and alternative smoking cessation treatments. Furthermore, smokers with COPD more often received triggers to quit from their environment and from their general practitioner, and they were more concerned about, and aware of, the health risks of smoking. Importantly, smokers with COPD reported higher levels of depression and cigarette dependence and a lower selfefficacy to refrain from smoking than smokers without COPD.

\section{Conclusion}

Smokers with COPD differ from smokers without COPD on several factors which are associated with tobacco smoking and quitting. Taking into account these differences may help to increase the effectiveness of smoking cessation treatments for the specific group of smokers with COPD. 


\section{Introduction}

In developed countries, tobacco smoking is the most important risk factor for developing chronic obstructive pulmonary disease (COPD) ${ }^{1}$. In the Netherlands, for example, $85 \%$ of new COPD cases is attributed to smoking ${ }^{2}$. Furthermore, smoking has a detrimental effect on the course of this disease ${ }^{3}$. An overview of the literature showed that the forced expiratory volume in one second in male smokers with mild to moderate COPD declined within a range of 42 to $82 \mathrm{~mL} / \mathrm{y}$ compared with 0 to $49 \mathrm{~mL} / \mathrm{y}$ in males with COPD who quit smoking ${ }^{4}$. Moreover, the Lung Health Study has shown that, after 11 years, 38\% of those with COPD who continued smoking had a forced expiratory volume in one second less than $60 \%$ of the predicted normal value compared with $10 \%$ for those who had quit ${ }^{5}$.

From this it becomes clear that smoking cessation is the intervention with the biggest positive impact on the course of $\mathrm{COPD}^{3}$. The Cochrane review on smoking cessation in smokers with COPD concluded that a combination of behavioural and pharmacological interventions is superior to any other treatment separately ${ }^{6}$. Despite the availability of these evidence-based interventions, the prevalence of smoking in patients with COPD is still high, exceeding the rate of smoking in the general population. For example, a large population-based English study showed that the prevalence of smoking currently was $35 \%$ among people with COPD compared with $22 \%$ among people without COPD ${ }^{7}$.

The higher prevalence of smoking among COPD patients, suggests that, compared with smokers from the general population, smokers with COPD find it more difficult to quit smoking. However, the results from studies that compared smokers with COPD with smokers without COPD have been ambiguous. For example, in a small longitudinal study from the Netherlands high smoking cessation rates were found in participants both with and without COPD $^{8}$, while in a different Dutch study smokers with mild-tosevere COPD were less likely to achieve abstinence than smokers without COPD ${ }^{9}$. A study from Scandinavia including an intervention with confrontation with spirometry showed that smokers with COPD quit smoking significantly more often than smokers without $\operatorname{COPD}^{10}$.

Research that characterizes smokers with COPD is scarce. There is little evidence that smokers with COPD are different from smokers without COPD and therefore may need tailored smoking cessation treatments. To our knowledge there are only two studies 
comparing characteristics of smokers with COPD with smokers without COPD ${ }^{11,12}$. Only one of these assessed determinants of attempts to quit and treatment utilization and showed that motivation for quitting and frequency of receiving physician counselling and pharmacotherapy for smoking cessation were similar in both groups ${ }^{12}$. The other study was not designed to assess determinants of attempts to quit and treatment utilization $^{11}$. In conclusion, there is not enough evidence to pinpoint the differences between smokers with and without COPD, and consequently it is still difficult to design smoking cessation interventions specifically for smokers with COPD. Therefore, we conducted a study to compare factors associated with attempts to quit and the use of evidence-based smoking cessation treatments between smokers with and without COPD.

\section{Materials and methods}

\section{Study design}

We conducted a cross-sectional study in 2013. Participants were recruited from the 'Eindhoven Corporation of Primary Health Care Centres', which is a network of ten primary health care centres in the city of Eindhoven, the Netherlands, covering 64,955 patients ${ }^{13}$.

\section{Study subjects}

All patients from the Eindhoven Corporation of Primary Health Care Centres with a recorded diagnosis of COPD in their electronic medical record (EMR) and twice as many controls matched for age, sex and health care centre were included in the study. Matching was done in order to equalize age and sex, important risk factors for the development of COPD, but not modifiable by an intervention, in smokers both with and without COPD. Cases for this study were all patients from the Eindhoven Corporation of Primary Health Care Centres with a diagnosis of COPD in their EMR (based on the international classification of primary care code R95) who were current smokers. Smokers were defined as patients who were currently daily or occasionally smoking tobacco cigarettes. The severity of COPD was categorized according to the Global Initiative for Chronic Obstructive Lung Disease guidelines ${ }^{3}$. Controls were smokers without a recorded diagnosis of COPD. All patients were checked by their general practitioners (GP) in order to validate their disease status and to identify any contraindications for participating in this study (Figure 3.1). 


\section{Methods}

The coordinating researcher sent the patients a package by postal mail, including an information letter about the study, a questionnaire, and an informed consent form. With these, a smoking cessation information leaflet was send, in which advice on quitting and information about smoking cessation treatments was given. Participants did not receive compensation for filling in the questionnaire. When there was no response within two to four weeks we sent a reminder with enclosed a reply card on which the smoking status could be specified. The study was approved by the Medical Ethics Committee at Maastricht University, the Netherlands (approval No. 11-4-145).

\section{Measurements}

We collected information on factors which, according to the literature ${ }^{14-21}$, have been associated with smoking and smoking cessation. We collected data on date of birth, sex, occupation and education. Socioeconomic status was computed from occupation and education and divided into three categories - high, moderate and low $^{22}$. Furthermore, information was collected on comorbidities, mental health (hospital anxiety and depression scale) ${ }^{23}$ and health perception (36-item short form health survey) $)^{24}$ for all patients. Additionally, there were specific questions for the COPD patients on Global Initiative for Chronic Obstructive Lung Disease status and COPD impact and symptoms (clinical COPD questionnaire) ${ }^{25}$.

Nicotine dependence was calculated using the 'Heaviness of Smoking Index'26 and pack-years were calculated by dividing the amount of cigarettes smoked a day by 20 and multiplying it by the number of smoking years. Furthermore, reasons for smoking ${ }^{27}$, self-exempting believes to justify smoking behaviour, and concern and risk perception of illness through smoking were evaluated ${ }^{28}$. Moreover, smoking and advice on quitting in the social environment was assessed.

We measured the frequency of advice from the GP on smoking cessation and motivation to quit (motivation to stop scale) ${ }^{29}$. Furthermore, self-efficacy to refrain from smoking in different situations was measured ${ }^{22}$. Participants who had ever undertaken an attempt to quit were additionally asked about their total number of attempts to quit and preference for abrupt or gradual quitting. 
We also included questions about the use of and level of faith in different kinds of smoking cessation treatments ${ }^{22}$. Finally, participants were asked about what they considered important when using different kinds of smoking cessation treatments ${ }^{30}$.

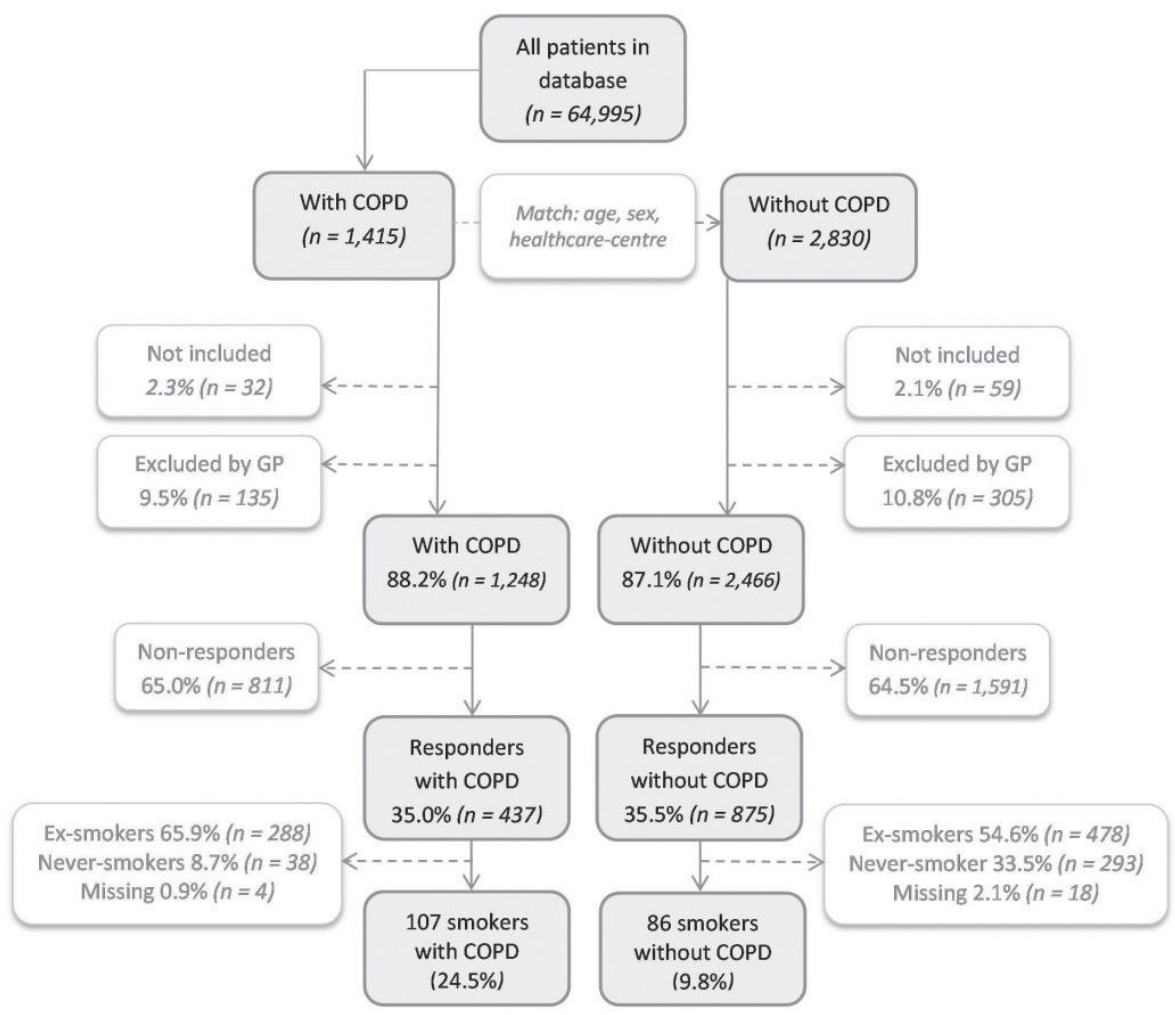

Figure 3.1 Flow chart of inclusion and exclusion. Not included: not included because they were not present anymore in the latest update from the electronic medical record because of death, GP switch or other reasons. Excluded by GP: excluded by GP because of illness, language, death, GP switch, social or other reasons.

\section{Analysis}

Data were analysed using SPSS 19. Data on attempts to quit, smoking cessation treatment utilization, and associated factors were compared between cases and controls using $\chi^{2}$ tests for categorical variables and t-tests for continuous variables.

All analyses were conducted with the total number of valid answers for every particular item in the different groups. As numbers of missing values could differ per item, 
different total numbers were obtained in the different analyses. If applicable, we imputed missing data corresponding the guidelines of the specific questionnaire. When there were no guidelines available, we derived these from original guidelines of similar questionnaires.

\section{Results}

\section{Study population}

From the total population of the 64,995 registered patients, we identified 1,415 patients (2.2\%) with COPD whom we matched with 2,830 patients without COPD. In total, 437 patients (31\%) with COPD and 875 patients (31\%) without COPD responded to the questionnaire. Amongst these, we identified 107 current smokers with COPD (24.5\% of 437 ) and 86 current smokers without COPD (9.8\% of 875$)$ who entered our main analysis (Figure 3.1).

We received reply cards with data on smoking status from 255 patients with COPD and 548 patients without COPD who did not respond to the questionnaire. Of these, $30.2 \%$ $(n=77)$ and $12.8 \%(n=70)$ were smokers and $57.3 \%(n=146)$ and $46.2 \%(n=253)$ were exsmokers, respectively. The ratio of smoking prevalence in patients with versus without $\operatorname{COPD}(30.2$ vs. $12.8 \%=2.4: 1)$ in the non-respondents was comparable with the ratio in the respondents to the questionnaire ( 24.5 vs. $9.8 \%=2.5: 1)$.

\section{Demographic and health characteristics}

As a result of the matching, there were no significant differences between smokers with and without COPD regarding their age and sex (Table 3.1). There was also no difference in socioeconomic status. The majority of smokers with COPD (54.2\%, $n=58$ ) had mild to moderate airflow limitation. They reported more psychological comorbidities than smokers without COPD and scored higher on the depression scale. Conversely, smokers with COPD perceived their own health better.

\section{Smoking characteristics and social influence}

Smokers with COPD reported higher levels of nicotine addiction than smokers without COPD (Table 3.1). Both groups reported different reasons for smoking; smokers with COPD more often smoked to socialize, to get a mental and/or physical energy boost and as a habit. Moreover, they were more concerned about getting ill due to smoking 
and believed that smoking caused illness. With regard to social influence, smokers with COPD experienced more stimulation to quit from their environment compared with smokers without COPD.

Table 3.1 Characteristics of smokers with and without COPD

\begin{tabular}{|c|c|c|c|}
\hline & With COPD $(n=107)$ & Without COPD $(n=86)$ & $p$ value \\
\hline \multicolumn{4}{|l|}{ Demographic characteristics } \\
\hline Age, years & $66.6 \pm 11.1$ & $66.3 \pm 11.7$ & 0.85 \\
\hline Female & $52.8(56)$ & $40.7(35)$ & 0.09 \\
\hline Socioeconomic status & & & 0.41 \\
\hline Low & $19.6(21)$ & $18.6(16)$ & \\
\hline Moderate & $62.6(67)$ & $55.8(48)$ & \\
\hline High & $17.8(19)$ & $25.6(22)$ & \\
\hline \multicolumn{4}{|l|}{ Health characteristics } \\
\hline \multicolumn{4}{|l|}{ Comorbidities } \\
\hline Cardiovascular & $25.5(27)$ & $24.4(21)$ & 0.87 \\
\hline Endocrine & $39.6(42)$ & $30.2(26)$ & 0.18 \\
\hline Musculoskeletal & $4.7(5)$ & $9.3(8)$ & 0.21 \\
\hline Neoplasms & $3.8(4)$ & $4.7(4)$ & 0.76 \\
\hline Psychological & $23.6(25)$ & $9.3(8)$ & 0.01 \\
\hline Respiratory & $96,2(102)$ & $39.5(34)$ & $<0.001$ \\
\hline \multicolumn{4}{|l|}{ Mental health } \\
\hline Anxiety $^{1}$ & $6.8 \pm 4.5$ & $5.6 \pm 4.0$ & 0.06 \\
\hline Depression ${ }^{1}$ & $6.0 \pm 4.8$ & $4.3 \pm 3.7$ & 0.01 \\
\hline Perception of one's health ${ }^{2}$ & $3.7 \pm 0.8$ & $3.1 \pm 0.8$ & $<0.001$ \\
\hline \multicolumn{4}{|l|}{ GOLD status (self-reported) } \\
\hline Mild & $27.1(29)$ & & \\
\hline Moderate & $27.1(29)$ & & \\
\hline Severe & $8.4(9)$ & & \\
\hline Very severe & $2.8(3)$ & & \\
\hline Do not know & $19.6(21)$ & & \\
\hline \multicolumn{4}{|l|}{ COPD health status } \\
\hline Respiratory symptoms ${ }^{3}$ & $2.3 \pm 1.2$ & & \\
\hline Mental state ${ }^{3}$ & $1.1 \pm 1.3$ & & \\
\hline Physical state $^{3}$ & $1.6 \pm 1.3$ & & \\
\hline \multicolumn{4}{|l|}{ Smoking characteristics } \\
\hline Pack-years & $35.3 \pm 21.2$ & $27.0 \pm 21.3$ & 0.09 \\
\hline Level of nicotine addiction & & & $<0.01$ \\
\hline Low & $35.0(36)$ & $60.0(48)$ & \\
\hline Medium & $53.4(55)$ & $33.8(27)$ & \\
\hline High & $11.7(12)$ & $6.3(5)$ & \\
\hline
\end{tabular}


Table 3.1 (continued)

\begin{tabular}{|c|c|c|c|}
\hline & With COPD $(n=107)$ & Without COPD $(n=86)$ & $\begin{array}{l}p \\
\text { value }\end{array}$ \\
\hline Justifying smoking behaviour $^{2}$ & $2.7 \pm 0.7$ & $2.6 \pm 0.6$ & 0.26 \\
\hline Concern of illness through smoking ${ }^{2}$ & $3.2 \pm 1.0$ & $2.9 \pm 0.9$ & 0.02 \\
\hline Believe in illness through smoking ${ }^{2}$ & $3.3 \pm 0.9$ & $3.0 \pm 0.8$ & 0.01 \\
\hline \multicolumn{4}{|l|}{ Social influence } \\
\hline \multicolumn{3}{|l|}{ Smoke status of partner } & 0.16 \\
\hline Never-smoker & $10.3(11)$ & $18.6(16)$ & \\
\hline Ex-smoker & $17.8(19)$ & $20.9(18)$ & \\
\hline Smoker & $29.0(31)$ & $16.3(14)$ & \\
\hline No partner & $40.2(43)$ & $37.2(32)$ & \\
\hline Partner's level of stimulation to quit ${ }^{2}$ & $3.1 \pm 1.4$ & $2.8 \pm 1.5$ & 0.26 \\
\hline \multicolumn{3}{|l|}{ Smoking status of environment } & 0.37 \\
\hline Few smokers & $57.9(62)$ & $67.5(58)$ & \\
\hline As many smokers as non- & $16.8(18)$ & $16.3(14)$ & \\
\hline smokers & $22.4(24)$ & $15.2(13)$ & \\
\hline More smokers & & & \\
\hline $\begin{array}{l}\text { Environments' level of stimulation to } \\
\text { quit }^{2}\end{array}$ & $3.0 \pm 1.3$ & $2.5 \pm 1.1$ & $<0.01$ \\
\hline
\end{tabular}

Data are presented as means \pm SD or $\%(n)$, as appropriate. Discrepancies between total numbers and numbers of added subcategories are due to missing values. GOLD = Global Initiative for Chronic Obstructive Lung Disease.

${ }^{1}$ 0-21: highest level of anxiety/depression. ${ }^{2}$ 1-5: highest level of perceived health, justification of smoking, concerns of and beliefs in illness, and partner's stimulation to quit. ${ }^{3} 0-6$ : highest level of respiratory symptoms and mental/physical complaints. ${ }^{4}$ 4-20: highest level of agreement. ${ }^{5}$ 3-15: highest level of agreement.

\section{Quit attempts}

Table 3.2 shows data on attempts to quit and use of smoking cessation treatments. There was no significant difference in the number of previous attempts to quit and motivation to quit in the future. Smokers with COPD, however, more often received advice to quit from their GP than smokers without COPD. They also reported lower levels of self-efficacy to refrain from smoking when they were feeling stressed or angry and when they were socializing.

\section{Smoking cessation treatments}

Both smokers with and without COPD had similar levels of faith in the efficacy of different smoking cessation treatments (Table 3.2). About twice as many smokers with COPD, however, had ever used nicotine replacement therapy and prescription medications (bupropion, nortriptyline, varenicline), behavioural interventions and alternative treatments for smoking cessation. Furthermore, smokers with COPD found 
the costs of such treatments and their reimbursement by the health care insurance more important than smokers without COPD when choosing whether or not to use such treatments (Table 3.2).

Table 3.2 Quit attempts and use of smoking cessation treatments in smokers with and without COPD

\begin{tabular}{|c|c|c|c|}
\hline & With COPD $(n=107)$ & $\begin{array}{l}\text { Without COPD } \\
(n=86)\end{array}$ & $\begin{array}{l}\mathrm{p} \\
\text { value }\end{array}$ \\
\hline \multicolumn{4}{|l|}{ Quit attempts } \\
\hline Frequency of advice to quit from $G P^{1}$ & $2.6 \pm 0.9$ & $1.7 \pm 0.7$ & $<0.01$ \\
\hline Motivation to quit ${ }^{2}$ & $3.1 \pm 1.7$ & $2.8 \pm 1.6$ & 0.30 \\
\hline \multicolumn{4}{|l|}{ Participants that have ever undertaken a quit } \\
\hline Number of quit attempts ${ }^{3}$ & $4.7 \pm 4.6$ & $4.0 \pm 5.6$ & 0.44 \\
\hline Preference for abrupt quitting ${ }^{3}$ & $33.3(25)$ & $38.4(33)$ & 0.05 \\
\hline \multicolumn{4}{|l|}{$\begin{array}{l}\text { Self-efficacy to refrain from smoking in } \\
\text { different situations }\end{array}$} \\
\hline When feeling stressed or angry ${ }^{4}$ & $2.4 \pm 1.0$ & $2.9 \pm 1.2$ & 0.01 \\
\hline When socializing $^{4}$ & $2.8 \pm 1.4$ & $3.2 \pm 1.3$ & 0.04 \\
\hline When sorely tempted ${ }^{4}$ & $2.8 \pm 1.2$ & $3.1 \pm 1.2$ & 0.11 \\
\hline \multicolumn{4}{|l|}{$\begin{array}{l}\text { Smoking cessation treatments } \\
\text { Treatments ever used }\end{array}$} \\
\hline NRT and prescription medication & $68.0(51)$ & $40.0(24)$ & 0.001 \\
\hline Behavioural interventions & $69.3(52)$ & $38.3(23)$ & $<0.001$ \\
\hline Self-help material & $13.3(10)$ & $6.7(4)$ & 0.2 \\
\hline Alternative treatments & $28.0(21)$ & $11.7(7)$ & 0.02 \\
\hline \multicolumn{4}{|l|}{$\begin{array}{l}\text { Level of faith in the efficacy of different } \\
\text { treatments }\end{array}$} \\
\hline NRT and prescription medication ${ }^{4}$ & $2.6 \pm 1.0$ & $2.3 \pm 0.9$ & 0.07 \\
\hline Behavioural interventions ${ }^{4}$ & $2.4 \pm 0.9$ & $2.3 \pm 0.8$ & 0.54 \\
\hline Self-help material ${ }^{4}$ & $1.9 \pm 0.9$ & $2.1 \pm 0.9$ & 0.21 \\
\hline Alternative treatments ${ }^{4}$ & $2.5 \pm 1.1$ & $2.5 \pm 1.0$ & 0.97 \\
\hline \multicolumn{4}{|l|}{$\begin{array}{l}\text { What influences the choice for a smoking } \\
\text { cessation treatment } \\
\text { Nicotine replacement therapy }\end{array}$} \\
\hline Evidence-based $^{4}$ & $3.1 \pm 1.0$ & $2.9 \pm 1.0$ & 0.20 \\
\hline Costs $^{4}$ & $3.5 \pm 1.2$ & $3.0 \pm 1.2$ & 0.01 \\
\hline Takes little effort ${ }^{4}$ & $3.2 \pm 1.0$ & $3.0 \pm 1.0$ & 0.08 \\
\hline Easily available $^{4}$ & $3.2 \pm 1.0$ & $3.0 \pm 1.1$ & 0.13 \\
\hline Reimbursed by insurance ${ }^{4}$ & $3.8 \pm 1.2$ & $3.2 \pm 1.8$ & $<0.01$ \\
\hline Side effects ${ }^{4}$ & $3.8 \pm 1.2$ & $3.5 \pm 1.2$ & 0.17 \\
\hline Advised by GP ${ }^{4}$ & $3.6 \pm 1.1$ & $3.3 \pm 1.0$ & 0.14 \\
\hline Experiences of friends ${ }^{4}$ & $3.3 \pm 1.1$ & $3.0 \pm 0.9$ & 0.09 \\
\hline
\end{tabular}


Table 3.2 (continued)

\begin{tabular}{|c|c|c|c|}
\hline & With COPD $(n=107)$ & Without COPD $(n=86)$ & $p$ value \\
\hline \multicolumn{4}{|l|}{ Antidepressants } \\
\hline Evidence-based $^{4}$ & $3.3 \pm 1.1$ & $3.1 \pm 1.0$ & 0.16 \\
\hline Costs $^{4}$ & $3.6 \pm 1.3$ & $3.2 \pm 1.1$ & 0.02 \\
\hline Takes little effort ${ }^{4}$ & $3.3 \pm 1.1$ & $3.0 \pm 1.0$ & 0.14 \\
\hline Easily available $^{4}$ & $3.3 \pm 1.2$ & $3.0 \pm 1.0$ & 0.31 \\
\hline Reimbursed by insurance $^{4}$ & $3.8 \pm 1.3$ & $3.3 \pm 1.2$ & 0.01 \\
\hline Side effects ${ }^{4}$ & $3.7 \pm 1.2$ & $3.4 \pm 1.2$ & 0.17 \\
\hline Advised by $G P^{4}$ & $3.5 \pm 1.1$ & $3.3 \pm 1.1$ & 0.19 \\
\hline Experiences of friends ${ }^{4}$ & $3.2 \pm 1.2$ & $3.0 \pm 1.0$ & 0.15 \\
\hline \multicolumn{4}{|l|}{ Varenicline } \\
\hline Evidence-based $^{4}$ & $3.5 \pm 1.1$ & $3.2 \pm 1.0$ & 0.14 \\
\hline Costs $^{4}$ & $3.6 \pm 1.3$ & $3.3 \pm 1.1$ & 0.30 \\
\hline Takes little effort $^{4}$ & $3.2 \pm 1.1$ & $3.1 \pm 1.0$ & 0.61 \\
\hline Easily available $^{4}$ & $3.3 \pm 1.2$ & $3.2 \pm 1.0$ & 0.31 \\
\hline Reimbursed by insurance $^{4}$ & $3.7 \pm 1.3$ & $3.4 \pm 1.2$ & 0.09 \\
\hline Side effects ${ }^{4}$ & $3.7 \pm 1.3$ & $3.5 \pm 1.2$ & 0.24 \\
\hline Advised by $G P^{4}$ & $3.5 \pm 1.2$ & $3.3 \pm 1.0$ & 0.22 \\
\hline Experiences of friends ${ }^{4}$ & $3.5 \pm 1.2$ & $3.0 \pm 1.0$ & 0.20 \\
\hline \multicolumn{4}{|l|}{ Counselling } \\
\hline Evidence-based $^{4}$ & $3.4 \pm 1.0$ & $3.3 \pm 1.0$ & 0.54 \\
\hline Costs ${ }^{4}$ & $3.6 \pm 1.3$ & $3.3 \pm 1.2$ & 0.12 \\
\hline Takes little effort ${ }^{4}$ & $3.4 \pm 1.2$ & $3.2 \pm 1.0$ & 0.15 \\
\hline Reimbursed by insurance ${ }^{4}$ & $3.8 \pm 1.3$ & $3.4 \pm 1.2$ & 0.08 \\
\hline Advised by GP $P^{4}$ & $3.7 \pm 1.1$ & $3.3 \pm 1.0$ & 0.05 \\
\hline Experiences of friends ${ }^{4}$ & $3.2 \pm 1.2$ & $3.0 \pm 0.9$ & 0.16 \\
\hline
\end{tabular}

Data are presented as means \pm SD or $\%(n)$, as appropriate. NRT $=$ Nicotine replacement therapy. ${ }^{1} 1-4$ : highest frequency. ${ }^{2}$ 1-7: highest level of motivation to quit. ${ }^{3}$ Response refers to the subgroup of smokers that have ever undertaken a quit attempt $(n=135) .{ }^{4} 1-5$ : highest level of self-efficacy, faith, and influence.

\section{Discussion}

We found that smokers with COPD tried to quit smoking just as often as smokers without COPD and were just as motivated to try again in the future, but they used smoking cessation treatments more often. Furthermore, smokers with COPD received triggers to quit more often, both from their environment and from their GP. In addition, they were more concerned about, and aware of, the health risks of smoking. Importantly, smokers with COPD reported higher levels of depression and cigarette dependence and a lower self-efficacy to refrain from smoking compared with smokers without COPD. 
We observed the same number of attempts to quit in smokers with and without COPD. Results from intervention studies vary from fewer attempts to quit to more attempts to quit in smokers with COPD compared with smokers without COPD ${ }^{8-10}$. In addition, there are no numbers available from population studies and this makes the quantity of quit attempts in smokers with and without COPD still a speculative matter. Therefore, it might be more important to focus on the quality of the quit attempts and stimulate all serious quit attempts by offering evidence-based smoking cessation interventions to all smokers.

Smokers with COPD were more often advised by their GP to stop smoking than smokers without COPD but, as previously mentioned, did not undertake more attempts to quit. In addition, their motivation to quit was similar to smokers without COPD. It was expected that smokers with COPD were more likely to receive advise from their GP, as they consulted their GP regularly for routine COPD management check-ups. A Cochrane review showed that brief advice given by the GP had a small but significant effect on cessation rates in the general smoking population ${ }^{31}$. As we were not able to ask about the specific content of the advice in our study, we do not know whether the advice given was adapted to the needs of the smokers with COPD at that moment or not. Hilberink et al. ${ }^{32}$ found that it would be advantageous to tailor COPD counselling to two distinct groups - motivated and unmotivated smokers. Furthermore, Tønnesen et al. ${ }^{33}$ suggested the possibility that smokers with respiratory disease at some stage develop a 'tolerance', indicating that they might get tired of the quit advice which they receive repeatedly from GPs.

Another result linked to this was that smokers with COPD were more concerned about and aware of becoming ill through smoking. Probably, the frequent quit advice given by GPs and peers draws the risks of illness to their attention. Contrary to this, however, was that the smokers with COPD perceived their health significantly better than the smokers without COPD. As this result contradicts rational reasoning, this outcome might be influenced by cognitive dissonance. This means that answers from smokers with COPD are likely to be biased by optimism in order to reduce the psychological need to quit smoking ${ }^{34}$.

In line with previous research, smokers with COPD reported higher levels of depression. Independent of smoking status, depression is more frequently seen in 
patients with COPD ${ }^{35}$. Furthermore, depression is likely to adversely affect the success of an attempt to quit ${ }^{36}$. In addition, as described in the literature, the COPD group had a higher level of nicotine dependence, which also makes it more difficult for them to quit smoking, 11, 21 .

Smokers with COPD were more likely to smoke for social reasons, to get an energy boost and as a habit. In line with this, smokers with COPD reported a lower level of selfefficacy to refrain from smoking in emotional and habitual situations than smokers without COPD. Self-efficacy interpretations are important predictors of smoking cessation $^{37,38}$, and frequent and intensive motivational support is likely to increase selfefficacy. As smokers with COPD have a lower level of self-efficacy, it is possible that motivational support is of even more importance to them during smoking cessation.

Finally, smokers with COPD found costs important in their decision whether or not to use smoking cessation treatments. This might be because they had less money to spend. However, contrary to results from other research, the socioeconomic status of both groups in this study was roughly similar, which might partly be due to the matching on health care centre. In the Netherlands smoking rates decreased when health insurances reimbursed smoking cessation treatments and increased again when reimbursement by health insurances was stopped ${ }^{39}$. This is in line with results from a systematic review which showed that full financial interventions directed at smokers when compared with no financial interventions increased the proportion of smokers who succeeded in quitting ${ }^{40}$.

\section{Strengths and limitations}

This study is one of the few studies looking at differences between smokers with and without COPD with regard to smoking. Besides, it is the first study looking at a large number of factors associated with smoking, attempts to quit and the use of smoking cessation treatments.

Due to the diversity in patient characteristics in this study (Table 3.1), the results can be extended to make predictions about smokers with COPD in primary health care in other western European countries with similar health care systems.

The cross-sectional study design involved collecting retrospective information which may have caused recall bias. However, this only counts for some particular questions 
about stimulation and advice on smoking cessation, attempts to quit and the use of smoking cessation treatments. Moreover, recall bias would have been equal in smokers both with and without COPD. Furthermore, with this observational design it is not possible to identify reverse causation. This makes it uncertain if differences between groups are fully explained by having COPD or not. However, age, sex and the number of pack-years, the most important risk factors for developing COPD, were not significantly different between smokers with and without COPD.

COPD status was derived from the EMR and the R95 code for COPD in the EMR was based on lung function test results. However, we were not able to check the lung function results again to verify the accuracy of the diagnosis. Similarly, no lung function testing was done in the group of patients without COPD in order to verify if they had undetected airway obstruction. Therefore, we cannot exclude that some misclassification of disease status has occurred.

The number of respondents who said they were smokers was lower in both groups than one would have expected based on the prevalence numbers in the Netherlands $(27 \%)^{41}$. It is known that in smoking cessation research less participation is to be expected from unmotivated smokers. However, the ratio of response and nonresponse from smokers in both groups was similar.

\section{Conclusion and implications}

Smokers with and without COPD have many smoking-related characteristics in common. However, smokers with COPD also seem to differ from smokers without COPD in various aspects. In smokers with COPD, depressive symptoms, high cigarette dependence and low self-efficacy are essential aspects which should be targeted in their smoking cessation treatment. Adding these elements to the content of an intensive behavioural counselling program for smokers with COPD and offering such counselling in combination with pharmacotherapy opportunistically and free of cost to all smokers with COPD should have an impact on reducing smoking in this patient population in the future. 


\section{Acknowledgements}

We would like to thank the Eindhoven Corporation of Primary Health Care Centres for its cooperation and all participants for taking the time to fill in the questionnaire. In addition, we would like to thank the research assistants Nicky Wijnen and Marloes Verstappen for their contribution to the administrative work and data processing. 


\section{References}

1. Eisner M.D., Anthonisen N., Coultas D., Kuenzli N., Perez-Padilla R., Postma D., et al. An official American Thoracic Society public policy statement: Novel risk factors and the global burden of chronic obstructive pulmonary disease. Am J Respir Crit Care Med. 182, 693-718 (2010).

2. Volksgezondheidenzorg.info. www.volksgezondheidenzorg.info. RIVM: Bilthoven. Accessed 8 November 2014.

3. From the Global Strategy for the Diagnosis, Management and Prevention of COPD, Global Initiative for Chronic Obstructive Lung Disease (GOLD) 2014. http://goldcopd.org. Accessed 10 November 2014.

4. Willemse B.W., Postma D.S., Timens W., ten Hacken N.H. The impact of smoking cessation on respiratory symptoms, lung function, airway hyperresponsiveness and inflammation. Eur Respir J. 23, 464-476 (2004).

5. Anthonisen N.R., Connett J.E., Murray R.P. Smoking and lung function of Lung Health Study participants after 11 years. Am J Respir Crit Care Med. 166, 675-679 (2002).

6. van der Meer R., Wagena E.J., Ostelo R., Jacobs A., van Schayck C. Smoking cessation for chronic obstructive pulmonary disease. Cochrane Database Syst Rev. 1, CD002999 (2009).

7. Shahab L., Jarvis M.J., Britton J., West R. Prevalence, diagnosis and relation to tobacco dependence of chronic obstructive pulmonary disease in a nationally representative population sample. Thorax. 61, 1043-1047 (2006).

8. Willemse B., Lesman-Leegte I., Timens W., Postma D., ten Hacken N. High cessation rates of cigarette smoking in subjects with and without COPD. Chest. 128, 3685-3687 (2005).

9. Wagena E.J., Knipschild P.G., Huibers M.J., Wouters E.F., van Schayck C.P. Efficacy of bupropion and nortriptyline for smoking cessation among people at risk for or with chronic obstructive pulmonary disease. Arch Intern Med. 165, 2286-2292 (2005).

10. Stratelis G., Molstad S., Jakobsson P., Zetterstrom O. The impact of repeated spirometry and smoking cessation advice on smokers with mild COPD. Scand J Prim Health Care. 24, 133-139 (2006).

11. Jimenez-Ruiz C.A., Masa F., Miravitlles M., Gabriel R., Viejo J.L., Villasante C., et al. Smoking characteristics: differences in attitudes and dependence between healthy smokers and smokers with COPD. Chest. 119, 1365-1370 (2001).

12. Vozoris N.T., Stanbrook M.B. Smoking prevalence, behaviours, and cessation among individuals with COPD or asthma. Respir Med. 105, 477-484 (2011).

13. Eindhoven corporation of primary healthcare centers. http://www.sge.nl/. Accessed 22 May 2013.

14. Breslau N., Peterson E.L. Smoking cessation in young adults: age at initiation of cigarette smoking and other suspected influences. Am J Public Health. 86, 214-220 (1996).

15. Borrelli B., Hayes R.B., Dunsiger S., Fava J.L. Risk perception and smoking behavior in medically ill smokers: a prospective study. Addiction. 105, 1100-1108 (2010).

16. Chaiton M.O., Cohen J.E., O'Loughlin J., Rehm J. A systematic review of longitudinal studies on the association between depression and smoking in adolescents. BMC Public Health. 9, 356 (2009). 
17. Bock B.C., Jennings E., Becker B.M., Partridge R., Niaura R.S. Characteristics and predictors of readiness to quit among emergency medical patients presenting with respiratory symptoms. Int J Emerg Med. 4, 24 (2011).

18. Borland R., Yong H.H., Balmford J., Cooper J., Cummings K.M., O'Connor R.J., et al. Motivational factors predict quit attempts but not maintenance of smoking cessation: findings from the International Tobacco Control Four country project. Nicotine Tob Res. 12 Suppl, S4-11 (2010).

19. Van den Putte B., Yzer M.C., Brunsting S. Social influences on smoking cessation: a comparison of the effect of six social influence variables. Prev Med. 41, 186-193 (2005).

20. Gwaltney C.J., Metrik J., Kahler C.W., Shiffman S. Self-efficacy and smoking cessation: a meta-analysis. Psychol Addict Behav. 23, 56-66 (2009).

21. Ferguson J.A., Patten C.A., Schroeder D.R., Offord K.P., Eberman K.M., Hurt R.D. Predictors of 6-month tobacco abstinence among 1224 cigarette smokers treated for nicotine dependence. Addict Behav. 28, 1203-1218 (2003).

22. Mudde A.N., Willemsen M.C., Kremers S., de Vries H. Measurements for research on smoking cessation. The Hague, STIVORO, 2000.

23. Snaith R.P., Zigmond A.S. Hospital Anxiety and Depression Scale. Windsor, NFER Nelson, 1994.

24. Ware J.E., Jr., Gandek B. Overview of the SF-36 Health Survey and the International Quality of Life Assessment (IQOLA) Project. J Clin Epidemiol. 51, 903-912 (1998).

25. Van der Molen T. Clinical COPD Questionnaire. Groningen, University Medical Center Groningen, 1999.

26. Heatherton T.F., Kozlowski L.T., Frecker R.C., Rickert W., Robinson J. Measuring the heaviness of smoking: using self-reported time to the first cigarette of the day and number of cigarettes smoked per day. Br J Addict. 84, 791-799 (1989).

27. Boudrez H., De Bacquer D. A Dutch version of the modified reasons for smoking scale: factorial structure, reliability and validity. J Eval Clin Pract. 18, 799-806 (2012).

28. Kotz D., Huibers M.J., West R.J., Wesseling G., van Schayck O.C. What mediates the effect of confrontational counselling on smoking cessation in smokers with COPD? Patient Educ Couns. 76, 16-24 (2009).

29. Kotz D., Brown J., West R. Predictive validity of the Motivation To Stop Scale (MTSS): a single-item measure of motivation to stop smoking. Drug Alcohol Depend. 128, 15-19 (2013).

30. Klaassen A., van Wensveen D. Survey - Continuous Investigation Smoking habits. The Hague, STIVORO, 2010.

31. Stead L.F., Bergson G., Lancaster T. Physician advice for smoking cessation. Cochrane Database Syst Rev. 2, CD000165 (2008).

32. Hilberink S.R., Jacobs J.E., Schlosser M., Grol R.P., de Vries H. Characteristics of patients with COPD in three motivational stages related to smoking cessation. Patient Educ Couns. 61, 449-457 (2006).

33. Tønnesen P., Carrozzi L., Fagerstrom K.O., Gratziou C., Jimenez-Ruiz C., Nardini S., et al. Smoking cessation in patients with respiratory diseases: a high priority, integral component of therapy. Eur Respir J. 29, 390-417 (2007).

34. Borland R., Yong H.H., Balmford J., Fong G.T., Zanna M.P., Hastings G. Do riskminimizing beliefs about smoking inhibit quitting? Findings from the International Tobacco Control (ITC) Four-Country Survey. Prev Med. 49, 219-223 (2009).

35. Mannino D.M., Buist A.S. Global burden of COPD: risk factors, prevalence, and future trends. Lancet. 370, 765-773 (2007). 
36. Glassman A.H., Helzer J.E., Covey L.S., Cottler L.B., Stetner F., Tipp J.E., et al. Smoking, smoking cessation, and major depression. JAMA. 264, 1546-1549 (1990).

37. Devins G.M., Edwards P.J. Self-efficacy and smoking reduction in chronic obstructive pulmonary disease. Behav Res Ther. 26, 127-135 (1988).

38. Dijkstra A., Wolde G.T. Ongoing interpretations of accomplishments in smoking cessation: positive and negative self-efficacy interpretations. Addict Behav. 30, 219-234 (2005).

39. Nagelhout G.E., Willemsen M.C., van den Putte B., de Vries H., Willems R.A., Segaar D. Effectiveness of a national reimbursement policy and accompanying media attention on use of cessation treatment and on smoking cessation: a real-world study in the Netherlands. Tob Control. 0, 1-7 (2014).

40. Reda A.A., Kotz D., Evers S.M., van Schayck C.P. Healthcare financing systems for increasing the use of tobacco dependence treatment. Cochrane Database Syst Rev. 16, CD004305 (2012).

41. STIVORO. Highlights - Smoking in the Netherlands 2012. The Hague, STIVORO, 2013. 
Chapter 4

\title{
Experiences of tobacco smoking and quitting in smokers with and without chronic obstructive pulmonary disease - a qualitative analysis
}

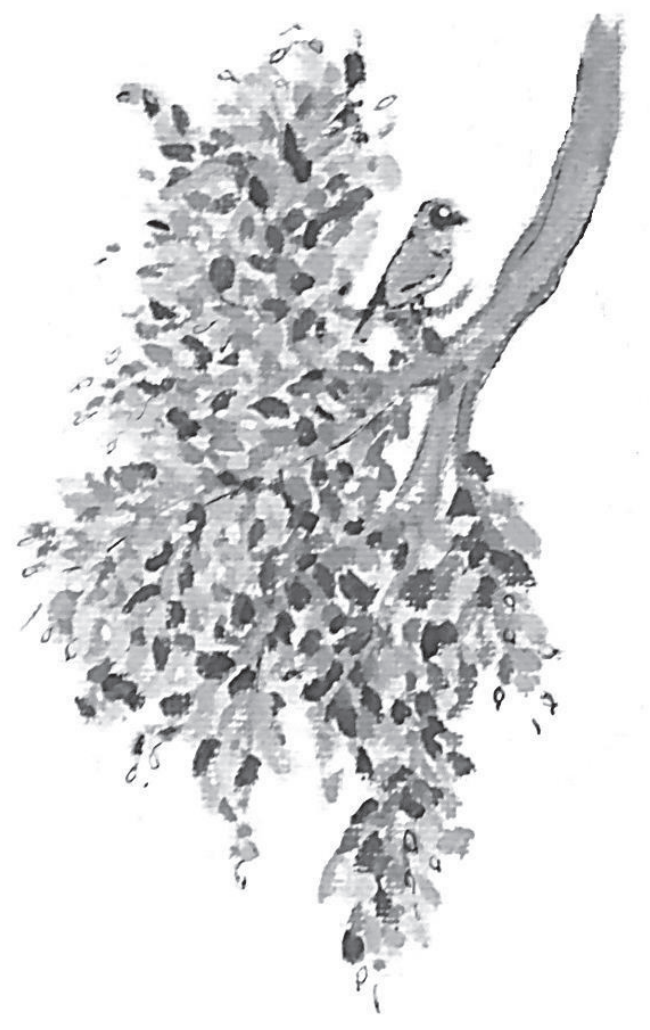

\author{
Eva van Eerd \\ Mette Bech Ris $\varnothing r$ \\ Carolien van Rossem \\ Onno van Schayck \\ Daniel Kotz
}

Published as BMC Family Practice 2015 Nov 4;16:164 


\section{Abstract}

\section{Background}

Smokers with chronic obstructive pulmonary disease (COPD) seem to be a special subgroup of smokers that have a more urgent need to quit smoking but might find it more difficult to do so. This study aimed to explore which justifications for tobacco smoking and experiences of quitting were commonly shared in smokers with and without COPD, and which, if any, were specific to smokers with COPD.

\section{Methods}

In ten primary health care centres in the Netherlands, we conducted semi-structured, in-depth interviews in 10 smokers with and 10 smokers without COPD.

\section{Results}

Three themes were generated: 'balancing the impact on health of smoking', 'challenging of autonomy by social interference', 'prerequisites for quitting'. All participants trivialized health consequences of smoking; those with COPD seemed to be less knowledgeable about smoking and health. Both groups of smokers found autonomy very important. Smokers with COPD were indignant about a perceived lack of empathy in their communication with doctors. Furthermore, smokers with COPD in particular had little faith in the efficacy of smoking cessation aids. Lastly, motivation for quitting was dominated by fluctuation and smokers with COPD specifically maintained that their vision of life was linked with quitting.

\section{Conclusions}

The participants showed many similarities in their reasoning about smoking and quitting. The corresponding themes argue for a less paternalistic regime in the communication with smokers with attention required for the motivational stage and room made for smokers' own views, and with clear information and education. Furthermore, addressing social interactions, health perceptions and moral agendas in the communication with smokers with COPD may help to make smoking cessation interventions more suitable for them. 


\section{Background}

Chronic obstructive pulmonary disease (COPD) holds a leading position in morbidity and mortality worldwide ${ }^{1}$. In the Netherlands, approximately 320,000 people have COPD. Approximately 6000 people died in 2010 in the Netherlands with COPD as the primary cause ${ }^{2}$.

Tobacco smoking is the most commonly encountered risk factor for COPD in developed countries $^{1,3,4}$. An estimated 10 to $15 \%$ of all smokers develop clinically significant airflow obstruction ${ }^{1}$. Furthermore, smokers with COPD have a higher mortality rate ${ }^{5}$ and a more rapid decline in lung function than non-smokers with COPD ${ }^{6}$. Smoking cessation is the only evidence-based intervention which has been proven to slow down the accelerated decline in lung function in smokers with COPD $^{1}$. Several evidencebased smoking cessation interventions are available but not yet widely used ${ }^{7-10}$. A systematic review has shown that smoking cessation support in smokers with COPD is best when a combination of psychological and pharmacological interventions is used ${ }^{11}$.

The majority of smokers know that smoking is harmful to their health; and it is estimated that $50 \%$ of smokers with COPD are amenable to smoking cessation support ${ }^{12}$. However, results from smoking cessation intervention studies comparing smokers with and without COPD have yielded ambiguous results. Higher, equal and lower smoking cessation rates in smokers with COPD were found compared to smokers without COPD ${ }^{13-16}$. Nevertheless, the prevalence of smoking in patients with COPD is still high and exceeds the rate of smoking in the general population ${ }^{17}$. A large population-based study showed that the prevalence of smoking currently was 35\% among patients with COPD compared with $22 \%$ among patients without COPD ${ }^{17}$. This implies that when patients get a diagnosis of COPD many still continue smoking even though quitting is their best treatment option. Their chances of quitting might partly be reduced because of a higher level of tobacco addiction and susceptibility to develop depressive symptoms ${ }^{18,19}$. Therefore, smokers with COPD seem to be a special subgroup of smokers that have a more urgent need to quit smoking, but might find it more difficult to do so ${ }^{18}$.

A specific approach for smokers with COPD, while probably needed, does not yet exist. In order to create smoking cessation programs tailored to the needs of smokers with COPD, we need to gain their own views on smoking and quitting. Up until now, there 
have been some qualitative studies reporting perspectives of smokers with $\operatorname{COPD}^{20-23}$. Few of them have been able to identify concrete clinical implications. For example, Eklund et al. described how important it is to make sure that the smoker has the right intrinsic motivation before starting an attempt to quit ${ }^{22}$. In addition, Wilson et al. pointed out the importance of taking into account volatility in patients' decision making and formulating realistic goals ${ }^{21}$. However, these studies only reported results of smokers with COPD, making it unclear whether these statements apply only to these smokers or are a reflection of smokers in general. As far as we are aware, there are only two studies comparing smokers with and without COPD ${ }^{24,25}$. These showed a lot of similarities between the two groups ${ }^{24,25}$, but also some differences; smokers with COPD had higher tobacco consumption, higher nicotine dependence and a different pattern of smoking compared with smokers without COPD ${ }^{24}$. However, in these studies there is no qualitative data on smokers' specific experiences regarding smoking cessation.

The aim of this qualitative study was to explore which justifications for tobacco smoking and experiences of quitting were commonly shared in smokers with and without COPD, and which, if any, were specific to smokers with COPD. Once researchers and health care providers understand the concerns of smokers with COPD regarding quitting and utilizing cessation treatments, they may address these problems in tailored smoking cessation interventions in order to increase smoking cessation in smokers with COPD.

\section{Methods}

\section{Setting and study population}

Participants for the interviews were derived from a cross-sectional survey focusing on factors associated with smoking cessation in smokers with and without COPD ${ }^{19}$. Participants were recruited from the 'Eindhoven Corporation of Primary Health care centres' (SGE), which is a network of ten primary health care centres in the city of Eindhoven, the Netherlands, covering approximately 65,000 patients ${ }^{26}$.

In January 2012, all patients from SGE with a recorded diagnosis of COPD ( $N=1248)$ in their electronic medical record (EMR) and twice as many patients without $\operatorname{COPD}(N=$ 2466) received a questionnaire per postal mail and an enclosed form on which they could indicate if they were willing to participate in an interview. A total of 437 patients 
(31 \%) with COPD and 875 patients (31 \%) without COPD responded to the questionnaire. Among these, we identified 107 current smokers with COPD (24.5\% of 437) and 86 current smokers without COPD (9.8\% of 875). Thirty-four percent (36/107) of the patients with COPD and 53\% (46/86) of the patients without COPD met the inclusion criteria for attendance at the interview: willing to participate and being a current smoker with a smoking history of at least five years. We obtained written informed consent from all participants.

To provide elaborate understanding of smoking behaviour and smoking cessation, and supplement the cross-sectional survey, a purposive sample of 10 smokers with and 10 smokers without COPD was chosen by the coordinating researcher (EE) for interviewing. They were selected in order to include maximum variation in age and sex within both groups. Furthermore, age and sex, important risk factors for the development of COPD, were equally distributed between both groups.

\section{Data collection}

Semi-structured in depth interviews of 60-90 minutes were conducted. An interview topic guide, consisting of four central topics, was developed, based on the literature and expertise in the research team [see Addendum 4.1] with the purpose of getting knowledge of the informants' smoking narratives.

The interviews were performed in the participants' homes to enable them to feel at ease and be open about their reflections on smoking. Furthermore, the interviewer attempted to adopt a non-judgmental attitude and bridle presumptions and prejudices to assure room for participants to express their thoughts freely on smoking and smoking cessation. The interviews were audio recorded. Furthermore, the interviewer (EE) wrote down non-verbal impressions and other notable information. Transcription was done by one researcher (EE).

Participants were given a $€ 15$ gift voucher after the interview was completed. The study was approved by the Medical Ethics Committee of Maastricht University, the Netherlands (approval number 11-4-145). 


\section{Analysis}

The topic of smoking and smoking cessation is, in most contexts, morally contentious. Attention must be paid to the questions posed by the interviewer and responses made by the interviewee, to avoid eliciting justifications or normative, ideal statements only. We believe that through a careful interview relationship we achieved data both consisting of justifications, explanations and patient-near experiences, reflecting what made sense to the participants as immediate concerns and thoughts. Still, in the analysis we paid attention to the moral context of the data and attempted not to infer what could not be justified.

Thematic analysis was used according to Braun and Clarke ${ }^{27}$. EE orthographically transcribed the interviews and imported them into NVivo $9^{27}$. Data collection and analysis were carried out concurrently by one researcher (EE). EE checked the transcripts against the original audio recordings for accuracy. Next, EE identified initial codes and formulated these in English. A semantic approach was used which identified both the explicit and surface meaning units as well as reflected the smokers' reality ${ }^{27}$. Primarily, we used an inductive thematic analysis, which means that EE coded the text without initially relating it to the aim of the study. The researchers, however, did have a certain interest in specific components regarding smoking cessation ${ }^{27}$. We realized a balance by giving some direction to the information-collection process (topic list) whilst also enabling different matters to evolve through the coding process. EE and DK checked the English codes back against the underlying Dutch quotes. Codes were then discussed in detail and sorted into categories and subcategories (EE and MBR). For example, there were categories titled 'experiences of not being able to quit' and 'beliefs about the relationship between health and smoking', with subcategories describing different experiences and beliefs the participants came up with. Next, the essential contents of the codes were interpreted into themes (EE and MBR). For example, the essence of all the codes describing thoughts about health and smoking resulted in the theme 'balancing the impact on health of smoking'. EE checked if the resulting thematic map accurately reflected the meaning units evident in the dataset as a whole ${ }^{27}$. EE discussed the resulting thematic map with MBR and DK. Afterwards we checked if the themes and underlying codes contained differences between smokers with and without COPD. 
Overall, we used a constant comparative approach to the data analysis with the aim to saturate the coded categories and themes. There was no need to extend the data collection to more than twenty participants, since the analysis made clear that the developing themes could be filled in and enriched from the data we had.

\section{Results}

Characteristics of participants are displayed in Table 4.1. All smokers had started smoking at a time when this was socially acceptable. Most had started smoking because of social reasons.

Table 4.1 Characteristics of smokers with and without chronic obstructive pulmonary disease (COPD)

\begin{tabular}{|c|c|c|}
\hline & With COPD $(n=10)$ & Without COPD $(n=10)$ \\
\hline Female sex & $40(4)$ & $40(4)$ \\
\hline Age, mean (SD) & $60.0(8.1)$ & $62.6(9.0)$ \\
\hline \multicolumn{3}{|l|}{ Socioeconomic status ${ }^{28}$} \\
\hline Low & $22(2)$ & 0 \\
\hline Moderate & $68(6)$ & $60(6)$ \\
\hline High & $11(1)$ & $40(4)$ \\
\hline \multicolumn{3}{|l|}{ GOLD a status (self-reported) } \\
\hline Mild & $33(3)$ & $\mathrm{n} / \mathrm{a}$ \\
\hline Moderate & $22(2)$ & $\mathrm{n} / \mathrm{a}$ \\
\hline Severe & $11(1)$ & $\mathrm{n} / \mathrm{a}$ \\
\hline Very severe & 0 & $\mathrm{n} / \mathrm{a}$ \\
\hline I do not know & $22(2)$ & $\mathrm{n} / \mathrm{a}$ \\
\hline \multicolumn{3}{|l|}{ Level of nicotine addiction ${ }^{29}$} \\
\hline Low & $33(3)$ & $40(4)$ \\
\hline Medium & $67(6)$ & $50(5)$ \\
\hline High & 0 & $10(1)$ \\
\hline Motivation to quit ${ }^{30}$, mean (SD) & $2.4(1.3)$ & $3.2(1.9)$ \\
\hline
\end{tabular}

Data are presented as \% (n) unless stated otherwise. Discrepancies between total numbers and numbers of added subcategories are due to missing values. ${ }^{a}$ GOLD $=$ Global Initiative for Chronic Obstructive Lung Disease ${ }^{b} 1-7=$ highest level of motivation

\section{Theme 1: Balancing the impact on health of smoking}

The participants weighted and interpreted facts on the relationship between smoking and health, and created their own judgements and justifications about the health risks of smoking. We noticed, for example, that some of them were balancing the health risks of smoking against the health risks of other addictive behaviours, such as eating too much. 
'...and if I can't smoke then I'll spend all day eating! What, then, is better for me? Because that way means you'll end up far too fat.' [interview 6 - without COPD]

Moreover, participants compared the impact on health of smoking with the impact on health of air pollution created by traffic and factories. They emphasized that air pollution is as bad or even worse for their health as smoking.

'Living here on the Kennedylaan with the balcony doors open, drinking a cup of coffee in the morning sun - that's much worse for you than smoking two packs of roll-up tobacco a day. Those cars that drive past and stop here for the traffic lights - now that's real filth!' [interview 4 - without COPD]

Examples such as these suggested that the participants did realize that smoking is bad for their health, because they compared it with something else which is unhealthy and stated that smoking is less bad. However, by talking about other people and other pollution mechanisms than their own smoking behaviour, they trivialized the health consequences of their own smoking behaviour. In other words, drawing on experiences and knowledge sources seemed to create a practical reasoning to justify their smoking behaviour.

Furthermore, the participants expressed inconsistent views about the causal relationship between smoking and disease. At the beginning of the interview, many participants in both groups said that they knew smoking is bad for their health. However, all through the interview, particular smokers with COPD would refine on their previous statement. Moreover, there were smokers with COPD who said they were unsure about the relation between smoking and having COPD.

'...now if smoking really is the cause of that COPD, I am not sure; I don't know. I have no real idea where it comes from.' [interview 9 - with COPD]

Overall, participants did not differ much in their expressions on the causal relationship between smoking and disease. However, smokers with COPD did not express more awareness after having had the diagnosis and some smokers with COPD even 
remarked, possibly as justification or as fact, that the doctors had never told them smoking was bad for their respiratory health.

Finally, existential reflections played a part in reasoning about smoking and health. Smokers with COPD particularly expressed that how they envisioned life and death was interrelated with quitting.

'...a while ago, I had a massive fear of death and that's the time that I had a total change of heart. I don't fear it at all anymore. That's one of the reasons why I ask myself why should I go without that cigarette that I like so much? Why deprive myself?' [interview 18 - with COPD]

Other smokers with COPD expressed similar feelings, reasoning that they did not mind dying, therefore giving up smoking was not relevant. One smoker with COPD argued that by continuing with smoking at least he knew what he would die of. As some of them had a particular fear of pining away [waste away in misery] if they were to quit smoking, they envisaged this not happening if they continued smoking. There was also one smoker without COPD who expressed such existential reflections. He had had an experience with a life-threatening disease, which made him realize that, in contrast with the smokers with COPD, he did not wish to die yet. In conclusion, smokers with COPD seemed to justify the fact that they were still smoking by existential reasoning; there was no need for them to quit because they did not mind dying from smoking. Conversely, the one smoker without COPD seemed interested to quit due to existential reasoning; he realized he did not want to die and this encouraged him to undertake a quit attempt.

\section{Theme 2: Challenging of autonomy by social interference}

The impact of comments or advice from different sources, such as government, health care providers and family, seemed to interfere greatly with the smokers' feelings and thoughts about smoking. Most comments in this regard had a negative weighting. The participants said that, in general people's comments on smoking were experienced as being meddlesome. They frequently described feeling irritated, especially by exsmokers' comments. 
'Sometimes I reckon it's exaggerated. Then I think, oh, come on, guys, please! Those who used to smoke the most have now stopped or are stopping, and they are the ones with the most to say when anyone else is smoking.' [interview 2 - with COPD]

These feelings of irritation may be connected with a strong feeling of autonomy. All participants felt they needed freedom to decide to do as they wished. Furthermore, they felt they understood why general practitioners (GP) advised them to stop smoking. However, the participants mentioned in passing that they were irritated by smoking cessation advice, especially when it was very insistent: most of them would thus cut short conversations about smoking.

'I just don't say anything, I refuse to discuss the matter. It's bad; I know that. I refuse to discuss it because you end up in an argument that leads nowhere: he [GP] makes all sorts of remarks such as, 'It is really bad,' and then I say, 'Yes, I know, but I am going to carry on doing it [smoking] anyway." [interview 17 without COPD]

Most of the participants had an opinion about continuing smoking and seemed not to be susceptible to external influences, such as advice from a GP. In addition, smokers did not feel like actively responding to the GP's advice because they said they would sort it out themselves. Again, feelings of autonomy dominated. Furthermore, some smokers with COPD were indignant about the communication with specialists and GPs. This indignation seemed to be related to the amount and type of emotional attention given by the health care provider.

'Personally, I think that the doctors of today are rather lax. You are left to scrabble after everything for yourself. There's no real expression of sympathetic interest in retrospect on their part.' [interview 9 - with COPD]

Smokers with COPD were indignant because they felt that, these days, health care providers did not show interest in them anymore. As one of the smokers with COPD justified: if doctors had more empathy for them, pieces of advice and comments on smoking and smoking cessation would stick in their memory better and would have a more encouraging effect. This might seem to be a justification only, but this also 
reflects the importance for doctors to build up solid relationships with their patients in order to gain trust. This trust is of particular importance for being able to discuss confidential and morally contentious topics, such as smoking. Finally, governmental regulations were not found to be motivating for quitting smoking according to all participants. Even though they had resigned themselves to the anti-smoking policies, they considered them to be ineffective, discriminating and out of proportion.

\section{Theme 3: Prerequisites for quitting}

The overall experience with regard to 'quitting', was presented in rather negative terms; it was about not being able to quit. The participants often stated it was very difficult to quit and that they had little faith that they would be able to do so.

'...and every time I decide to stop...for one reason or another, I just can't manage...I really do want to and my wife does as well but that little bit of...will power...that is what's lacking.' [interview 3 - with COPD]

In addition, many smokers found a wide variety of preconditions that had to be fulfilled before they would be ready to make an attempt to quit. These preconditions, however, were susceptible to changes.

'I did have something once...it was last year. It was my voice; it disappeared. Yes. Then I had to go to the Ear, Nose and Throat specialist and he told me that I had cancer of the vocal cords. And still I thought to myself, 'Now, listen; if they were able to remove it then, then they can do the same next time.' So that's why I started smoking again.' [interview 9 - with COPD]

Furthermore, some of these conditions were not tangible, which made it difficult for outsiders to understand these conditions.

'I say, 'Yes, if a switch is flicked here [points at her head], then I'll quit." [interview 2 - with COPD]

A lot of participants reasoned that if they really wanted to quit, they could do it. They described this motivation as a feeling from inside. One of the participants illustrated this by saying 'it's all in the mind'. Many of these examples relate to intrinsic motivation 
to quit smoking. Most of the participants had changeable explanations and justifications concerning their willingness to quit. They seemed to lack intrinsic motivation and had difficulties obtaining it. However, they could give examples of extrinsic motivators such as health education or comments from significant others, but these were mostly only potential motivators, and might interfere with feelings of autonomy (theme 2). We did not find examples showing that in the end they actually persuaded them to quit. In addition, some motivators, such as health complaints, would disappear over time and therefore not stimulate long-term abstinence. When these health problems faded away, smoking again would easily start.

Furthermore, participants often said that life-events interfered with their motivation to quit and with the maintenance of an attempt to quit. Life-events would prevent them from starting an attempt to quit and also from maintaining the effort.

Finally, the availability of various smoking cessation aids was not motivating for quitting either and smokers with COPD in particular expressed that using smoking cessation aids would only make sense and be effective if one were 'ready' to quit. Nicotine replacement therapies were not found to be effective by all participants because, afterwards, it was claimed that they did not work or had a dirty taste or, beforehand, it was thought that they did not stop the craving which was seen to be the main difficulty in smoking cessation. The participants reported diverse views on medication, such as bupropion and varenicline. However, smokers with COPD were more negative about these medications. Finally, all participants were sceptical about the use of e-cigarettes. Some stated that by using them it made them smoke more and they would not solve the craving problem. Those who were somewhat positive about e-cigarettes did not use them as an aid to quit but as a temporary alternative. In general, smokers wanted aids to solve their craving to smoke and fully to replace the effect of a cigarette.

\section{Discussion}

All participants reported a lot of shared justifications concerning smoking and experiences of quitting. They all trivialized the health consequences of smoking and also felt a threat of social interference in their autonomy which did not motivate them to quit. However, smokers with COPD seemed less knowledgeable about the relationship between their health and smoking; were indignant about a perceived lack 
of empathy from doctors; expressed in particular that their view of life was interrelated with quitting; and had less faith in the efficacy of smoking cessation medications.

It became apparent from the interviews that smokers generally trivialized the health consequences of smoking. However, most of the smokers did make comments that showed at least some consciousness of this relationship. It is possible that answers on this topic from smokers in general, and smokers with COPD in particular, reflect a construction of justification of smoking as a certain style of reasoning. However, we also argue that this is also what made sense to their situation and lived experience of being a smoker, the performance and embodiment of a distinct health and risk discourse. Another aspect is that answers on this topic in general might be biased by optimism in order to reduce the psychological need to quit smoking. This cognitive dissonance could be a coping mechanism to manage their lifestyle ${ }^{31}$. In general, trivializing, comparing and, in that way, balancing different knowledge sources are ingredients often involved in creating and justifying a certain lifestyle ${ }^{32,33}$.

Autonomy was another key issue for smokers. It seemed that advice and comments were mostly experienced as being meddlesome, even when well-intended. This made it challenging for health care providers to win acceptance to discuss smoking and quitting. In the Netherlands, individualism is highly valued, as in other western European countries where qualitative research on smokers with COPD has found that these smokers had a great need for autonomy, and decisions had to be taken independently in order to retain that autonomy ${ }^{22}$. In that study, smokers with COPD sympathized with the idea of receiving help and support, but without being patronized $^{22}$. The same need for supportive emotional communication was seen in our smokers with COPD, who found that doctors lacked empathy for, and interest in, their patients.

We found that motivation for quitting was volatile and sometimes intangible, both in smokers with and without COPD. In several behavioural change models, motivation is one of the key elements to explain changes in health behaviour ${ }^{34-36}$. In previous research, smokers with COPD have acknowledged the need for intrinsic motivation and will power to stop smoking, but they were unsure about how to obtain and maintain will power ${ }^{21}$. Similarly, in our study, motivation for quitting was often referred to as 'something from inside' which was not tangible and smokers were unsure how to 
achieve it. Nevertheless, smokers described intrinsic motivation as the most important motivator for successful quitting. In addition, extrinsic motivation can stimulate quitting as a result of an external source ${ }^{21,37}$. In our study, smokers did not seem to believe in the efficacy of extrinsic motivators. Similar to the findings of previous research, external sources were found to be demotivating at times; life events often provided reasons for never finding the time to focus on smoking cessation ${ }^{22}$. In conclusion, motivating and demotivating factors were volatile, which was also seen in previous research on smokers with COPD $^{21}$.

Most smokers thought of smoking cessation aids as being ineffective. Smokers with COPD in particular stated that using smoking cessation aids would only make sense and be effective if one were 'ready' to quit. With these expressions they seemed to have little faith in the efficacy of smoking cessation aids. A recent study in the Netherlands showed that a low level of knowledge about the evidence-base of aids was possibly due to the promotion of ineffective commercial cessation methods ${ }^{38}$. Furthermore, the lower socio-economic status in the group of smokers with COPD might have been negatively associated with their level of faith in smoking cessation aids, as they are likely to be less educated, hence more likely to dismiss or misunderstand the evidence for smoking cessation aids. In addition, one could also discuss the perception of when a treatment is effective: smokers in our study often expressed that smoking cessation aids were ineffective because they did not make them quit smoking after their use. Smokers with COPD in particular were negative about the side effects and inefficacy of medication such as bupropion and varenicline, both before and after they had used them. This attitude might be counterproductive because smokers with COPD are more nicotine-dependent ${ }^{19,24}$, which makes this evidence-based medication of particular importance to this group of smokers ${ }^{39,40}$.

The study has strengths: the background and interview training of the interviewer (EE) increased the quality of the interviews. Participants were interviewed in their own home for comfort which contributed to open conversations about a confidential and morally contentious topic. During the interview EE tried not to be guided by the knowledge of whether an interviewee was a smoker with or without COPD and also coded both groups as a whole in order to prevent guidance by potential differences. EE wrote down non-verbal impressions during the interview and transcription: in this way, an analysis of both verbal statements, non-verbal impressions and contextual 
conditions for data production was realized. In addition, researcher triangulation was used in order to overcome intrinsic bias.

Some limitations also need to be mentioned: selection bias might have occurred as the participants engaged in the interviews could have held stronger views about smoking and quitting than the ones that were not interested to participate. However, we still saw a diversity of characteristics and opinions coming up, which may indicate that the results reflect the views of the general population of smokers. A pragmatic number of interviews was done initially, however we found that the analytic process made our arguments coherent, i.e. we decided that no further interviews were necessary. The generation of the initial codes was done by one researcher (EE) only and MBR, who helped initiate the codebook, was not able to read the interviews herself because of a language mismatch. However, considerable time was spent on discussion and explanation of the contents of the interviews. The study's generalizability may be limited but is determined by its overall design. However, we believe a thorough and consistent design as well as analysis gives credibility to analytic generalisation, i.e. the development of valid, rich findings feeding into a general understanding of a field of research which we hope to have presented ${ }^{41}$.

\section{Conclusions}

The participants showed many similarities in their reasoning about smoking and quitting. Both groups trivialized the health consequences of smoking and had no faith in the efficacy of smoking cessation aids. Furthermore, all participants reported fluctuation in motivation to quit and the importance of autonomy in making their own decisions. With regards to the smokers with COPD, some specific remarks should be made: they seemed less knowledgeable regarding the relation between their health and smoking and had less faith in the efficacy of medication. Besides, they expressed more existential reflections on their smoking behaviour and were indignant about the perceived lack of empathy from doctors.

For future smoking cessation interventions the corresponding themes argue for a less paternalistic regime when communicating with smokers. Smokers' views need to be explored, particularly regarding their motivation to quit. Clear information and education needs to be provided on the efficacy of smoking cessation aids and the negative consequences of smoking on health. In addition to these general 
recommendations for smoking cessation interventions, some recommendations for COPD tailored smoking cessation interventions can be made: GPs should, in their communication with smokers with COPD, take more time to explore social interactions, health perceptions and moral agendas that influence thoughts, feelings and what makes sense concerning smoking and quitting. Once the health care provider has gained a common understanding and trust, information and education about the relationship between COPD and smoking, and the use and efficacy of various smoking cessation aids, will possibly be appreciated more and absorbed better by the smokers with COPD.

\section{Acknowledgements}

We would like to thank the SGE for its cooperation and all participants for taking the time to participate in the interviews. In addition, we thank Carol Herman for language checking.

Funding was obtained from the 'Lung Foundation Netherlands'. Project number 3.4.11.041. 


\section{References}

1. From the Global Strategy for the Diagnosis, Management and Prevention of COPD, Global Initiative for Chronic Obstructive Lung Disease (GOLD) 2014. http://goldcopd.org. Accessed 10 November 2014.

2. Volksgezondheidenzorg.info. www.volksgezondheidenzorg.info. RIVM: Bilthoven. Accessed 8 November 2014.

3. Celli B.R., MacNee W. Standards for the diagnosis and treatment of patients with COPD: a summary of the ATS/ERS position paper. Eur Respir J. 23, 932-946 (2004).

4. Kohansal R., Martinez-Camblor P., Agusti A., Buist A.S., Mannino D.M., Soriano J.B. The natural history of chronic airflow obstruction revisited: an analysis of the Framingham offspring cohort. Am J Respir Crit Care Med. 180, 3-10 (2009).

5. American Thoracic Society. Cigarette Smoking and Health. Am J Respir Crit Care Med. 153, 861-865 (1996).

6. Willemse B.W., Postma D.S., Timens W., ten Hacken N.H. The impact of smoking cessation on respiratory symptoms, lung function, airway hyperresponsiveness and inflammation. Eur Respir J. 23, 464-476 (2004).

7. Stead L.F., Perera R., Bullen C., Mant D., Hartmann-Boyce J., Cahill K., et al. Nicotine replacement therapy for smoking cessation. Cochrane Database Syst Rev. 11, CD000146 (2012).

8. Cahill K., Stead L.F., Lancaster T. Nicotine receptor partial agonists for smoking cessation. Cochrane Database Syst Rev. 3, CD006103 (2008).

9. Hughes J., Stead L., Lancaster T. Antidepressants for smoking cessation. Cochrane Database Syst Rev. 1, CD000031 (2011).

10. Stead L.F., Lancaster T. Behavioural interventions as adjuncts to pharmacotherapy for smoking cessation. Cochrane Database Syst Rev. 12, CD009670 (2012).

11. van der Meer R., Wagena E.J., Ostelo R., Jacobs A., van Schayck C. Smoking cessation for chronic obstructive pulmonary disease. Cochrane Database Syst Rev. 1, CD002999 (2009).

12. Hilberink S.R., Jacobs J.E., Schlosser M., Grol R.P., de Vries H. Characteristics of patients with COPD in three motivational stages related to smoking cessation. Patient Educ Couns. 61, 449-457 (2006).

13. Willemse B., Lesman-Leegte I., Timens W., Postma D., ten Hacken N. High cessation rates of cigarette smoking in subjects with and without COPD. Chest. 128, 3685-3687 (2005).

14. Wagena E.J., Knipschild P.G., Huibers M.J., Wouters E.F., van Schayck C.P. Efficacy of bupropion and nortriptyline for smoking cessation among people at risk for or with chronic obstructive pulmonary disease. Arch Intern Med. 165, 2286-2292 (2005).

15. Stratelis G., Molstad S., Jakobsson P., Zetterstrom O. The impact of repeated spirometry and smoking cessation advice on smokers with mild COPD. Scand J Prim Health Care. 24, 133-139 (2006).

16. Kotz D., Wesseling G., Huibers M.J., van Schayck O.C. Efficacy of confronting smokers with airflow limitation for smoking cessation. Eur Respir J. 33, 754-762 (2009).

17. Shahab L., Jarvis M.J., Britton J., West R. Prevalence, diagnosis and relation to tobacco dependence of chronic obstructive pulmonary disease in a nationally representative population sample. Thorax. 61, 1043-1047 (2006). 
18. Tønnesen P., Carrozzi L., Fagerstrom K.O., Gratziou C., Jimenez-Ruiz C., Nardini S., et al. Smoking cessation in patients with respiratory diseases: a high priority, integral component of therapy. Eur Respir J. 29, 390-417 (2007).

19. van Eerd E.A., van Rossem C.R., Spigt M.G., Wesseling G., van Schayck O.C., Kotz D. Do we need tailored smoking cessation interventions for smokers with COPD? A comparative study of smokers with and without COPD regarding factors associated with tobacco smoking. Respiration. 90, 211-219 (2015).

20. Schofield I., Kerr S., Tolson D. An exploration of the smoking-related health beliefs of older people with chronic obstructive pulmonary disease. J Clin Nurs. 16, 1726-1735 (2007).

21. Wilson J.S., Elborn J.S., Fitzsimons D. 'It's not worth stopping now': why do smokers with chronic obstructive pulmonary disease continue to smoke? A qualitative study. $J$ Clin Nurs. 20, 819-827 (2011).

22. Eklund B.M., Nilsson S., Hedman L., Lindberg I. Why do smokers diagnosed with COPD not quit smoking? - a qualitative study. Tob Induc Dis. 10, 17 (2012).

23. Lundh L., Hylander I., Tornkvist L. The process of trying to quit smoking from the perspective of patients with chronic obstructive pulmonary disease. Scand J Caring Sci. 26, 485-493 (2012).

24. Jimenez-Ruiz C.A., Masa F., Miravitlles M., Gabriel R., Viejo J.L., Villasante C., et al. Smoking characteristics: differences in attitudes and dependence between healthy smokers and smokers with COPD. Chest. 119, 1365-1370 (2001).

25. Vozoris N.T., Stanbrook M.B. Smoking prevalence, behaviours, and cessation among individuals with COPD or asthma. Respir Med. 105, 477-484 (2011).

26. Eindhoven corporation of primary healthcare centers. http://www.sge.nl/. Accessed 22 May 2013.

27. Braun V., Clarke V. Using thematic analysis in psychology. Qual Res Psychol. 3, 77-101 (2006).

28. Mudde A.N., Willemsen M.C., Kremers S., de Vries H. Measurements for research on smoking cessation. The Hague, STIVORO, 2000.

29. Heatherton T.F., Kozlowski L.T., Frecker R.C., Rickert W., Robinson J. Measuring the heaviness of smoking: using self-reported time to the first cigarette of the day and number of cigarettes smoked per day. Br J Addict. 84, 791-799 (1989).

30. Kotz D., Brown J., West R. Predictive validity of the Motivation To Stop Scale (MTSS): a single-item measure of motivation to stop smoking. Drug Alcohol Depend. 128, 15-19 (2013).

31. Festinger L. A theory of cognitive dissonance. Stanford, California, Stanford University Press; 1962.

32. Davison C., Frankel S., Smith G.D. The limits of lifestyle: re-assessing 'fatalism' in the popular culture of illness prevention. Soc Sci Med. 34, 675-685 (1992).

33. Frich J.C., Malterud K., Fugelli P. Experiences of guilt and shame in patients with familial hypercholesterolemia: a qualitative interview study. Patient Educ Couns. 69, 108-113 (2007).

34. Michie S., van Stralen M.M., West R. The behaviour change wheel: a new method for characterising and designing behaviour change interventions. Implement Sci. 6, 42 (2011).

35. Ajzen I., Albarracin C., Hornik R. Prediction and Change of Health Behavior; Applying the Reasoned Action Approach. Mahwah, New Jersey, Lawrence Erlbaum Associated, Inc.; 2007. 
36. Schwarzer R. Modeling health behavior change: how to predict and modify the adoption and maintenance of health behaviors. Appl Psychol. 57, 1-29 (2008).

37. Stead L.F., Bergson G., Lancaster T. Physician advice for smoking cessation. Cochrane Database Syst Rev. 2, CD000165 (2008).

38. Willems R.A., Willemsen M.C., Smit E.S., Nagelhout G.E., Janssen E., de Vries H. Which smoking cessation aids are proven effective according to smokers who want to quit smoking? A report from the Netherlands. Tob Control. 23, 525-526 (2014).

39. Tashkin D.P., Rennard S., Hays J.T., Ma W., Lawrence D., Lee T.C. Effects of varenicline on smoking cessation in patients with mild to moderate COPD: a randomized controlled trial. Chest. 139, 591-599 (2011).

40. Tashkin D., Kanner R., Bailey W., Buist S., Anderson P., Nides M., et al. Smoking cessation in patients with chronic obstructive pulmonary disease: a double-blind, placebo-controlled, randomised trial. Lancet. 357, 1571-1575 (2001).

41. Polit D.F., Beck C.T. Generalization in quantitative and qualitative research: myths and strategies. Int J Nurs Stud. 47, 1451-1458 (2010). 


\section{Addendum 4.1 - Interview guide}

\section{The rationale of smoking and its significance in everyday life}

Can you tell me about your smoking habits in general?

How did you start smoking? (when? influencing factors?)

How did it develop? (smoking habit)

What does smoking mean to you? (why do you smoke?)

When do you smoke? (specific situations)

Where do you smoke? (specific room)

\section{The influence of the environment on smoking and smoking cessation}

Can you tell me about the influence of your environment on your smoking habits?

Are there any persons in your family who influence your smoking habits?

How/when are they influencing your smoking habits?

Are there any other persons in your environment who influence your smoking habits?

How/when are they influencing your smoking habits? (legislation?)

Are there any health-care professionals in your environment that influence your smoking habits?

How/when are they influencing your smoking habits?

How do your smoking habits influence your interaction with other people, your daily contacts? (social isolation?)

\section{Emotional dimensions of being a smoker}

Can you tell me about the emotional aspects of being a smoker?

When do you feel good about smoking? Why do you feel good about smoking then?/What do you feel? (self-esteem? motivations?)

When do you feel bad about smoking? Why do you feel bad about smoking then?/What do you feel? (self-blame, guilt, shame, personal weakness, psychological distress)

How do you feel when you are asked about smoking? (judged? do you feel able to be honest about your smoking?)

How do you believe other people think about smoking? Why do you believe that?

Do you think people blame you when you are ill? Do you blame yourself? 
How do you feel when you attend the health-care appointments? (do you feel that you can be honest about your smoking habits? do you feel health care providers understand you? do you feel able to approach your doctor for help to give up smoking?)

How do you respond to advice about smoking and your smoking habits? (avoid confrontation?) (patronizing?)

\section{Current barriers and potential facilitators of making a quit attempt and using primary care smoking cessation treatments}

Now I would like to talk about quitting and quit attempts

Have you ever tried to quit?/Have you ever thought about quitting? -> IF YES, keep your last attempt in mind while answering the next questions (if possible compare with other previous quit attempts):

What triggers you to make a quit attempt?/What triggers you to think about a quit attempt? (circumstances, experiences, knowledge, money)

How does a quit attempt make you feel?/How does thinking about a quit attempt make you feel?

How does it feel when the quit attempt does not succeed?

What holds you back from making a quit attempt? (circumstances, experiences, knowledge, money, fill the void)

What information did you receive about the benefits of quitting? From whom? (primary care?)

Are any persons more legitimate to you to help you quit? Significant others? (primary care?)

What information did you receive about the side-effects of quitting? (primary care?)

What treatments have you tried, if any? (pharmaceutical, behavioural)

What do you think about these treatments; (intensive) counselling, NRT/bupropion/varenicline? (even if you did not try them)

How do you think about smoking less as an alternative for complete cessation?

How do you think about slow reduction to quit smoking as an alternative for abrupt quitting?

Is there anything healthcare could do to help you attempt to change your smoking habit? (counselling/treatment?) 

Chapter 5

Predictors of long-term smoking cessation in patients with COPD: results from a randomised controlled trial

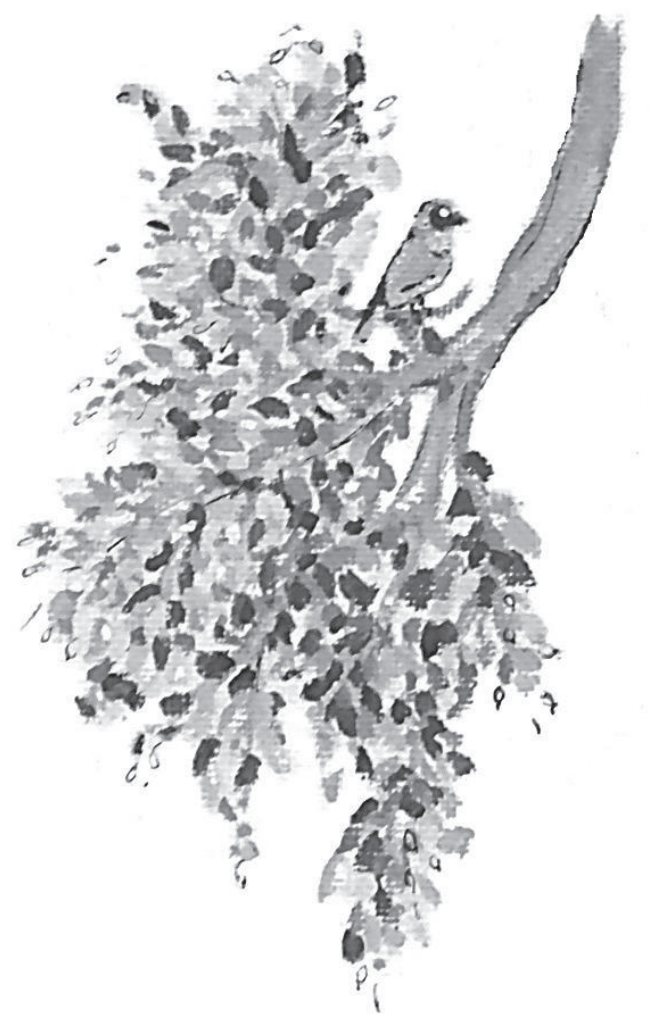

Eva van Eerd Onno van Schayck Geertjan Wesseling Daniel Kotz 


\section{Abstract}

\section{Objective}

It is important to identify predictors for long-term abstinence in patients with chronic obstructive pulmonary disease (COPD) in order to be able to support this group of smokers better with successful quitting.

\section{Methods}

We used data from a randomised controlled smoking cessation trial in 296 smokers with previously undetected mild-moderate airflow limitation. Based on theory and existing evidence, we selected various demographic, health and smoking characteristics, as well as social influence, for the prediction of cotinine-validated 52week prolonged abstinence. We adjusted the model for the type of smoking cessation treatment received. We used manual backward elimination to determine the best-fit model with significant predictors.

\section{Results}

The odds of abstinence were 3.23 times higher in smokers with high level of education than in smokers with low level of education (95\% Cl 1.03-10.15); 1.03 times higher per point increase in general health perception (scale 1-100, 95\% $\mathrm{Cl} 1.01-1.06$ ); and 3.89 times higher in smokers not having a partner at all compared with smokers having a partner that smoked (95\% Cl 1.23-12.31).

\section{Conclusions}

We identified patient-specific factors that predict prolonged abstinence in COPD patients undergoing smoking cessation treatment. When supporting smokers with COPD with quitting, health care providers should take into account the patients' health perceptions and social environment in order to increase their chance of successful quitting. 


\section{Introduction}

Estimates by the World Health Organization show that in 2030 chronic obstructive pulmonary disease (COPD) will become the third leading cause of death worldwide ${ }^{1}$. In Western countries cigarette smoking is the most important risk factor for developing COPD $^{2}$. Besides, patients with COPD who continue to smoke have a higher prevalence of respiratory symptoms, a greater decline in lung function and also a greater mortality rate than non-smokers ${ }^{2}$. Therefore, smoking cessation is the single most effective way to prevent COPD and to reduce the progression of COPD ${ }^{2}$.

However, still many patients with COPD smoke. A large population based English study showed that the prevalence of smoking was 35\% among people with COPD compared with $22 \%$ among people without COPD ${ }^{3}$. This implies that when patients get a diagnosis of COPD many still continue smoking even though several evidence-based smoking cessation interventions are available ${ }^{4,5}$. Indeed, from the Cochrane review on smoking cessation interventions for people with COPD it becomes clear that even with the use of evidence-based smoking cessation interventions the chances of successful quitting are low and relapse rates are high in this group of smokers ${ }^{5}$. For example, prolonged (6-12 months) abstinence rates ranged from $14 \%$ to $27 \%$ in randomised controlled trials comparing pharmacotherapy plus high intensity counselling, with placebo ${ }^{5}$. In all probability these numbers are even lower in daily practice without controlled study circumstances.

The efficacy of smoking cessation interventions does not only depend on the intensity and type of treatment that is used but also on patient's characteristics ${ }^{6}$. Lower nicotine dependence ${ }^{7-9}$ and low levels of psychological distress ${ }^{8,9}$ predict successful quitting in smokers. Only few studies described predictors of smoking cessation in smokers with COPD $^{10-14}$. These studies show that COPD patients were more likely to successfully quit smoking if they were older ${ }^{11,13,14}$, had a higher income or were employed ${ }^{11,13}$, or were living together, irrespective of partner's smoking status ${ }^{13}$. Regarding clinical symptoms patients were more likely to quit if they had heavier COPD symptoms or were more impaired due to these symptoms ${ }^{11,13}$. Better mental health was also related to higher success rates for quitting ${ }^{10,14}$. However, in these studies most of the patients were from outpatient clinics and smoking cessation was self-reported. Besides, these studies were cross-sectional studies, making it more difficult to assess causal effects, and they lacked controlled circumstances, so they might be more likely biased by unknown 
characteristics and circumstances. Only Christenhusz et al. ${ }^{12}$ studied predictors of smoking cessation under controlled circumstances. They found only two predictors in one of the intervention groups: a positive attitude towards smoking cessation seemed important for the success and surprisingly, a higher cotinine level at baseline increased the chance of successful quitting ${ }^{12}$.

In conclusion, data on this subject from controlled studies are lacking, particularly from studies in primary care where most patients with COPD are treated. Therefore, we wanted to examine patient-specific predictors of successful quitting in COPD patients participating in a randomised controlled trial on smoking cessation in primary care ${ }^{15,16}$. Knowing which factors are associated with successful quitting might help designing more effective smoking cessation interventions for patients with COPD.

\section{Methods}

We performed a secondary analysis of data from a randomised controlled trial comparing three smoking cessation treatments. The protocol of that trial ${ }^{15}$ and the results from the primary analysis have been published elsewhere ${ }^{16}$. The trial was designed to assess the efficacy of confronting smokers with airflow limitation for smoking cessation. The trial was approved by the medical ethics committee of Maastricht University Medical Centre (Maastricht, the Netherlands) and registered at the Netherlands Trial Register (ISRCTN 64481813).

\section{Sample}

A total of 296 smokers with previously undetected mild to moderate airflow limitation gave informed consent and were included in the trial. Current smokers aged 35-70 years interested in quitting were recruited from the general population and from primary care practices in Dutch- and Belgian-Limburg. Inclusion criteria were: a smoking history of >10 pack-years; competency in reading and speaking Dutch; reporting at least one respiratory symptom (cough, sputum production, or shortness of breath); and a post-bronchodilator forced expiratory volume in one second (FEV1)/forced vital capacity (FVC) $<70 \%$ in combination with post-bronchodilator FEV1 $>50 \%$ predicted, compatible with mild to moderate COPD ${ }^{2,17}$. Exclusion criteria were: having contraindications for using nortriptyline; a prior respiratory diagnosis; and having undergone spirometry during the preceding 12 months $^{15,16}$. 


\section{Treatment}

In the trial the 296 smokers were randomly allocated to: confrontational counselling by a nurse with nortriptyline for smoking cessation (experimental group); regular counselling by a nurse with nortriptyline (control group 1); or 'care as usual' for smoking cessation by their own general practitioner (control group 2$)^{15,16}$.

\section{Measurements}

The primary outcome was prolonged abstinence from smoking from week 5-52 after the target quit date. Prolonged abstinence was defined as urine cotinine validated $(<50 \mathrm{ng} / \mathrm{mL})$ abstinence from smoking at three follow-up visits; week 5, 26 and 52. From all the data collected during the baseline measurement of the trial (i.e., prior to randomisation) we selected those measurements which were clinically relevant or, according to the literature, were candidate predictors of abstinence. We selected age, sex and level of education (high, moderate, low) ${ }^{18}$. Furthermore, we selected body mass index (BMI) and FEV1. Regarding respiratory health complaints we used information from the clinical COPD questionnaire $(C C Q)^{19}$ and the Medical Research Council $(M R C)^{20}$ dyspnoea scale. The hospital anxiety and depression scale (HADS) ${ }^{21}$ informed us about the mental health of the participants. Health-related quality of life was measured with the 36-Item short form survey (SF-36) ${ }^{22}$; health perception, health change and physical role impairment (sc. problems with work or daily activities due to physical health problems). Furthermore, various smoking-related characteristics were used; number of cigarettes smoked per day, Fagerström Test for Nicotine Dependence $\left(\right.$ FTND) ${ }^{23}$, number of previous quit attempts, and previous use of smoking cessation aids. We also used information on health concerns, risk perception and self-exempting believes ${ }^{24}$. Finally, social influence was measured by asking about the smoking status of the partner; 'Does your partner smoke?'. For this question there were three possible answer options; 'yes', 'no' and 'not applicable'. We assumed that participants who ticked the 'not applicable' option, did not have a partner. We verified this assumption ('not applicable' = not having a partner) by comparing the response to this question with the response to a different question - 'Do you live together with your partner?' and we found that none of the participants that ticked 'not applicable' were living together. 


\section{Analysis}

Subjects not attending a follow-up visit or with missing data on the measure of abstinence were regarded as smokers. We imputed missing data corresponding the guidelines of the specific questionnaire. Seventy five cases remained with missing values on either baseline characteristics or predictor variables. Data were missing when questions were not filled in in the questionnaire, but exact reasons for missing data were unknown. We imputed all missing values by using multiple imputation techniques. As a start the baseline characteristics of participants with and without missing values were compared. Reported differences on four baseline variables were based on the Pearson $\chi^{2}$ test for categorical variables and the Student $t$ test for continuous variables (Appendix 5.1). Prolonged abstinence (5-52 weeks) did not differ between participants with $(8 \%, n=6)$ and without $(11 \%, n=24)$ missing data. The assumption was made that the data were missing at random (MAR). All baseline and predictor variables were included in the initial multiple imputation model. For all continuous variables with limited possible values we restricted the range of imputed values so that they would be plausible. We performed 20 imputations as this is the advised minimum in recent literature and is approximate to the percentage of cases that have missing data ${ }^{25}$. Next, we choose 20 iterations to make sure the Markov chain had converged ${ }^{25}$.

A logistic regression analysis was used to determine baseline predictors of validated prolonged abstinence from week 5 to 52 . In total, 21 predictor variables were entered into the initial model (i.e., approximately one variable per 15 cases). We adjusted the model for the type of smoking cessation treatment received by including the 'allocation' variable (even though abstinence rates did not differ statistically between groups, OR $\left.0.96 \mathrm{Cl} 0.43-2.18^{16}\right)$. We then used manual backward elimination $(p<0.02)$ to determine the best-fit model. In the elimination process we kept categorical variables in the model if another variable had a higher $p$-value on the Wald test than one of the subcategories.

We used SPSS (version 21.0) for the analyses. 


\section{Results}

Baseline characteristics of the 296 participants are presented in Table 5.1. Thirty of the 296 participants (10\%) were prolonged abstinent and 266 participants (90\%) had relapsed into smoking during week 5 to 52 after the target quit date. Both groups were quite homogeneous regarding several characteristics e.g. age, FEV1, COPD health status, level of shortness of breath and nicotine dependence. For other characteristics there appeared to be a difference between both groups. For example, participants with high education and mild COPD seemed to be overrepresented in those who remained abstinent. Furthermore, participants that relapsed seemed to have more depressive symptoms. Also, the group that remained abstinent seemed to report a higher health perception and less physical role impairment. Those who relapsed, had previously used different kinds of smoking cessation aids more frequently, including alternative aids, such as acupuncture and laser therapy. Finally, the partners' smoking status seemed to be different in both groups.

Table 5.1 Baseline characteristics of participants who were prolonged abstinent from week 5-52 and those who relapsed into smoking

\begin{tabular}{|c|c|c|c|}
\hline & Total $(n=296)$ & $\begin{array}{l}\text { Prolonged } \\
\text { abstinent }(n=30)\end{array}$ & $\begin{array}{l}\text { Sustained } \\
\text { smoker } \\
(n=266)\end{array}$ \\
\hline \multicolumn{4}{|l|}{ Demographic characteristics } \\
\hline Age, years ${ }^{*}$ & $54.0 \pm 7.5$ & $53.3 \pm 6.6$ & $54.1 \pm 7.6$ \\
\hline Female $^{*}$ & $37.5(111)$ & $36.7(11)$ & $37.6(100)$ \\
\hline \multicolumn{4}{|l|}{ Level of education $^{*}$} \\
\hline Low & $30.1(89)$ & $16.7(5)$ & $31.6(84)$ \\
\hline Moderate & $45.3(134)$ & $46.7(14)$ & $45.1(120)$ \\
\hline High & $24.7(73)$ & $36.7(11)$ & $23.3(62)$ \\
\hline \multicolumn{4}{|l|}{ Health characteristics } \\
\hline $\mathrm{BMI}$ & $25.1 \pm 4.1$ & $25.2 \pm 3.5$ & $25.0 \pm 4.2$ \\
\hline FEV1\% predicted post bronchodilation ${ }^{*}$ & $81.6 \pm 15.5$ & $81.9 \pm 14.9$ & $81.5 \pm 15.6$ \\
\hline \multicolumn{4}{|l|}{ GOLD status } \\
\hline Mild & $53.0(157)$ & $60(18)$ & $52.3(139)$ \\
\hline Moderate & $47.0(139)$ & $40(12)$ & $47.7(127)$ \\
\hline \multicolumn{4}{|l|}{ COPD health status } \\
\hline Respiratory symptoms ${ }^{* 1}$ & $2.0 \pm 1.1$ & $1.8 \pm 0.7$ & $2.0 \pm 1.1$ \\
\hline Physical state ${ }^{* 1}$ & $0.9 \pm 0.8$ & $0.8 \pm 0.7$ & $0.9 \pm 0.8$ \\
\hline Level of shortness of breath ${ }^{* 2}$ & $1.5 \pm 1.0$ & $1.4 \pm 0.7$ & $1.5 \pm 1.0$ \\
\hline
\end{tabular}


Table 5.1 (continued)

\begin{tabular}{|c|c|c|c|}
\hline & Total $(n=296)$ & $\begin{array}{l}\text { Prolonged } \\
\text { abstinent }(n=30)\end{array}$ & $\begin{array}{l}\text { Sustained smoker } \\
(\mathrm{n}=266)\end{array}$ \\
\hline \multicolumn{4}{|l|}{ Mental health } \\
\hline Anxiety $^{* 3}$ & $5.8 \pm 3.9$ & $5.3 \pm 2.8$ & $5.9 \pm 4.0$ \\
\hline Depression ${ }^{* 3}$ & $4.4 \pm 3.7$ & $3.4 \pm 3.1$ & $4.5 \pm 3.8$ \\
\hline Perception of one's health ${ }^{* 4}$ & $49.6 \pm 17.3$ & $56.8 \pm 18.5$ & $48.8 \pm 17.0$ \\
\hline Health change $^{* 4}$ & $43.5 \pm 16.7$ & $47.5 \pm 13.7$ & $43.1 \pm 17.0$ \\
\hline Physical role impairment ${ }^{* 4}$ & $76.2 \pm 35.8$ & $88.3 \pm 25.2$ & $74.8 \pm 36.5$ \\
\hline \multicolumn{4}{|l|}{ Smoking characteristics } \\
\hline Cigarettes per day & $23.6 \pm 8.9$ & $21.4 \pm 9.2$ & $23.8 \pm 8.8$ \\
\hline Pack-years & $43.5 \pm 18.9$ & $37.7 \pm 17.3$ & $44.2 \pm 19.0$ \\
\hline Level of nicotine addiction ${ }^{* 5}$ & $4.6 \pm 1.5$ & $4.4 \pm 1.4$ & $4.6 \pm 1.5$ \\
\hline $\begin{array}{l}\text { Number of previous quit } \\
\text { attempts }^{*}\end{array}$ & $4.0 \pm 4.4$ & $3.6 \pm 4.0$ & $4.0 \pm 4.5$ \\
\hline \multicolumn{4}{|l|}{$\begin{array}{l}\text { Previous use of aids for smoking } \\
\text { cessation }\end{array}$} \\
\hline Counselling & $8.4(25)$ & $6.7(2)$ & $8.6(23)$ \\
\hline $\begin{array}{l}\text { Nicotine replacement } \\
\text { therapy }\end{array}$ & $64.2(190)$ & $53.3(16)$ & $65.0(173)$ \\
\hline Bupropion & $23.3(69)$ & $23.3(7)$ & $23.3(62)$ \\
\hline Alternative & 40.2 (119) & $30(9)$ & $41.4(110)$ \\
\hline Health concern ${ }^{* 6}$ & $3.9 \pm 0.9$ & $3.9 \pm 1.0$ & $3.9 \pm 0.9$ \\
\hline Importance of risk reduction ${ }^{* 7}$ & $4.3 \pm 0.9$ & $4.4 \pm 0.7$ & $4.3 \pm 1.0$ \\
\hline Risk perception ${ }^{* 8}$ & $4.0 \pm 0.9$ & $3.9 \pm 0.8$ & $4.0 \pm 0.8$ \\
\hline Self-exempting beliefs ${ }^{* 9}$ & $2.3 \pm 0.6$ & $2.3 \pm 0.6$ & $2.3 \pm 0.6$ \\
\hline \multicolumn{4}{|l|}{ Social influence } \\
\hline \multicolumn{4}{|l|}{ Smoking status of partner ${ }^{*}$} \\
\hline no smoker & 50.7 (150) & $50(15)$ & $36.1(96)$ \\
\hline smoker & 34.8 (103) & $23.3(7)$ & $50.8(135)$ \\
\hline N/A (no partner) & $14.5(43)$ & $26.7(8)$ & $13.2(35)$ \\
\hline
\end{tabular}

Data are presented as means \pm SD or $\%(n)$, as appropriate. GOLD = Global Initiative for Chronic Obstructive Lung Disease. FEV1 = Forced expiratory volume in 1 second.

* Variable included in the starting prediction model. ${ }^{1} 0-6$ : highest level of respiratory symptoms and mental/physical complaints. ${ }^{2} 0-5$ : highest level of shortness of breath. ${ }^{3} 0-21$ : highest level of anxiety/depression. ${ }^{4} 1-100$ : highest level of perceived health/better health than previous year/lowest level of physical role impairment. ${ }^{5} 0-10$ : highest level of nicotine dependence. ${ }^{6}$ 'How worried are you to get a disease or disorder which is caused by smoking (such as a serious heart or lung disease)?' 1-5: very worried. ${ }^{7}$ 'How important is it to you to reduce your risk of getting a disease or disorder which is caused by smoking?' 1-5: highest level of importance. ${ }^{8}$ 'How high do you estimate your risk of getting a serious disease within the next ten years when you do not stop smoking?' 1-5: highest level of risk. ${ }^{9} 1-5$ : highest level of self-exempting beliefs. 
Table 5.2 Odds ratios (OR) and 95\% confidence intervals $(95 \% \mathrm{Cl})$ of predictors of prolonged abstinence from week 5-52 in the multivariate model $(n=296)$

\begin{tabular}{lll}
\hline $\begin{array}{l}\text { Demographic characteristics } \\
\text { Level of education } \\
\text { Low }\end{array}$ & OR & $95 \% \mathrm{Cl}$ \\
$\quad$ Moderate & 1 & \\
$\quad$ High & 1.79 & $0.60-5.32$ \\
$\quad 3.23^{*}$ & $1.03-10.15$ \\
\hline $\begin{array}{l}\text { Health characteristics } \\
\text { Perception of one's health }\end{array}$ & $1.03^{*}$ & $1.01-1.06$ \\
\hline $\begin{array}{l}\text { Social influence } \\
\text { Smoking status of partner } \\
\quad \text { no smoker }\end{array}$ & & \\
$\quad$ smoker & 1.55 & $0.59-4.07$ \\
$\quad$ N/A (no partner) & 1 & $1.23-12.31$ \\
\hline
\end{tabular}

${ }^{*}$ Significant predictor $(\mathrm{p}<0.05)$.

${ }^{1} 1$-100: lowest level of perceived health/physical functioning/social functioning.

We started the logistic regression model with 21 variables (Table 5.1, variables included in the model are indicated with an asterisk). After manual backward elimination, three of the variables remained significant predictors of prolonged abstinence: level of education, perception of one's health, and smoking status of partner (Table 5.2). The odds of abstinence were 3.23 times higher in smokers with high level of education than in smokers with low level of education $(95 \% \mathrm{Cl} 1.03$ 10.15); 1.03 times higher per point increase in general health perception ( $95 \% \mathrm{Cl} 1.01$ 1.06); and 3.89 times higher in smokers not having a partner at all compared with smokers having a partner that smoked ( $95 \% \mathrm{Cl} 1.23-12.31$ ).

\section{Discussion}

In our smoking cessation trial in participants with mild to moderate COPD, 10\% achieved prolonged abstinence. High level of education, higher general health perception and not having a partner were statistically significant predictors of abstinence.

There is evidence from the literature for a positive relation between higher socioeconomic status (SES) and successful quitting in the general smoking population ${ }^{26-32}$. It has also been reported that patients with COPD with a higher income or an employment have higher chances of becoming abstinent ${ }^{11,13}$. In our randomised 
controlled study we also found evidence that smokers with a low level of education were less likely to remain abstinent. Several reasons for this inequality have been mentioned in the literature; smokers with a low SES might be more likely to have a partner or social environment wherein people smoke ${ }^{33}$, they might have less resources for obtaining smoking cessation aids ${ }^{34}$ or have higher levels of nicotine dependence ${ }^{35}$ or psychological distress ${ }^{33,36}$.

Those who experienced a higher level of general health were more likely to quit successfully. A previous study showed that when one's health deteriorates, based on GOLD A-D criteria, motivation for quitting increases ${ }^{13}$. Activity limitation due to lung problems is also found to predict successful quitting ${ }^{11}$. We are not aware of any other studies using subjective health measures ${ }^{10}$ and can only speculate that, in our study, better perceived health might have been associated with stronger self-efficacy to refrain from smoking, resulting in more successful quit attempts.

When comparing the baseline characteristics of successful and unsuccessful quitters, the latter one seemed to be more likely to have a partner who smoked. In the final prediction model not having a partner at all (sc. answer option 'not applicable', see Methods) predicted abstinence. Unfortunately, we were not able to confirm if these participants really did not have a partner. Therefore, the results should be interpreted with caution. From the literature we know that cohabitation with a non-smoker is a strong predictor for successful quitting ${ }^{37}$. In a different study, patients with COPD who were living together, irrespective of partner's smoking status, were more likely to quit successfully ${ }^{13}$. Others found that smoking cessation was not affected by cohabitation status $^{32}$.

As previously mentioned, difficulties in obtaining smoking cessation aids for smokers with a low SES, might make them less likely to remain abstinent. Literature suggests that wealthier people are more likely to use treatment when trying to quit ${ }^{34,38}$. In contrast, a study from England did not find this difference ${ }^{27}$, possibly due to reimbursement of smoking cessation aids in England, and other cultural and economic factors $^{27}$. In our study we saw that those who relapsed, seemed to have used different kinds of smoking cessation aids more frequently, including alternative treatments. However, we did not include this variable in the initial prediction model. 
Other factors such as higher nicotine dependence and psychological distress may also account for the differences found between different socio-economic classes. Smokers from socio-economically disadvantaged groups seem to have higher levels of nicotine dependence ${ }^{39,40}$, whereas low nicotine dependence has been associated with successful quitting ${ }^{7-9}$. In our study nicotine dependence seemed to be similar in those who relapsed and those who remained abstinent, possibly, due to the fact that the participants of the trial were selected by very strict criteria, resulting in a very homogeneous group of smokers. Finally, psychological distress, including depressive

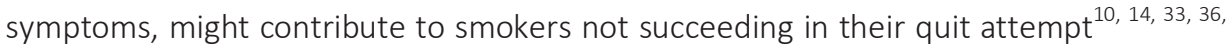
41,42 . The chances of having depressive symptoms are high in patients with COPD, regardless of smoking status ${ }^{43}$. In our study the participants in both groups had a low level of depressive symptoms. The major cause of this was probably the exclusion of all people from the trial that took antidepressants ${ }^{16}$. However, smokers that relapsed seemed to report more depressive symptoms at baseline than the ones that successfully quit. Nevertheless, no significant difference came up from the prediction model.

Finally, we hypothesised that a higher level of health concerns and risk perception would predict successful quitting, as well as a lower level of self-exempting beliefs. However, these variables were not found to be predictors. This may be due to lack of statistical power or to the homogeneous group of people who all received a diagnosis of COPD at start of the trial. From the literature we were not able to find information regarding health concerns, risk perception and self-exempting beliefs in relation to successful quitting.

\section{Strengths and limitations}

The original study was a randomised controlled trial, which applied selection criteria. People were excluded if they took antidepressants and only people with previously undetected mild to moderate airflow limitation were included, limiting the external validity. The controlled circumstances of the trial can be seen as a strength, as they reduced the risk of confounding. Furthermore, abstinence was biochemically validated. However, the sample size ( $n=296)$ for our current analysis limited the statistical power to determine significant predictors. We saw differences in baseline characteristics between those who became abstinent and those who relapsed, however, these did not arise as predictors for successful quitting in the final model. We combined the three 
treatment groups in order to get a more substantial group size for predicting successful quitting. We included 'allocation' as a variable in the model in order to correct for any effect of the treatment group on long-term abstinence. Long-term abstinence in the three groups was not significantly different. Still, there might have been some interaction between variables in the model and treatment allocation. Unfortunately, the sample size was too small to further correct for this by including interaction terms in the model or conducting sensitivity analyses for the three treatment groups separately. We used multiple imputation to complete our data and concluded data were MAR. However, more missing values might be expected in the group of smokers, as they tend to drop-out of studies. Nevertheless, we only included measures from the baseline questionnaire of the trial. These measures were, therefore, not subject to be missing due to drop-out. Furthermore, we saw that there was no statistical significant difference for long-term abstinence between the participants with missing values and the ones without.

\section{Conclusions and implications}

Highly-educated smokers with COPD, with a higher general health perception and without a partner, were more likely to successfully quit smoking. These predictors are similar to predictors in the general smoking population. Health care providers should take into account the patients' health perceptions and social environment in order to increase their chance of successful quitting. 


\section{References}

1. World Health Organization. www.who.int. Accessed 29 September 2016.

2. From the Global Strategy for the Diagnosis, Management and Prevention of COPD, Global Initiative for Chronic Obstructive Lung Disease (GOLD) 2015. http://goldcopd.org. Accessed 17 November 2015.

3. Shahab L., Jarvis M.J., Britton J., West R. Prevalence, diagnosis and relation to tobacco dependence of chronic obstructive pulmonary disease in a nationally representative population sample. Thorax. 61, 1043-1047 (2006).

4. Stead L.F., Lancaster T. Behavioural interventions as adjuncts to pharmacotherapy for smoking cessation. Cochrane Database Syst Rev. 12, CD009670 (2012).

5. van Eerd E.A., van der Meer R.M., van Schayck O.C., Kotz D. Smoking cessation for people with chronic obstructive pulmonary disease. Cochrane Database Syst Rev. CD010744 (2016).

6. US Department of Health and Human Services. Public Health Service. Clinical practice guideline. Treating tobacco use and dependence: 2008 update. www.ncbi.nlm.nih.gov/books/NBK63952/. Accessed 17 November 2015.

7. Vangeli E., Stapleton J., Smit E.S., Borland R., West R. Predictors of attempts to stop smoking and their success in adult general population samples: a systematic review. Addiction. 106, 2110-2121 (2011).

8. Cosci F., Corlando A., Fornai E., Pistelli F., Paoletti P., Carrozzi L. Nicotine dependence, psychological distress and personality traits as possible predictors of smoking cessation. Results of a double-blind study with nicotine patch. Addict Behav. 34, 28-35 (2009).

9. Augustson E.M., Wanke K.L., Rogers S., Bergen A.W., Chatterjee N., Synder K., et al. Predictors of sustained smoking cessation: a prospective analysis of chronic smokers from the alpha-tocopherol Beta-carotene cancer prevention study. Am J Public Health. 98, 549-555 (2008).

10. Kupiainen H., Kinnula V.L., Lindqvist A., Postma D.S., Boezen H.M., Laitinen T., et al. Successful Smoking Cessation in COPD: Association with Comorbidities and Mortality. Pulm Med. 2012, 725024 (2012).

11. Schiller J.S., Ni H. Cigarette smoking and smoking cessation among persons with chronic obstructive pulmonary disease. Am J Health Promot. 20, 319-323 (2006).

12. Christenhusz L., Pieterse M., Seydel E., van der Palen J. Prospective determinants of smoking cessation in COPD patients within a high intensity or a brief counseling intervention. Patient Educ Couns. 66, 162-166 (2007).

13. Tottenborg S.S., Thomsen R.W., Johnsen S.P., Nielsen H., Lange P. Determinants of Smoking Cessation in Patients With COPD Treated in the Outpatient Setting. Chest. 150, 554-562 (2016).

14. Adams S.G., Pugh J.A., Kazis L.E., Lee S., Anzueto A. Characteristics associated with sustained abstinence from smoking among patients with COPD. Am J Med. 119, 441447 (2006).

15. Kotz D., Wesseling G., Huibers M.J., van Schayck O.C. Efficacy of confrontational counselling for smoking cessation in smokers with previously undiagnosed mild to moderate airflow limitation: study protocol of a randomized controlled trial. BMC Public Health. 7, 332 (2007).

16. Kotz D., Wesseling G., Huibers M.J., van Schayck O.C. Efficacy of confronting smokers with airflow limitation for smoking cessation. Eur Respir J. 33, 754-762 (2009). 
17. American Thoracic Society. Cigarette Smoking and Health. Am J Respir Crit Care Med. 153, 861-865 (1996).

18. Mudde A.N., Willemsen M.C., Kremers S., de Vries H. Measurements for research on smoking cessation. The Hague, STIVORO, 2000.

19. Van der Molen T. Clinical COPD Questionnaire. Groningen, University Medical Center Groningen, 1999.

20. Bestall J.C., Paul E.A., Garrod R., Garnham R., Jones P.W., Wedzicha J.A. Usefulness of the Medical Research Council (MRC) dyspnoea scale as a measure of disability in patients with chronic obstructive pulmonary disease. Thorax. 54, 581-586 (1999).

21. Snaith R.P., Zigmond A.S. Hospital Anxiety and Depression Scale. Windsor, NFER Nelson, 1994.

22. Ware J.E., Jr., Gandek B. Overview of the SF-36 Health Survey and the International Quality of Life Assessment (IQOLA) Project. J Clin Epidemiol. 51, 903-912 (1998).

23. Heatherton T.F., Kozlowski L.T., Frecker R.C., Fagerstrom K.O. The Fagerstrom Test for Nicotine Dependence: a revision of the Fagerstrom Tolerance Questionnaire. Br J Addict. 86, 1119-1127 (1991).

24. Kotz D., Huibers M.J., West R.J., Wesseling G., van Schayck O.C. What mediates the effect of confrontational counselling on smoking cessation in smokers with COPD? Patient Educ Couns. 76, 16-24 (2009).

25. van Buuren S. Flexible imputation of missing data. London, Chapman and Hall/CRC; 2012.

26. Hiscock R., Judge K., Bauld L. Social inequalities in quitting smoking: what factors mediate the relationship between socioeconomic position and smoking cessation? J Public Health (Oxf). 33, 39-47 (2011).

27. Kotz D., West R. Explaining the social gradient in smoking cessation: it's not in the trying, but in the succeeding. Tob Control. 18, 43-46 (2009).

28. Fernandez E., Schiaffino A., Borrell C., Benach J., Ariza C., Ramon J.M., et al. Social class, education, and smoking cessation: Long-term follow-up of patients treated at a smoking cessation unit. Nicotine Tob Res. 8, 29-36 (2006).

29. Edwards R., McElduff P., Jenner D., Heller R.F., Langley J. Smoking, smoking cessation, and use of smoking cessation aids and support services in South Derbyshire, England. Public Health. 121, 321-332 (2007).

30. Hymowitz N., Cummings K.M., Hyland A., Lynn W.R., Pechacek T.F., Hartwell T.D. Predictors of smoking cessation in a cohort of adult smokers followed for five years. Tob Control. 6 Suppl 2, S57-62 (1997).

31. Kaleta D., Korytkowski P., Makowiec-Dabrowska T., Usidame B., Bak-Romaniszyn L., Fronczak A. Predictors of long-term smoking cessation: results from the global adult tobacco survey in Poland (2009-2010). BMC Public Health. 12, 1020 (2012).

32. Osler M., Prescott E., Godtfredsen N., Hein H.O., Schnohr P. Gender and determinants of smoking cessation: a longitudinal study. Prev Med. 29, 57-62 (1999).

33. Wiltshire S., Bancroft A., Parry O., Amos A. 'I came back here and started smoking again': perceptions and experiences of quitting among disadvantaged smokers. Health Educ Res. 18, 292-303 (2003).

34. Shiffman S., Brockwell S.E., Pillitteri J.L., Gitchell J.G. Individual differences in adoption of treatment for smoking cessation: demographic and smoking history characteristics. Drug Alcohol Depend. 93, 121-131 (2008).

35. Jarvis M.J., Wardle J., Waller J., Owen L. Prevalence of hardcore smoking in England, and associated attitudes and beliefs: cross sectional study. BMJ. 326, 1061 (2003). 
36. Siahpush M., Carlin J.B. Financial stress, smoking cessation and relapse: results from a prospective study of an Australian national sample. Addiction. 101, 121-127 (2006).

37. Kaleta D., Usidame B., Dziankowska-Zaborszczyk E., Makowiec-Dabrowska T. Correlates of cessation success among Romanian adults. Biomed Res Int. 2014, 675496 (2014).

38. Beard E., Brown J., Michie S., Kaner E., Meier P., West R. Use of aids for smoking cessation and alcohol reduction: A population survey of adults in England. BMC Public Health. 16, 1237 (2016).

39. Bobak M., Jarvis M.J., Skodova Z., Marmot M. Smoke intake among smokers is higher in lower socioeconomic groups. Tob Control. 9, 310-312 (2000).

40. Hiscock R., Bauld L., Amos A., Fidler J.A., Munafo M. Socioeconomic status and smoking: a review. Ann N Y Acad Sci. 1248, 107-123 (2012).

41. Graham H., Inskip H.M., Francis B., Harman J. Pathways of disadvantage and smoking careers: evidence and policy implications. J Epidemiol Community Health. 60 Suppl 2, 712 (2006).

42. Glassman A.H., Helzer J.E., Covey L.S., Cottler L.B., Stetner F., Tipp J.E., et al. Smoking, smoking cessation, and major depression. JAMA. 264, 1546-1549 (1990).

43. Mannino D.M., Buist A.S. Global burden of COPD: risk factors, prevalence, and future trends. Lancet. 370, 765-773 (2007). 


\section{Addendum 5.1}

Table Baseline differences between individuals with and without imputations.

\begin{tabular}{|c|c|c|c|}
\hline & $\begin{array}{l}\text { Original dataset } \\
(n=296)\end{array}$ & $\begin{array}{l}\text { Participants without } \\
\text { imputed values }(n=221)\end{array}$ & $\begin{array}{l}\text { Participants with } \\
\text { imputed values } \\
\text { (n=75) }\end{array}$ \\
\hline \multicolumn{4}{|l|}{ Demographic characteristics } \\
\hline Age, years & $54.0 \pm 7.5$ & $53.5 \pm 7.4^{*}$ & $55.6 \pm 7.9^{*}$ \\
\hline Female & $37.5(111)$ & $36.2(80)$ & $41.3(31)$ \\
\hline \multicolumn{4}{|l|}{ Level of education } \\
\hline Low & $29.4(87)$ & $26.2(58)^{*}$ & $38.7(29)^{*}$ \\
\hline Moderate & $43.9(130)$ & $47.1(104)^{*}$ & $34.7(26)^{*}$ \\
\hline High & $23.6(70)$ & $26.7(59)^{*}$ & $14.7(11)^{*}$ \\
\hline \multicolumn{4}{|l|}{ Health characteristics } \\
\hline BMI & $25.1 \pm 4.1$ & $25.1 \pm 4.1$ & $24.9 \pm 4.0$ \\
\hline FEV1\% predicted post bronchodilation & $81.2 \pm 15.4$ & $81.8 \pm 16.3$ & $80.6 \pm 12.2$ \\
\hline \multicolumn{4}{|l|}{ GOLD status } \\
\hline Mild & $51.7(153)$ & $52.9(117)$ & $48.0(36)$ \\
\hline Moderate & $45.9(136)$ & $47.1(104)$ & $42.7(32)$ \\
\hline \multicolumn{4}{|l|}{ COPD health status } \\
\hline Respiratory symptoms ${ }^{1}$ & $1.9 \pm 1.1$ & $2.0 \pm 1.0$ & $1.9 \pm 1.2$ \\
\hline Physical state ${ }^{1}$ & $0.9 \pm 0.8$ & $0.8 \pm 0.8$ & $0.9 \pm 0.8$ \\
\hline Level of shortness of breath ${ }^{2}$ & $1.5 \pm 1.0$ & $1.5 \pm 1.0$ & $1.4 \pm 0.9$ \\
\hline \multicolumn{4}{|l|}{ Mental health } \\
\hline Anxiety $^{3}$ & $5.8 \pm 3.9$ & $5.5 \pm 3.6^{*}$ & $6.7 \pm 4.5^{*}$ \\
\hline Depression $^{3}$ & $4.4 \pm 3.7$ & $4.2 \pm 3.6$ & $4.8 \pm 4.1$ \\
\hline Perception of one's health ${ }^{4}$ & $49.7 \pm 17.2$ & $49.6 \pm 16.7$ & $50.1 \pm 18.8$ \\
\hline Health change $^{4}$ & $43.5 \pm 16.7$ & $43.7 \pm 16.2$ & $42.8 \pm 18.4$ \\
\hline Physical role impairment ${ }^{4}$ & $76.6 \pm 35.7$ & $80.0 \pm 32.9^{*}$ & $66.0 \pm 41.6^{*}$ \\
\hline \multicolumn{4}{|l|}{ Smoking characteristics } \\
\hline Cigarettes per day & $23.6 \pm 8.9$ & $23.9 \pm 9.0$ & $22.6 \pm 8.6$ \\
\hline Pack-years & $43.5 \pm 18.9$ & $43.4 \pm 19.0$ & $44.0 \pm 18.8$ \\
\hline Level of nicotine addiction ${ }^{5}$ & $4.5 \pm 1.5$ & $4.6 \pm 1.5$ & $4.5 \pm 1.6$ \\
\hline Number of previous quit attempts & $3.9 \pm 4.4$ & $4.0 \pm 3.5$ & $3.4 \pm 6.8$ \\
\hline \multicolumn{4}{|l|}{ Previous use of aids for smoking cessation } \\
\hline Counselling & $6.8(20)$ & $7.2(16)$ & $5.3(4)$ \\
\hline Nicotine replacement therapy & $60.1(178)$ & $62.9(139)$ & $52.0(39)$ \\
\hline Bupropion & $21.6(64)$ & $22.2(49)$ & $20.0(15)$ \\
\hline Alternative & $37.5(111)$ & $37.1(89)$ & $39.3(22)$ \\
\hline Health concern ${ }^{6}$ & $3.9 \pm 0.9$ & $3.9 \pm 0.9$ & $3.8 \pm 1.0$ \\
\hline Importance of risk reduction ${ }^{7}$ & $4.4 \pm 0.9$ & $4.4 \pm 0.9$ & $4.2 \pm 1.0$ \\
\hline Risk perception ${ }^{8}$ & $4.0 \pm 0.8$ & $4.0 \pm 0.8$ & $3.9 \pm 0.8$ \\
\hline Self-exempting beliefs ${ }^{9}$ & $2.3 \pm 0.6$ & $2.3 \pm 0.6$ & $2.3 \pm 0.6$ \\
\hline \multicolumn{4}{|l|}{ Social influence } \\
\hline \multicolumn{4}{|l|}{ Smoking status of partner } \\
\hline no smoker & $50.0(148)$ & $50.7(112)$ & $48.0(36)$ \\
\hline smoker & $34.1(101)$ & $34.8(77)$ & $32.0(24)$ \\
\hline N/A (no partner) & $13.5(40)$ & $14.5(32)$ & $10.7(8)$ \\
\hline
\end{tabular}

Data are presented as means \pm SD or $\%(n)$, as appropriate. Discrepancies between total numbers and numbers of added subcategories are due to missing values. GOLD = Global Initiative for Chronic Obstructive Lung Disease. FEV1 $=$ Forced expiratory volume in 1 second.

"Significant difference between the two groups $(\mathrm{p}<0.05) .{ }^{1} 0-6$ : highest level of respiratory symptoms and mental/physical complaints. ${ }^{2} 0-5$ : highest level of shortness of breath. ${ }^{3} 0-21$ : highest level of anxiety/depression. ${ }^{4} 1-100$ : highest level of perceived health/better health than previous year/lowest level of physical role impairment. ${ }^{5} 0$-10: highest level of nicotine dependence. ${ }^{6}$ How worried are you to get a disease or disorder which is caused by smoking (such as a serious heart or lung disease)?' 1-5: very worried. ' 'How important is it to you to reduce your risk of getting a disease or disorder which is caused by smoking?' 1-5: highest level of importance. ${ }^{8}$ 'How high do you estimate your risk of getting a serious disease within the next ten years when you do not stop smoking?' $1-5$ : highest level of risk. ${ }^{9} 1-5$ : highest level of self-exempting beliefs. 
Chapter 6

\section{Why do physicians lack engagement with smoking cessation treatment in their COPD patients? A multinational qualitative study}

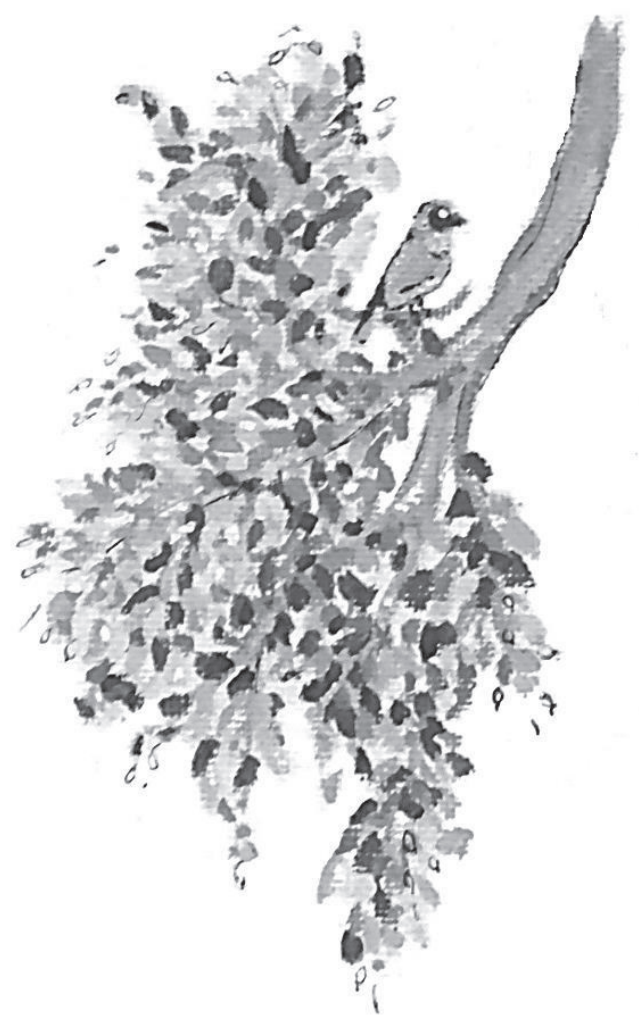

Eva van Eerd Mette Bech Risør Mark Spigt Maciek Godycki-Cwirko Elena Andreeva Nick Francis Anja Wollny Hasse Melbye Onno van Schayck Daniel Kotz

Accepted for publication npj Primary Care Respiratory Medicine 


\section{Abstract}

Smoking cessation is the only effective intervention to slow down the accelerated decline in lung function in smokers with chronic obstructive pulmonary disease (COPD). Nevertheless, physicians often do not routinely provide evidence-based smoking cessation treatment to their patients. To understand underlying reasons, we explored how physicians engage in smoking cessation treatment in their COPD patients. In total, 21 focus group discussions were held with general practitioners and pulmonologists in seven different countries in Europe and Asia. We generated three themes, whereby some of the issues concerned smokers in general: first, 'physicians' frustration with COPD patients who smoke'. These frustrations interfered with the provision of evidence-based treatment and could result in this group of patients being treated unequally. Second: 'physicians' limited knowledge of, and negative beliefs about, smoking cessation treatment'. This hindered treating smokers effectively. Third: 'health care organisational factors that influence the use of smoking cessation treatments'. Money and time issues, as well as the failure to regard smoking as a disease, influenced how physicians engaged in smoking cessation treatment. Our results indicate that there is a number of barriers to the provision of effective smoking cessation treatment in patients with COPD and smokers in general. Introducing an informative smoking cessation program, including communication skills and ethical issues, in the vocational and postgraduate medical training may help to address these barriers. This is important in order to increase engagement with smoking cessation treatment and to improve quality of COPD care. 


\section{Introduction}

Chronic obstructive pulmonary disease (COPD) is a major public and individual health problem. Experts think that, by 2020, COPD will rank fifth worldwide in terms of burden of disease and third in terms of mortality ${ }^{1}$. Higher mortality rates and an accelerated decline in lung function are seen in patients with COPD who continue smoking ${ }^{1}$. Smoking cessation is therefore the most important treatment for patients with COPD, as it is the only evidence-based intervention which has been proven to slow down the accelerated decline in lung function ${ }^{1}$.

To promote smoking cessation, international COPD guidelines include recommendations for effective smoking cessation interventions ${ }^{1,2}$. They state, in accordance with the Cochrane review on smoking cessation in patients with COPD, that a combination of behavioural and pharmacological treatment is superior to any other treatment ${ }^{3}$. Nevertheless, the prevalence of smoking in patients with COPD is still high and there is evidence that it exceeds the rate of smoking in the general population ${ }^{4}$. There is only limited evidence that patients get motivated to quit on receiving a diagnosis of COPD ${ }^{5}$. This implies that many COPD patients still continue smoking even though quitting is their best treatment option.

Physicians play a very important role in providing effective smoking cessation treatment for these patients. However, literature shows that they do not routinely deal with smoking cessation during their consultations with smokers ${ }^{6-8}$. According to a large European review, several factors seem to influence physicians' engagement in smoking cessation: patient characteristics; physician-characteristics, including attitude and cessation-specific knowledge and skills; structural factors, including reimbursement and time required ${ }^{8}$. A different review found that some physicians had negative thoughts about smoking cessation treatment as they considered it time-consuming and ineffective, and they lacked confidence in their ability to discuss smoking cessation with their patients ${ }^{9}$.

To our knowledge, no attention has been given in the literature specifically to physicians' views on smoking cessation treatment for smokers with COPD. Whereas, for this group of smokers, it is more urgent that they quit smoking, while it is even more difficult due to their higher addiction levels and higher susceptibility to developing depressive symptoms ${ }^{10-12}$. There are studies exploring experiences with 
COPD care in general, but these studies do not specifically address smoking cessation ${ }^{13-}$ ${ }^{16}$. From these studies, it is apparent that engagement in COPD care is influenced by physician-related factors such as perceived low self-efficacy in the provision of treatment and lack of confidence in the effects of treatments ${ }^{13,16}$. Also, patient-related factors such as being non-compliant and not taking responsibility for their condition were barriers for carrying out COPD care $^{15}$. Furthermore, awareness of available treatments and support for patients with COPD as well as the time required for such treatments seemed to create organisational barriers ${ }^{14}$. It is not clear whether these factors also hinder smoking cessation care in patients with COPD or if there are different issues in this specific population.

The aim of this study was therefore to explore how physicians engage in smoking cessation treatment for their COPD patients, by exploring their attitudes, reported practice and experienced problems in this regard. Once researchers and physicians understand specific needs and concerns regarding utilising cessation treatments for this particular group of smokers, they may address these problems in order to increase smoking cessation in COPD patients.

\section{Methods}

\section{Data collection}

We used focus group discussions (FGDs) to explore how physicians comment on their engagement in smoking cessation treatment for COPD patients. A FGD design was found suitable as FGDs serve to create data within a group setting, and we wished to take advantage of the different inputs from physicians and their co-construction of meaning, rather than relying on individual interview data. Further, FGDs have the potential to bring forth and discuss different spontaneous viewpoints in relatively understudied domains, such as this domain ${ }^{17,18}$. We performed a secondary analysis together with researchers who had held the FGDs for the primary research. The FGDs were held in seven different countries in 2011-2012: Wales, the Netherlands, Poland, Russia, Germany, Norway and Hong Kong. These countries were selected due to earlier research collaboration on respiratory diseases. The FGDs were originally designed to explore general practitioners' (GPs) and pulmonologists' views and concerns on the management of COPD exacerbations in general $^{15,19}$. 
Each country performed three FGDs with 4-7 participants considering that the chosen participants and the number of FGDs would provide sufficient information to answer the original study questions. The number of participants in each FGD should ideally be between 6-8 as often recommended ${ }^{20}$, but due to cancellations the number differed in the end. For each FGD new participants were recruited: FGD 1 with only GPs; FGD 2 with only pulmonologists; FGD 3 with a mix of GPs and pulmonologists. In FGD 1 and 2, GPs and pulmonologists got the chance to discuss issues from the viewpoint of their discipline without being interfered by the other discipline. In FGD 3 these issues could then be combined in an interdisciplinary discussion. The GPs and pulmonologists were sampled in order to cover both rural and urban GP practices, as well as private- and hospital-based pulmonologists ${ }^{15,19}$.

All researchers who were responsible for conducting the FGDs participated in a 3-day workshop in order to streamline the methods across countries. All countries used the same interview guide containing topics based on known issues of concern to GPs (see Addendum 6.1-6.3). The interview guide used in FGD 1 was revised before FGD 2 due to intermediary analysis and this revised version with specific sub questions was used in FGD 2. The pulmonologists were asked to discuss the routines in general practice as they were known to them, but inviting them to be open about their own views and concerns. Between FGD 2 and 3 another revision of the interview guide was made in order to make FGD 3 focus especially on topics that were still unclear but also on solutions to identified problems. All FGDs were transcribed verbatim from audio recording by the local researchers and translated into English by a skilled translator. However, some inconsistencies in English language occurred and we show adjusted quotes in the results section with the original quotes in Addendum 6.4. For this analysis, the focus group transcripts were imported into Nvivo 10.

\section{Data assessment}

To address the additional research question for this secondary analysis, we assessed the quality of the available dataset and discussed whether the existing dataset had the potential to inform us about physicians' engagement in smoking cessation. All transcripts were reviewed by EE in order to discover whether they were relevant for this secondary analysis. This was then discussed within the research team (MBR, MS, DK) and it was agreed that the dataset as a whole offered rich data on physicians' engagement in smoking cessation. Most of the data for the secondary analysis arose 
from questions in all FGDs about difficult COPD patients. FGD 1 and 2 included a question asking, 'Could you describe specifically challenging or difficult clinical situations with COPD-patients in general?' FGD 3 included a question asking, 'Who are the difficult patients and how do you reach them? What do you think are the key issues/bottlenecks regarding the difficult patients?' These questions led to discussions about smoking and smoking cessation in COPD patients. Furthermore, we found valuable information in discussions on challenges when coping with patients with COPD; how to improve care and own views and concerns. Also, sections in which exacerbation management, self-management and guidelines were discussed provided interesting information. Information from FGD 3 contributed the most to this secondary analysis.

\section{Analysis}

The available data were then analysed using an inductive thematic analysis ${ }^{21}$ and we coded the text without initially relating it to the aim of the study. As there were no predefined categories, this enabled the evolution of different categories through the coding process. EE formulated codes for all text that was linked to smoking and smoking cessation. Codes were then discussed in detail and sorted into categories and subcategories (EE, MBR). For example, 'patients not open to physicians' smoking cessation advice' was a subcategory of 'patients who do not quit'. The codes were then discussed within the research team (MBR, MS, DK) and the essential contents of the codes were divided into three candidate themes related to the overall aim. Simultaneously, the final aim of the study was discussed within the team (OCP, MBR) and the themes could then be finalised. This process resulted in three themes: (1) 'physicians' frustration with COPD patients who smoke'; (2) 'physicians' limited knowledge of, and negative beliefs about, smoking cessation treatment'; (3) 'health care organisational factors that influence the use of smoking cessation treatments'. EE checked to ensure that the resulting thematic map accurately reflected the meaning of units evident in the dataset as a whole ${ }^{21}$.

\section{Ethical considerations}

Methods were performed in accordance with relevant regulations and guidelines; relevant ethical approval was obtained from the appropriate bodies in the participating countries. Participants provided written informed consent. Identifiers were removed from the transcriptions locally prior to distribution among the network. 


\section{Results}

\section{Physicians' frustration with COPD patients who smoke}

Many physicians shared negative feelings towards patients with COPD who continued smoking. This seems to hinder them in providing evidence-based treatment, including smoking cessation treatment.

Physicians seemed to feel responsible for motivating patients to quit smoking.

'Yes, make them, make them to wish to stop smoking (laughs a bit) is what we should do.' [FGD 1, Norway, GP]

Several discussions focused on how exhausting it is for physicians to spend their valuable time on COPD patients and to prescribe expensive medication to relieve symptoms. Nevertheless, many physicians seemed to conflate the importance of supporting patients to quit smoking with a personal desire to try and make them stop. They reported frustration regarding patients who demanded treatment but refused to accept responsibility for the treatment themselves.

'They [COPD patients that smoke] are a very difficult patient group, especially those that are just on the cusp of needing long term oxygen and you're trying to convince them that you're not going to give it to them if they don't stop smoking ... it's very frustrating if they still persist...' [FGD 3, Wales, Pulmonologist]

Other frustrations that hindered physicians in working with smokers with COPD were difficulties in communication. Physicians reported that some patients no longer attended surgery because they do not like hearing about smoking cessation or feel guilty about their smoking behaviour.

'It's difficult to treat and handle this group of patients, right? You need to strongly motivate them in order to [make them stop smoking] ... if you press them too much you will reject them; if you press them too hard to make them 
stop smoking you will make them your enemies: that's the fine line.' [FGD 1, Norway, GP]

Some also believed patients were 'lying' about their smoking behaviour. Others reported that COPD patients, when questioned about their smoking behaviour, consciously or unconsciously, trivialized their smoking behaviour.

'I switched to 'light' cigarettes' and, 'Doctor, I've quit! I have not smoked for three days!' He smoked for 50 years before'. [FGD 2, Russia, pulmonologists]

Eventually, all these frustrations resulted in a general feeling of dissatisfaction with regards to supporting COPD patients with quitting smoking.

'...it is almost like tilting against windmills.' [FGD 3, Poland, pulmonologist]

These negative experiences with smokers with COPD seemed to contribute to physicians being prejudiced against smokers with COPD. Some physicians discussed the issue that these prejudgements provoke the risk of treating smokers with COPD differently. Some said that they found smokers with COPD 'nonsensical' and it was their own fault they had COPD, and were more reluctant to prescribe expensive medication. Another physician said that if a COPD patient had quit smoking 'he has a plus in our view and we should take care of him' [FGD 1, Poland, GP].

In conclusion, these physicians felt responsible for 'making' COPD patients quit smoking. However, they experienced many patient-related barriers which frustrated them. These frustrations provoked the risk of developing negative feelings about this group of patients, and subsequently treating them unequally and potentially depriving them of the most effective treatments.

\section{Physicians' limited knowledge of, and negative beliefs about, smoking cessation treatment}

Many of the physicians felt they lacked experience and confidence in helping patients to stop smoking. Some also questioned the effectiveness of smoking cessation treatments. In the discussion of this, the physicians seemed inclined to switch from COPD-specific topics to topics regarding the general smoking population. 
Even though all the physicians emphasized that smoking cessation is the most essential treatment for smokers with COPD, some of them questioned whether this also applied to particular groups of patients, e.g. late stages of COPD.

'No, it has been proven that if you do not smoke you are better off; if you quit at a young age you are better off... but those people who are at a certain stage of COPD ...those data are not convincing.' [FGD 3, Netherlands, pulmonologist $]^{\mathrm{a}}$

Physicians from the Netherlands, Germany and Norway expressed the view that there were COPD patients who did not necessarily feel better after quitting smoking. It was difficult for them to explain the benefits of quitting to their patients without the prospect of a positive result.

Furthermore, several physicians stated that they were inexperienced in providing smoking cessation treatment. They reported finding it hard to talk to patients about smoking habits, regarding it as a delicate subject. They would also like to have tools for the promotion of smoking cessation, such as tools for communication and patient education. This was one of the topics of discussion about smoking cessation in general and not only about smokers with COPD.

'We need resources on creating an atmosphere and educating patients...in order to increase their motivation to quit smoking and increase the success rate...' [FGD 3, Hong Kong, GP]

Besides Hong-Kong, Norway and Russia in particular brought up this issue. In Russia, they also discussed the effectiveness of pharmacotherapy in the general smoking population. In Germany, there seemed to be a lack of trust in nicotine replacement therapy (NRT). Physicians in both Russia and Germany discussed the view that these aids would only delay quitting and not cure these patients ${ }^{\mathrm{b}}$. In addition, smoking cessation medication was said to be very expensive and therefore not widely used. In Germany, the physicians concluded that the most important element in smoking cessation is the communication with the patient.

\footnotetext{
a There are studies that show that also smokers in severe and very severe stages of COPD benefit from quitting smoking in terms of their quality of life and lung function ${ }^{22,23}$

${ }^{\mathrm{b}} \mathrm{NRT}$ has been proven to improve long-term abstinence from tobacco ${ }^{24}$
} 
'And the communicative intervention, so to say, is more successful [in motivating quitting] than, for instance, a nicotine patch.' [FGD 3, Germany, pulmonologist]

Besides these general discussions, there were some conversations that focussed more on smokers with COPD. The tenor of these discussions was speculative about communication, educational and social tools for motivating COPD patients to quit. For example, some physicians thought it might help to dramatize and scare the patient and they would like to have tools to illustrate the harm smoking does to your lungs ${ }^{c}$. Furthermore, social influences were discussed as motivational tool: for example, a story was told about a grandfather who quit smoking when his granddaughter said he was not allowed to die yet.

\section{Health care organisational factors that influence the use of smoking cessation treatments}

In this theme, the influence of health care organisational factors on smoking cessation treatment is discussed. In these discussions, the physicians broadened their views to include issues related to smoking cessation in general.

Smoking cessation treatment, in most countries, did not appear to be common practice in COPD care. Physicians from the Netherlands, Wales, Germany and Hong Kong reported lack of time and financial reimbursement as important obstacles for providing smoking cessation treatment.

'It [quitting smoking] is part of the questionnaire, it is one of the items on the list you need to cover... but it is so time-consuming.' [FGD 1, Netherlands, GP]

The physicians in the Netherlands felt there was not sufficient time in the COPD checkup appointment to discuss smoking cessation. In Germany, they grumbled about the price/quality ratio of the existing smoking cessation treatments.

\footnotetext{
${ }^{c}$ Confronting smokers with undetected COPD in a randomised controlled trial did not increase the rate of smoking cessation ${ }^{25}$; however, in a recent cohort study, a new diagnosis of COPD seemed to be linked to smoking cessation $^{5}$
} 
'It's not economical but you shouldn't lose your enthusiasm there.' [FGD 3, Germany, pulmonologist]

The time spent on smoking cessation treatments is not recovered, as only a few people eventually quit smoking. In Russia and Germany, they discussed the importance of how smokers are 'labelled'. This was not a COPD-specific discussion but concerned all smokers.

'I consider that for some people, smoking is a disease, the same as alcohol dependency, for example.' [FGD 3, Russia, GP]

In line with this, they discussed the availability and reimbursement of facilities for smoking cessation and compared it to facilities for other addictions in Germany.

'Every alcoholic receives a detox, but a nicotine patient has to pay for his addiction himself. And this isn't fair as both are partly recognised as addictions.' [FGD 3, Germany, GP]

Apparently, in some countries, insurance companies and other important institutions in health care organisation consider smoking addiction to be different from other addictions. They do not provide the same facilities for smokers as for other addicted patients, such as alcoholics, whilst smoking is officially recognised as a drug-related illness by addiction treatment care.

\section{Discussion}

\section{Main findings}

In the focus group discussions, the physicians mentioned patient-related, physicianrelated and health care organisational factors that hindered the routine provision of evidence-based smoking cessation treatment to patients with COPD. Some of the issues were not specific for smokers with COPD, but concerned smokers in general. Firstly, physicians experienced great frustration regarding smokers with COPD. In their view, smokers with COPD tended not to accept responsibility for their treatment; often were not honest about their smoking habits; trivialized the consequences of smoking and avoided health care visits. These frustrations provoked the risk of developing 
negative feelings about this group of patients, and treating them unequally by depriving them of effective treatments. Secondly, physicians lacked experience with different smoking cessation treatments. Thirdly, money and time issues, but also the failure to regard smoking as a disease, influenced physicians' treatment of smokers with COPD and also smokers in general.

\section{Interpretation of findings in relation to previously published work}

Physicians experienced frustration when working with smokers with COPD, as these patients were perceived as not taking responsibility for their disease. Present societal norms emphasize personal responsibility for one's health ${ }^{26}$ and physicians expect their patients to act in the interest of successful health maintenance ${ }^{27}$. Smokers with COPD fall short of these expectations as their disease has been caused by their own smoking behaviour, and many do not act to stop the progression of their disease by quitting. In this societal context, smokers with COPD feel stigmatised and they might be hesitant to contact their physicians because they fear criticism ${ }^{26}$ and become irritated by their advice to stop smoking ${ }^{28}$. However, research shows the vast majority of smokers are happy for their physician to raise the topic of smoking, if the advice is given in an empathetic and patient-centred manner ${ }^{28-30}$. In order to create an environment with less frustration, it is important that physicians contribute to reducing the negative effect of stigma ${ }^{26}$, as this interferes with the physician-patient relationship. In our view, some physicians need to develop a less paternalistic style, and create room for the smokers' own views ${ }^{12,26}$.

Many physicians reported limited knowledge, confidence and skills regarding evidencebased smoking cessation treatments. A Europe-wide literature review demonstrated that the proportion of GPs that offer intensive smoking cessation interventions is low and that one of the reasons for this was limited knowledge and skills ${ }^{8}$. This is confirmed by studies examining risk factor management and COPD management in general ${ }^{14,31}$. In national and international guidelines, there are overviews of the different effective smoking cessation options ${ }^{32,33}$, but literature has shown that physicians are not always familiar with these guidelines ${ }^{13}$. Several factors can influence physicians' adherence to guidelines, such as physicians' view of their role in COPD care and how complex certain care is ${ }^{14}$. In this study, we have seen that many physicians do not have faith in the guideline recommendations. Besides, the physicians mentioned that they thought communication was more important than prescribing pharmacotherapy and that it is 
difficult to familiarise oneself with communicative tools via theory. In order to increase skills and knowledge, it seems important to provide a smoking cessation program in vocational training and postgraduate smoking cessation training for GPs. In this training, physicians should be taught evidence-based smoking cessation treatment and practise communication, besides reflection on personal norms and values.

Health care organisational factors influence how physicians engage in COPD care and smoking cessation. Each of the seven countries involved in this study organises COPD care in a different way. The Netherlands ${ }^{34}$, Germany $^{35}$, Wales ${ }^{36}$ and Norway ${ }^{37}$ have the most structured COPD care. In Poland ${ }^{38}$, Russia and Hong-Kong, the disease management programs seem to be less established. Even with structured care, however, there are several issues that complicate providing evidence-based smoking cessation treatment. Lack of time is often mentioned in the literature as a barrier to giving smoking cessation treatment ${ }^{8,9}$. In this study, the physicians further complained that the financial reward is insufficient. To our knowledge, there are no studies on the differences in outcomes when comparing the different health care systems. We can, however, see that in the Netherlands, Germany, Wales, Norway and Poland, the smoking rate is between $20 \%-26 \%{ }^{39}$. In Russia, this number is much higher: $37.3 \%$ of people over 15 years of age smoke ${ }^{39}$. In China, almost $50 \%$ of men smoke, but almost no women ${ }^{39}$. It would be interesting to know if the way the health care system is organised influences smoking cessation, especially for smokers with COPD who, even at the best of times, experience difficulties in quitting ${ }^{40}$.

As smoking is officially recognised as an illness in addiction treatment care, it is interesting to note that in none of the countries rehabilitation programs for smoking are offered in the same way as rehabilitation from other drugs. This shows that there is still a stigma attached to smoking that considers it to be different from other addictions. If smoking is seen as an addiction such as with other drug addictions, then structured nicotine dishabituation programmes might be established and reimbursed.

\section{Strengths and limitations of this study}

The primary dataset that we used was extensive, therefore the strength of this study is to be found in the participation of several countries in order to find common concerns regarding smoking cessation in different health care settings. We did not aim for a comparative study as a strict comparison between countries could not be made due to 
the plethora of information and scattered quotes on smoking. Furthermore, both GPs and pulmonologists attended the FGDs. This gave a fuller picture of physicians' concerns regarding smoking cessation. In theme three, we briefly mention the importance of the different health care contexts for the interpretation and analysis of the information. A weakness in this study is that we were not able to specify exactly what role the different health contexts played for the construction of the concerns. Analysis of the data was done together with two researchers that participated in the primary data collection and analysis, and was proof read by all representatives from the different countries that participated. One other limitation is that the FGDs were originally designed to explore GPs' and pulmonologists' views and concerns on the management of COPD exacerbations in general. Smoking cessation is, of course, very important herein, but was not the main focus of the FGDs. On the other hand, this concomitantly resulted in important gut reactions on smoking related issues. This means that the results are reflections of most discussed concerns and we see them as hypothesis generating for future in-depth research in this field.

\section{Implications for future research, policy and practice}

To promote physicians' engagement in smoking cessation treatment, we advise introducing an informative smoking cessation program, including communication and ethic, into the vocational training and postgraduate medical training. The attachment of stigma should be considered in this training and how this interferes with giving professional smoking cessation support. In addition evidence-based smoking cessation treatment should be taught and communication should be practiced. For future research, it would be interesting to take a more detailed look into the hypothesis generating results of this analysis including the influence of different health care systems on how smoking cessation treatment is performed. This will inform us about which elements are essential for performing effective smoking cessation treatment.

\section{Conclusions}

Our results show physicians' barriers to providing effective smoking cessation treatment in patients with COPD and smokers in general. This is influenced by general issues and attitudes regarding smoking cessation treatment and the management of patients with COPD. We saw a lot of frustration, inexperience and stigmatisation in physicians regarding smoking cessation in their COPD patients and in the general 
smoking population. Also, money and time issues hindered the physicians. It is important to increase engagement with smoking cessation treatment and thereby improve quality of COPD care.

\section{Acknowledgements}

This study is published on behalf of the PEXACO research team. Thanks to all those who arranged and participated in the focus groups. We thank Carol Herman for language checking.

\section{Funding}

PEXACO was funded by the Norwegian Research Council, grant number 202650//H10. OS received institutional funds from Pfizer. 


\section{References}

1. From the Global Strategy for the Diagnosis, Management and Prevention of COPD, Global Initiative for Chronic Obstructive Lung Disease (GOLD) 2015. http://goldcopd.org. Accessed 17 November 2015.

2. National Clinical Guideline Centre. Chronic obstructive pulmonary disease: management of chronic obstructive pulmonary disease in adult in primary and secondary care. http://guidance.nice.org.uk/CG101/Guidance/pdf/English. Accessed 20 April 2016.

3. van Eerd E.A., van der Meer R.M., van Schayck O.C., Kotz D. Smoking cessation for people with chronic obstructive pulmonary disease. Cochrane Database Syst Rev. CD010744 (2016).

4. Shahab L., Jarvis M.J., Britton J., West R. Prevalence, diagnosis and relation to tobacco dependence of chronic obstructive pulmonary disease in a nationally representative population sample. Thorax. 61, 1043-1047 (2006).

5. Danielsen S.E., Lochen M.L., Medbo A., Vold M.L., Melbye H. A new diagnosis of asthma or COPD is linked to smoking cessation - the Tromso study. Int J Chron Obstruct Pulmon Dis. 11, 1453-1458 (2016).

6. Coleman T., Wynn A., Barrett S., Wilson A. Discussion of NRT and other antismoking interventions in UK general practitioners' routine consultations. Nicotine Tob Res. 5, 163-168 (2003).

7. Ellerbeck E.F., Ahluwalia J.S., Jolicoeur D.G., Gladden J., Mosier M.C. Direct observation of smoking cessation activities in primary care practice. J Fam Pract. 50, 688-693 (2001).

8. Stead M., Angus K., Holme I., Cohen D., Tait G. Factors influencing European GPs' engagement in smoking cessation: a multi-country literature review. Br J Gen Pract. 59, 682-690 (2009).

9. Vogt F., Hall S., Marteau T.M. General practitioners' and family physicians' negative beliefs and attitudes towards discussing smoking cessation with patients: a systematic review. Addiction. 100, 1423-1431 (2005).

10. Tønnesen P., Carrozzi L., Fagerstrom K.O., Gratziou C., Jimenez-Ruiz C., Nardini S., et al. Smoking cessation in patients with respiratory diseases: a high priority, integral component of therapy. Eur Respir J. 29, 390-417 (2007).

11. van Eerd E.A., van Rossem C.R., Spigt M.G., Wesseling G., van Schayck O.C., Kotz D. Do we need tailored smoking cessation interventions for smokers with COPD? A comparative study of smokers with and without COPD regarding factors associated with tobacco smoking. Respiration. 90, 211-219 (2015).

12. van Eerd E.A., Risor M.B., van Rossem C.R., van Schayck O.C., Kotz D. Experiences of tobacco smoking and quitting in smokers with and without chronic obstructive pulmonary disease-a qualitative analysis. BMC Fam Pract. 16, (2015).

13. Salinas G.D., Williamson J.C., Kalhan R., Thomashow B., Scheckermann J.L., Walsh J., et al. Barriers to adherence to chronic obstructive pulmonary disease guidelines by primary care physicians. Int J Chron Obstruct Pulmon Dis. 6, 171-179 (2011).

14. Johnston K.N., Young M., Grimmer-Somers K.A., Antic R., Frith P.A. Why are some evidence-based care recommendations in chronic obstructive pulmonary disease better implemented than others? Perspectives of medical practitioners. Int J Chron Obstruct Pulmon Dis. 6, 659-667 (2011). 
15. Risor M.B., Spigt M., Iversen R., Godycki-Cwirko M., Francis N., Altiner A., et al. The complexity of managing COPD exacerbations: a grounded theory study of European general practice. BMJ Open. 3, (2013).

16. Perez X., Wisnivesky J.P., Lurslurchachai L., Kleinman L.C., Kronish I.M. Barriers to adherence to COPD guidelines among primary care providers. Respir Med. 106, 374381 (2012).

17. Kvale S B.S. Interviews: Learning the Craft of Qualitative Research Interviewing. California, SAGE Publications; 2009.

18. Bourgeault I., Dingwall R., de Vries R. The SAGE handbook of qualitative methods in health research. SAGE Publications Ltd; 2010.

19. Davies F., Risor M.B., Melbye H., Spigt M., Brookes-Howell L., O'Neill C., et al. Primary and secondary care clinicians' views on self-treatment of COPD exacerbations: a multinational qualitative study. Patient Educ Couns. 96, 256-263 (2014).

20. Carlsen B., Glenton C. What about N? A methodological study of sample-size reporting in focus group studies. BMC Med Res Methodol. 11, 26 (2011).

21. Braun V., Clarke V. Using thematic analysis in psychology. Qual Res Psychol. 3, 77-101 (2006).

22. Chen J., Chen Y., Chen P., Liu Z., Luo H., Cai S. Effectiveness of individual counseling for smoking cessation in smokers with chronic obstructive pulmonary disease and asymptomatic smokers. Exp Ther Med. 7, 716-720 (2014).

23. Tønnesen P., Mikkelsen K., Bremann L. Nurse-conducted smoking cessation in patients with COPD using nicotine sublingual tablets and behavioral support. Chest. 130, 334342 (2006).

24. Cahill K., Stevens S., Perera R., Lancaster T. Pharmacological interventions for smoking cessation: an overview and network meta-analysis. Cochrane Database Syst Rev. CD009329 (2013).

25. Kotz D., Wesseling G., Huibers M.J., van Schayck O.C. Efficacy of confronting smokers with airflow limitation for smoking cessation. Eur Respir J. 33, 754-762 (2009).

26. Halding A.G., Wahl A., Heggdal K. 'Belonging'. 'Patients' experiences of social relationships during pulmonary rehabilitation. Disabil Rehabil. 32, 1272-1280 (2010).

27. Dieterich A. The modern patient - threat or promise? Physicians' perspectives on patients' changing attributes. Patient Educ Couns. 67, 279-285 (2007).

28. Butler C.C., Pill R., Stott N.C. Qualitative study of patients' perceptions of doctors' advice to quit smoking: implications for opportunistic health promotion. BMJ. 316, 1878-1881 (1998).

29. George J., Kong D.C., Thoman R., Stewart K. Factors associated with medication nonadherence in patients with COPD. Chest. 128, 3198-3204 (2005).

30. Coleman T., Wilson A. Anti-smoking advice from general practitioners: is a populationbased approach to advice-giving feasible? Br J Gen Pract. 50, 1001-1004 (2000).

31. Ampt A.J., Amoroso C., Harris M.F., McKenzie S.H., Rose V.K., Taggart J.R. Attitudes, norms and controls influencing lifestyle risk factor management in general practice. BMC Fam Pract. 10, 59 (2009).

32. Chavannes N.H., Kaper J., Frijling B.D., Van der Laan J., Jansen P., Guerrouj S., et al. NHG-Standaard Stoppen met roken. Huisarts Wet. 50, 306-314 (2007).

33. Anderson J.E., Jorenby D.E., Scott W.J., Fiore M.C. Treating tobacco use and dependence: an evidence-based clinical practice guideline for tobacco cessation. Chest. 121, 932-941 (2002).

34. Struijs J.N., Baan C.A. Integrating care through bundled payments--lessons from The Netherlands. N Engl J Med. 364, 990-991 (2011). 
35. Busse R., Blumel M. Germany: Health system review. Health Syst Transit. 16, 1-296 (2014).

36. National Leadership and Innovation Agency for Healthcare. Chronic Conditions Management: Compendium of work from across Wales http://www.wales.nhs.uk. Accessed 4 October 2016.

37.

http://international.commonwealthfund.org/countries/norway/. Accessed 4 October 2016.

38. Godycki-Cwirko M., Zakowska I., Kosiek K., Wensing M., Krawczyk J., Kowalczyk A. Evaluation of a tailored implementation strategy to improve the management of patients with chronic obstructive pulmonary disease in primary care: a study protocol of a cluster randomized trial. Trials. 15, 109 (2014).

39. World Health Organization. Global report on trends in tobacco smoking 2000-2025. http://www.who.int. Accessed 5 October 2016.

40. Boytsov S.A., Yablonskiy P.K., Gambaryan M.G., Sukhovskaya O.A., Drapkina O.M. The implementation of health care aimed at the cessation of tobacco use, treatment of tobacco dependence and consequences of tobacco consumption in the Russian Federation. Ration Pharmacother Cardiol. 12, 403-413 (2016). 


\section{Addendum 6.1 - Interview guide}

For FGDs with GPs on assessment and medical treatment of patients with COPD

Aim: to gain knowledge on current treatment of exacerbations and attitudes to selftreatment and to improve quality of life

*A question that initiated a discussion or provoked statements on smoking or smoking cessation.

\section{Introduction}

Present to the participants what the idea of a FGD is and what the topic of the discussion is.

\section{Opening question}

*1) Tell us who you are, where you practice, what are your general thoughts on the management of COPD patients? (all should speak) (5 minutes)

\section{Patient story 1 (told or read aloud)}

2) What does the story bring to your mind?

*3) How do you assess and manage exacerbations? (10 minutes)

- How should the symptoms of the patients be weighted in the assessment?

- Which examinations and tests would be relevant?

- When would you prescribe systemic (per oral) corticosteroids?

- When would you prescribe antibiotics?

\section{Patient story 2 (told or read aloud)}

4) With this we wish to focus on treatment of severe exacerbations more specifically. When would you consider to hospitalize a patient with COPD exacerbation? (10 minutes)

- If you find it risky to treat the patient in their home, do you see other options than to hospitalize the patient?

('Think back'- questions could be used here for prompting) 
5) What do you think of self-treatment with antibiotics and oral corticosteroids? (10 minutes)

- Is it common in your setting?

- Do people understand how and why to take the medication?

\section{Patient story 3 (told or read aloud) (optional, depending on the flow of the interview)}

6) What could be important areas of self-management for COPD-patients in your opinion?

- What do you think the patients think about self-treatment?

- What role could the patient play in treating their exacerbations?

7) Could you describe in what way you use national and/or international guidelines in your approach to a COPD patient with exacerbations? (15 minutes)

- Do you think the guidelines are specific enough to guide you in your everyday care for COPD patients?

- Do you think the guidelines are validly constructed; good literature search for example?

- Do you know the most important advice from the guideline COPD by heart, or do you need to check papers or internet for that?

*8) Could you describe specifically challenging or difficult clinical situations with COPDpatients in general? (15 minutes)

- in what way are they challenging/difficult?

- how do you deal with them?

- what does your approach depend on?

\section{Summary by moderator or assistant moderator}

9) Do you think this is an adequate summary? (5 minutes)

*10) Of the topics discussed so far, what do you consider to be the most important problem concerning management of COPD patients? (10 minutes)

*11) Of the problems discussed concerning COPD patients and treatment, are there any ideas on areas where clinical practice could be improved? (10 minutes) 
- think back on the discussion above of challenges and difficulties

- do not think in terms of solutions necessarily, more on topics.

- try to reflect on everyday problems with an overall view

*12) Are there any topics we missed? That you feel we only treated superficially or that we simply forgot? Anything that you thought you would mention but did not get the chance to? Anything may be important, so feel free! (10 minutes)

\section{Patient stories}

1. A 60 year old male patient with moderate COPD has called your practice and asked for medicine, due to increased coughing and shortness of breath the last week. He quit smoking a year ago. You have prescribed anticholinergics for inhalation as maintenance medication. Now he thinks a course of antibiotics might be helpful. He was treated with amoxicillin and prednisolone last winter 9 months ago, and recovered after a few weeks.

2. A 70 year old female patient, still smoking, visits your practice. She was hospitalized due to her COPD one year ago. She uses a combination of inhaled corticosteroids and long acting beta2agonists, and short acting beta 2 agonists on demand. She had a common cold a week ago. Now she has no fever, but breathes heavily and rather fast. She had to sit in her bed last night, and she feels somewhat exhausted. Although you hear wheezes all over her chest, you do not think the obstruction is very severe. You believe her illness is worsened by her anxiety, but consider admitting her to hospital.

3. A 72 year old woman visit you for a follow-up examination. She had a COPD exacerbation three weeks ago, for the second time this winter. She is now in her normal shape. FEV1/FVC ratio is 0.55 and her FEV1 \% predicted is $45 \%$. She has reduced her smoking considerably, and smokes only 5 cigarettes a day. She will continue the regular use of a long acting anticholinergic, and is encouraged to use a short-acting beta2 agonist on demand. You consider giving her inhaled corticosteroid in addition. You also consider prescribing courses of oral corticosteroids and antibiotics which she could administer herself if she develops a new exacerbation. 


\section{Addendum 6.2 - Interview guide}

For FGDs with pulmonologists on assessment and medical treatment of patients with COPD

Aim: to gain knowledge on current treatment of exacerbations and attitudes to selftreatment and to improve guidelines

*A question that initiated a discussion or provoked statements on smoking or smoking cessation.

\section{Introduction}

Present to the participants what the idea of a FGD is and what the topic of the discussion is.

\section{Opening question}

*1) Tell us who you are, where you work and what you think of when talking about COPD patients in general?

\section{Patient story 1 (told or read aloud)}

2) What does the story bring to your mind?

*3) What is your opinion about the way primary care manages exacerbations? (10 minutes)

- How should GPs manage exacerbations?

- How should the symptoms of the patients be weighted in the assessment?

- Which examinations and tests would be relevant?

- When should the GP prescribe systemic (per oral) corticosteroids?

- When should the GP prescribe antibiotics?

- How may you describe the treatment approaches to COPD in a hospital context? What takes place? What is being prescribed and advised?

\section{Patient story 2 (told or read aloud)}

4) When would you consider hospitalization of a patient with COPD relevant?

- $\quad$ are there any specific criteria? 
5) What do you think of self-treatment with antibiotics and oral corticosteroids? (10 minutes)

- Is it common in your setting?

- Do people understand how and why to take the medication?

\section{Patient story 3 (told or read aloud) (optional, depending on the flow of the interview)}

6) What do you think the patients think about self-treatment?

- What is important for optimal self-treatment for COPD patients in your opinion?

7) Could you describe in what way you use national and/or international guidelines in your approach to a COPD patient with exacerbations? (15 minutes)

- Are the guidelines relevant for example in a GP setting?

- Do you think the guidelines are specific enough to guide you in your everyday care for COPD patients?

- In what way could they be improved?

- Do you know the most important advice from the guideline COPD by heart, or do you need to check papers or internet for that?

*8) Could you mention specifically challenging or difficult clinical situations with COPDpatients?

- in what way are they challenging/difficult?

- how do you deal with them?

- what does the approach depend on?

\section{Summary by moderator or assistant moderator}

9) Do you think this is an adequate summary?

*10) Of the topics discussed so far, what do you consider to be the most important concerning management of COPD patients?

*11) Of the problems discussed concerning COPD patients and treatment, are there any ideas on areas where clinical practice could be improved? 
*12) Are there any topics we missed? That you feel we only treated superficially or that we simply forgot? Anything that you thought you would mention but did not get the chance to? Anything may be important, so feel free! (time enough for this is important)

(Question 13 could be asked at the end if not previously discussed during the FGD - but you also may ask this question whenever you like during the interview if the topic is brought up and you wish to elaborate it)

13) How do you cooperate with general practitioners?

- how can cooperation be improved?

- do you experience delay from general practice or too many admissions?

- how should the division of work be? 


\section{Addendum 6.3 - Interview guide}

For FGDs with GPs and pulmonologists on assessment and medical treatment of patients with COPD

Aim: to gain knowledge on current treatment of exacerbations and attitudes to selftreatment and to improve guidelines

*A question that initiated a discussion or provoked statements on smoking or smoking cessation.

\section{Introduction}

Present to the participants what the idea of an FGD is and what the topic of the discussion is.

\section{Opening question}

*1) Tell us who you are, where you work and what you think of when talking about COPD patients in general?

2) During our previous discussions in the groups with both pulmonologists and GPs we found that they mostly agreed on how to treat exacerbations, that is when to prescribe antibiotics and steroids and according to which examinations and objective measures. There was however some uncertainty regarding how to diagnose an exacerbation. So our question for you is:

- What do you find difficult when diagnosing a possible exacerbation?

- Is there a diagnostic test you find useful in the situation?

- What are the key issues/bottlenecks in management of exacerbations outside hospital?

- What would be the ideal way to manage exacerbations outside hospital (if you had all the money and resources you could think of)?

- How can you get closer to this ideal and improve the situation?

3) In the previous discussions the physicians tend to agree on severe cases of exacerbation when it comes to hospitalization, whereas there seems to be more confusion about the borderline cases. We are interested in your opinions about who should be admitted apart from severe cases. 
- Who should be seen in the hospital and who should not?

- How should the decision be made to admit a patient?

- What should hospitals be used for, only patients in need of intensive care?

- How could admissions of patients with exacerbations be avoided and managed otherwise?

- What do you see as the key issues/bottlenecks/challenges regarding hospitalization?

- What would be the ideal way to manage it (if you had all the money and resources you could think of)?

- How can you get closer to this ideal and improve the situation?

4) When it comes to self-treatment the previous FGDs reveals that the majority thinks it is a feasible and good idea. They do however specify that only certain patients are deemed capable of administering their own medicines. But no one could refer to specific criteria for deciding which patients are capable. Overall we felt the doctors had little experience with self-treatment despite the general positive attitude towards it.

- Why do you think you do not apply self-treatment more?

- What do you need to do this?

- Is it needed in the guidelines?

- What do patients think about self-treatment?

- What do you think are the key issues/bottlenecks regarding self-treatment?

- What would be the ideal way to manage it (if you had all the money and resources you could think of)?

- How can you get closer to this ideal and improve the situation?

5) The next thing we wish to talk about is the collaboration between primary and secondary care.

- How do you collaborate?

(Since there seems to be a consensus in the previous FGDs that there is a need for more collaboration between primary and secondary care, we expect it to be in FGD3 too. If this is not the case, please leave out the first sentence of the following introduction) 
There seems to be an agreement that you need to collaborate more, that there is a need to communicate more. This is also what came up in the previous discussions. The physicians mentioned that they liked when there was exchange of experience (at seminars, conferences), and when direct contacts and involvement was made concerning e.g. admission and diagnostics (calling, meetings etc). But they also lacked more of both. It's easy to say, but apparently difficult to do.

- What do you think are the key issues/bottlenecks regarding collaboration during exacerbations?

- What is the key reason to communicate?

- What can go wrong if you don't?

- What would be the ideal way to collaborate (if you had all the money and resources you could think of)?

- How can you get closer to this ideal and improve the situation?

*6) The last topic we want you to discuss are the difficult COPD patients in general. In the previous discussions they were described as for example the patients that kept on smoking and the patients who had little to no visible effects of the treatment. Both these factors made it difficult for the doctors to motivate the patients and themselves for further treatment endeavors.

- Who are the difficult patients and how do you reach them?

- What do you think are the key issues/bottlenecks regarding the difficult patients?

- What would be the ideal way to manage them (if you had all the money and resources you could think of)?

- How can you get closer to this ideal and improve the situation?

\section{Summary by moderator or assistant moderator:}

7) Do you think this is an adequate summary?

8) Are there any topics we missed? That you feel we only treated superficially or that we simply forgot? Anything that you thought you would mention but did not get the chance to? Anything may be important, so feel free! (time enough for this is important) 


\section{Addendum 6.4 - Original quotes}

\section{Theme 1}

'Yes, make them, make them to wish to stop smoking (laughs a bit) is what we should do.' [FGD 1, Norway, GP]

'They [COPD patients that smoke] are a very difficult patient group, especially those that are just on the cusp of needing long term oxygen and you're trying to convince them that you're not going to give it to them if they don't stop smoking ... it's very frustrating if they still persist...' [FGD 3, Wales, Pulmonologist]

'It's difficult to treat and handle this group of patients, right, you need to strongly motivate them in order to, if you press them too much you will reject them, if you press them too hard to make them stop smoking you will make them your enemies, that's the fine line.' [FGD 1, Norway, GP]

'I switched to 'light' cigarettes', and 'Doctor, I've dropped out, I do not smoke for three days!' He smoked for 50 years before'. [FGD 2, Russia, pulmonologists]

'...it is almost like fighting windmills' [FGD 3, Poland, pulmonologist]

\section{Theme 2}

'No it is proven if you do not smoke you are better off, if you quit at a young age you are better off, but those people who are in a certain stage of COPD, those data are not convincing...' [FGD 3, Netherlands, pulmonologist]

'We need resources on creating an atmosphere and educating patients...in order to increase their motivation to quit smoking and increase the success rate...' [FGD 3, Hong Kong, GP]

'And the communicative intervention so to say is more successful than, for instance, a nicotine patch.' [FGD 3, Germany, pulmonologist] 


\section{Theme 3}

'It is part of the questionnaire, it is one of the items of the list you need to cover... But it is so time-consuming.' [FGD 1, Netherlands, GP]

'It's not economical but you shouldn't lose your enthusiasm there.' [FGD 3, Germany, pulmonologist]

'I understand that some people have smoking as a disease the same as alcohol dependency, for example.' [FGD 3, Russia, GP]

'Because every alcoholic gets detoxicated, but a nicotine patient has to pay for it alone. And this injustice, both are partly recognised as addictions.' [FGD 3, Germany, GP] 

Chapter 7

General discussion

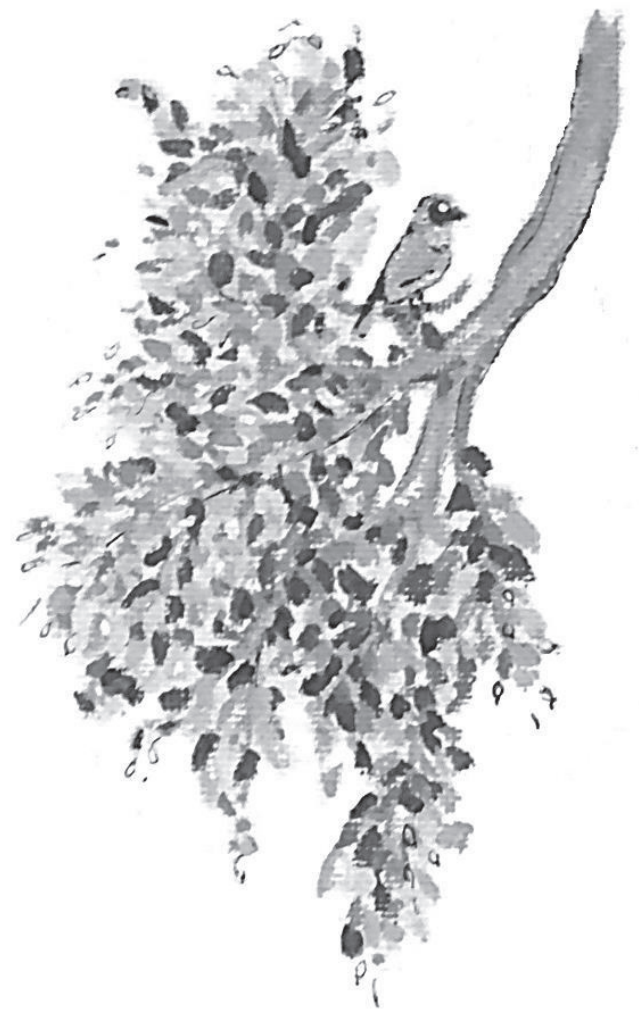





\section{General discussion}

Giving up smoking is the most effective way to reduce the risk of smoking related diseases, such as COPD, and prevent premature death ${ }^{1}$. For smokers who already developed COPD smoking cessation is the only evidence-based treatment that decreases the accelerated decline in lung function ${ }^{1,2}$. Nevertheless, many patients with COPD continue smoking, even though several evidence-based smoking cessation interventions are available. We hypothesised that COPD specific patient- and physicianrelated factors influence the effectiveness of smoking cessation treatments. We assumed that addressing these factors in COPD-tailored smoking cessation interventions, would increase chances of successful quitting. After reviewing the literature we noticed that no such COPD-specific smoking cessation interventions exist $^{3}$. In the process of developing such tailored interventions we, in the first place, had to gain more insight into patient- and physician-related needs and concerns regarding smoking cessation in these patients. From different perspectives and with different methodologies we tried to enlighten these needs and concerns in this dissertation. By looking at different perspectives we tried to create support for the results among patients as well as physicians. Furthermore, combining quantitative and qualitative data allowed for a more comprehensive analysis of the research questions ${ }^{4}$. The quantitative data provided us with objective information, while the qualitative data gave us a complementary rich description of what lied beneath this objective information ${ }^{4}$. In Chapter 5 and 6 we presented information from secondary analyses on existing quantitative and qualitative data respectively. The advantage of the quantitative data (Chapter 5) was that it provided us with information about a rather understudied subject under controlled circumstances. However, the original study methods limited our external validity. In Chapter 6 we also addressed a new research question by analysing previously collected data. The original dataset from the focus group discussions included a lot of information on issues beyond the original research questions. By applying a new perspective on the original dataset we obtained most discussed issues from physicians regarding smoking and smoking cessation in patients with COPD. Such secondary analysis is useful for giving a sketch of existing concerns and needs. In the current chapter, we will first describe the bottlenecks in smoking cessation in general and difficulties concerning the care for patients with COPD. Then, we will summarise the key findings of the different studies in this dissertation and consider these in a broader perspective in the final paragraph. 


\section{Difficulties in smoking cessation}

Despite the knowledge that smoking is one of the world's leading causes of preventable premature death, many people continue smoking ${ }^{5}$. In the Netherlands, still $25 \%$ of the population is smoking ${ }^{6}$. Worldwide, over 1.1 billion people smoked tobacco in 2015, and the prevalence of smokers per country ranged between $5-52 \%{ }^{7}$. Effective smoking cessation interventions are available but underutilised. Pharmacotherapy in combination with behavioural treatment is currently the most effective smoking cessation treatment ${ }^{5}$. Furthermore, more intensive behavioural treatment is likely to increase the chances of successful quitting. However, many smokers do not use evidence-based smoking cessation aids and the ones that do use pharmacotherapy often do not take up the offer of intensive behavioural treatment.

\section{Smokers' perspectives}

In the first place, most smokers use tobacco regularly because they are addicted to nicotine ${ }^{8}$. The chances of becoming addicted to nicotine are higher compared to, for example, cocaine ${ }^{8}$. In common with other addictions, nicotine addiction is included as a disorder in the Diagnostic and Statistical Manual of Mental Disorders (DSM-5) ${ }^{9}$. The nicotine addiction sets in due to a rapid increase of the number of nicotine receptors by smoking a cigarette. Furthermore, the sensitivity of the receptors decreases; desensitisation ${ }^{10}$. Literature suggests the latter might already be happening after smoking one cigarette ${ }^{11}$. This results in smokers craving for the next cigarette to keep the nicotine at a certain level; to experience positive effects and to prevent withdrawal symptoms ${ }^{10}$. Positive effects of nicotine arise due to stimulation of the central nerve system, resulting in a release of neurotransmitters. Consequently, these neurotransmitters act as stimulants and account for an increase in concentration. High doses of nicotine result in an opposite, calming effect ${ }^{10}$. People also continue to smoke because they experience psychological dependence. Furthermore, social factors often contribute to continuing smoking ${ }^{10,12}$.

All previous mentioned factors that contribute to continuation of smoking are at the same time potential barriers for quitting. However, nicotine dependence is found to be the most important reason why most unassisted quit attempts fail within a week ${ }^{13}$. In smokers with COPD, we might find additional barriers to quitting because many patients with COPD still continue smoking even when getting a diagnosis of COPD ${ }^{14}$. COPD patients' chances of quitting might be reduced due to their higher level of 
tobacco addiction and susceptibility to develop depressive symptoms (see Chapter 3$)^{15}$, ${ }^{16}$. Furthermore, smokers with COPD might be put at a disadvantage due to a lower self-efficacy to refrain from smoking in certain situations (see Chapter 3$)^{16}$. We will further discuss COPD-specific patient characteristics in a following paragraph.

Besides these physical, psychological and social issues that influence smoking cessation, autonomy is a key issue for smokers (see Chapter 4). In the Netherlands, individualism is highly valued, as in other Western European countries. In our qualitative study on smokers' experiences of smoking and quitting, smoking cessation advice and comments were often labelled as being meddlesome, even when wellintended $^{17}$. In order for the patients to retain their autonomy, they need to get the feeling their decisions are taken independently ${ }^{18}$. Smokers with COPD sympathise with the idea of receiving help and support, but without being patronised ${ }^{18}$. Eventually, the vast majority of smokers are happy to discuss the topic of smoking, if this is done in an empathetic and patient-centred manner ${ }^{19-21}$.

Then there is the question of smokers being ignorant about the smoking-related health consequences. A lot of smokers might not feel the need to quit smoking as a fair amount of them seems to misunderstand the health risks of smoking ${ }^{17,22,23}$. Research from the Netherlands showed that only $51 \%$ of the general population and $46 \%$ of the smokers acknowledged that smoking could induce a heart attack ${ }^{22}$. Smokers might not be adequately informed of the health risks of smoking, while knowledge about this is positively associated with the person's intention to stop smoking ${ }^{12,24}$. Furthermore, even when they are aware of the health risks of smoking, they might underestimate these health risks ${ }^{17,24}$. One reason for trivialising health risks might be to reduce cognitive dissonance. This means that expressions from smokers on this topic might be biased by optimism in order to salve their guilty conscience about their smoking behaviour ${ }^{17}$.

Finally, smokers' knowledge of smoking cessation treatments is often poor (see Chapter 4$)^{17,25}$. In Chapter 3 we showed that, in general, smokers had a low level of faith in the efficacy of smoking cessation treatments ${ }^{16}$ and that alternative treatments which are not evidence-based were widely being used (see Chapter 3 and 5) ${ }^{16,26}$. A recent study in the Netherlands showed that a low level of knowledge about the 
evidence-base of aids was possibly due to the promotion of ineffective commercial cessation methods ${ }^{25}$.

\section{Physicians' perspectives}

Several guidelines advise physicians to use the 'five A's' when discussing smoking with their patients (i.e.: ask, advise, assess, assist, arrange) ${ }^{27}$. However, studies show that physicians not necessarily act upon this model as it might not always fit with what physicians see as their role and what patients need ${ }^{28}$. General practitioners seem to believe that smoking cessation advice is more effective when linked to smoking-related symptoms patients present with ${ }^{29,30}$. Furthermore, a lot of barriers seem to exist for delivering effective smoking cessation treatment; physicians consider it time consuming, lack knowledge and skills, and think it might be ineffective (see Chapter $6)^{30,31}$. In the end physicians do not seem to routinely discuss smoking in their consultations with smokers ${ }^{30,32,33}$. This is unfortunate as it is crucial to offer help; when faced with an offer of support many smokers will respond positively ${ }^{28}$. Evidence clearly shows that what doctors say and do about smoking in consultations makes a huge difference to their patients ${ }^{28}$. Short stop smoking advice already makes 1 out of 40 patients quit smoking ${ }^{10}$. But, as mentioned in the previous paragraph it is often a challenge for physicians to win acceptance to discuss the topic of smoking. Patients might experience the smoking cessation advice and comments as being meddlesome, even when well-intended (see Chapter 4$)^{17}$. So, another challenge physicians face in their consultations with smokers is trying not to condemn these patients, because this might make smokers feel discriminated ${ }^{34}$. Negative encounters may increase severity of symptoms, arouse despair, shame and guilt; positive encounters are important for hope and coping ${ }^{35,36}$. As previously stated, the vast majority of smokers are happy to discuss the topic of smoking, if this is done in an empathetic and patient-centred manner ${ }^{19,21}$.

\section{Health care organisational influence}

Governments play a very important role in smoking and smoking cessation. Implementing any anti-smoking policy already makes quit rates increase ${ }^{37}$. An increase in cigarette taxes and the passage of comprehensive clean air laws are the cornerstone of strategies that have been successful in reducing smoking rates ${ }^{38}$. Mass media campaigns and cessation policies also play an important role in reducing the smoking rates $^{38}$. In the Netherlands, we saw that a national reimbursement policy accompanied 
by media attention was followed by an increase in quit attempts and quit rates ${ }^{39}$. An increasing use of cessation treatments was one of the reasons for this ${ }^{40}$. Furthermore, as previously mentioned, in the Netherlands commercial cessation methods are widely promoted and people lack knowledge of evidence-based smoking cessation treatments ${ }^{25}$. Therefore, it is highly recommended that evidence-based smoking cessation methods are promoted and alternative, non- evidence-based treatments, are banned. Campaigns on the health consequences of smoking are very important too. Unfortunately, governments seem to fail to inform people about the health consequences of smoking ${ }^{42}$. A dissenting opinion often heard in this regard is that tobacco control policies would harm economics. However, a recent report from the World Health Organisation showed that tobacco control does not harm economics $^{42}$.

\section{Patients with COPD}

Patients with COPD are a special subgroup of patients. They receive the label 'difficult' from physicians because they need complex care ${ }^{43}$. Furthermore, they are described as being time consuming, irresponsible and non-compliant ${ }^{43}$. COPD is, in Western countries, often caused by many years of smoking. Therefore, it is seen as a selfinflicted disease. This can contribute to blame from self and others ${ }^{44}$. When blamed by others, this might result in insufficient social support, whereas this is of extreme importance for managing their illness ${ }^{45}, 46$. Patients with COPD might also feel blamed by physicians ${ }^{45}$. These feelings and experiences of being blamed by others creates a stigma. Stigma arises from the awareness that a person has an undesirable trait or characteristic $^{44}$ and people with COPD often seem to be aware of this stigma ${ }^{44}$. The most reported triggers for stigma include the presence of cough and dyspnoea and the use of inhalers and supplemental oxygen ${ }^{44}$. In public places this will draw the attention and continuously remind patients that they are sick $^{44}$. This might evoke negative reactions and little sympathy, which can have a devastating effect on the individual with COPD $^{44}$. Consequently, patients withdraw from social activities to avoid unpleasant or embarrassing situations and become isolated. This may lead to further emotional consequences; loss of self-esteem, feelings of uselessness and depressive symptoms ${ }^{44}$. 


\section{Main findings from this dissertation}

We started this dissertation with a Cochrane review wherein we evaluated all smoking cessation interventions studied for patients with COPD. We saw that no COPD-specific smoking cessation interventions yet exist and that pharmacotherapy in combination with behavioural treatment is the most effective treatment at the moment (see Chapter 2). In order to find out if there is a need for COPD-specific smoking cessation interventions, we first looked into COPD-specific characteristics that are potential barriers for successful quitting. Our cross-sectional quantitative study that compared smokers with and without COPD (see Chapter 3 ) showed that smokers with COPD had higher levels of depression and cigarette dependence, and a lower self-efficacy to refrain from smoking. Thereupon, we interviewed both smokers with and without COPD to obtain more in-depth insight in previous findings (see Chapter 4). Patients with COPD seemed to be less knowledgeable about smoking and health, expressed that they experienced a lack of empathy from their physicians, seemed to have less faith in the efficacy of smoking cessation aids and maintained that their vision of life was linked with quitting. Besides these subjective patient perspectives, we gathered more objective information on COPD-specific predictors for successful quitting (see Chapter 5). We found a significant relationship between high level of education, higher general health perception and not having a partner, and prolonged abstinence. Finally, to complete the whole range of perspectives, we added physicians' ideas on smoking and smoking cessation in patients with COPD (see Chapter 6). Physicians expressed as lot of frustrations regarding smokers with COPD. Furthermore, they lacked experience with evidence-based smoking cessation treatments and had limited knowledge about these treatments. In the end, unsatisfactory financial incentive, limited time and stigma seemed to influence how physicians engaged in smoking cessation treatments. These results indicated that there is a number of patient- and physician-related barriers that negatively contribute to effective smoking cessation treatment in patients with COPD.

\section{Do we need tailored smoking cessation interventions?}

So far, we have seen that giving up smoking is the only effective way for smokers with COPD to reduce the accelerated decline of their lung function ${ }^{1,2}$. Pharmacotherapy in combination with behavioural treatment is advised to aid quit attempts, also in smokers with COPD. However, even with the use of these evidence-based smoking cessation interventions only a minority of smokers quits successfully. The chances of quitting smoking for the long-term, in the general smoking population, increased by 10 - 
$25 \%$ when using the advised aids ${ }^{5}$. In this dissertation we found a number of patientand physician-related barriers that negatively affect successful quitting in the general smoking population and in COPD patients in particular. Smoking cessation interventions for patients with COPD might be more effective once we address these barriers. Literature suggests that behaviour change interventions that are tailored to the individuals' specific needs are more effective ${ }^{47}$. Tailored messages are more likely to be read, understood, recalled, rated highly, and perceived as credible ${ }^{47}$.

In smoking cessation, an example of tailoring is adjusting the smoking cessation advice to the motivational stage a persons is $\mathrm{in}^{48}$. It is advisable to adjust the advice to what occupies the patients' mind at that moment. However, there is certain amount of controversy about how well the motivational stage model assists in smoking cessation $^{49}$. Evidence shows that smokers do not necessarily follow all these motivational stages and a substantial proportion of quit attempts are made without any previous planning ${ }^{49}$. This made us wonder if such tailored interventions are helpful in smoking cessation ${ }^{49,50}$. Nevertheless, in psychological treatments the procedure of tailoring is widely used and found effective in the treatment of, for example, depression and anxiety disorders ${ }^{51-53}$.

When we explored COPD-specific factors related to smoking and quitting in patients and physicians, there appeared to be a lot of general issues and attitudes (see Chapter 4 and 6). Therefore, we would suggest to follow existing smoking cessation interventions and add patient-specific factors to them. For example, for smokers with COPD, we would advise to pay special attention to discuss depressive symptoms, nicotine dependence and self-efficacy, as these factors might be COPD-specific barriers to quitting (see next paragraph and Chapter 3). This might also be useful for other specific groups of patients, e.g. patients with lung cancer or diabetes. In the end all patients with chronic conditions might benefit of this as well, as they are also more likely to develop depressive symptoms. For further research we would, therefore, recommend focussing on smoking cessation programs for all smokers. But, it would be useful to add some patient-specific advices to these general recommendations for those patients wherefore it is of utmost importance to quit smoking. Therefore, it would be useful to further map out which patients need what kind of specific attention. 
Let us take a more detailed look into what this would mean for everyday consultations with COPD patients. As previously mentioned, several guidelines advise physicians to use the 'five A's' when guiding patients with smoking cessation. The Dutch guideline on treating tobacco also recommends using this model ${ }^{10}$. This model starts by advising to ask and document the smoke status of every patient. The next step would then be advising the smokers to quit. That might be the first part where the model should be adjusted to specific patient groups. Because, as previously said, advice is more likely to be understood and perceived as credible when tailored to the individual person ${ }^{47}$. When distinguishing certain specific patient groups it is very important to keep sight of the individual patient. Each individual patient with COPD will have their own needs and concerns. In the individual interviews (see Chapter 4) smokers with COPD emphasized the importance of personal attention from their physician. In the following phases of the 'five A' model, assessing, assisting and arranging, physicians should go ahead with the previously discussed personal matters.

Another important aspect arising from this dissertation is how physicians should communicate with their patients when delivering tailored or untailored smoking cessation interventions. As previously described, in Western European countries individualism is highly valued, and patients, nowadays, demand more influence and participation in consultations ${ }^{18}$. However, physicians have the educational task to make patients able to actually participate in consultations ${ }^{18}$. This emphasizes the need of shared decision making in consultations these days ${ }^{54}$, wherein patients should be able to retain their autonomy. In Chapter 4 we saw that patients with COPD in particular requested a less paternalistic doctor-patient communication. This is underlined by the literature; most smokers accept discussing smoking cessation provided that they are not being patronised ${ }^{19-21}$. For smokers with COPD it seems important they receive some personal attention from the physician in order to discuss their own views on smoking and how this is part of their life (see Chapter 4). Physicians should, in their communication with smokers with COPD, take more time to explore social interactions, health perceptions and moral agendas that influence thoughts, feelings and what makes sense concerning smoking and quitting (see Chapter 4). Once the physician has gained a common understanding and trust, information and education about the relationship between COPD and smoking, and the use and efficacy of various smoking cessation aids, will possibly be appreciated more and absorbed better by the smokers with COPD (see Chapter 4). Furthermore, such a patient-centred approach might have 
beneficial effects on patient outcomes, such as symptom relief and emotional health ${ }^{55}$. To help physicians' engage with these recommendation for smoking cessation support, we advise introducing an informative smoking cessation program, including communication and ethic, into the vocational training and postgraduate medical training. The attachment of stigma should be considered in this training and how this interferes with giving professional smoking cessation support. In addition evidencebased smoking cessation treatment should be taught and communication should be practiced (see Chapter 6).

Although the first contact with the patient still runs through the physician, practice nurses expand their activities increasingly in the Netherlands. Most of the chronic care, including COPD care, and smoking cessation treatment is done by practice nurses. It would therefore be useful to explore how nurses engage in smoking cessation treatments for their chronic care patients. If we verify their specific needs and concerns, we will get a clearer picture of what needs to be done to increase the effectiveness of smoking cessation treatments. 


\section{References}

1. From the Global Strategy for the Diagnosis, Management and Prevention of COPD, Global Initiative for Chronic Obstructive Lung Disease (GOLD) 2015. http://goldcopd.org. Accessed 17 November 2015.

2. Anthonisen N.R., Connett J.E., Murray R.P. Smoking and lung function of Lung Health Study participants after 11 years. Am J Respir Crit Care Med. 166, 675-679 (2002).

3. van Eerd E.A., van der Meer R.M., van Schayck O.C., Kotz D. Smoking cessation for people with chronic obstructive pulmonary disease. Cochrane Database Syst Rev. CD010744 (2016).

4. $\quad$ Tariq S., Woodman J. Using mixed methods in health research. JRSM short reports. 4, 18 (2013).

5. Stead L.F., Koilpillai P., Fanshawe T.R., Lancaster T. Combined pharmacotherapy and behavioural interventions for smoking cessation. Cochrane Database Syst Rev. 3, CD008286 (2016).

6. Volksgezondheidenzorg.info. www.volksgezondheidenzorg.info. RIVM: Bilthoven. Accessed 8 November 2016.

7. World Health Organisation. Global Health Observatoy. www.who.int/en/. Accessed 22 January 2017.

8. Knol K., Hilvering C., Wagener D., Willemsen M. Tabaksgebruik: gevolgen en bestrijding. Utrecht, Lemma; 2005.

9. American Psychiatric Association. Diagnostic and Statistical Manual of Mental Disorders (DSM-5 ${ }^{\circledR}$ ). Arlington, American Psychiatric Association Publishing; 2013.

10. Chavannes N.H., Kaper J., Frijling B.D., Van der Laan J., Jansen P., Guerrouj S., et al. NHG-Standaard Stoppen met roken. Huisarts Wet. 50, 306-314 (2007).

11. Pidoplichko V.I., DeBiasi M., Williams J.T., Dani J.A. Nicotine activates and desensitizes midbrain dopamine neurons. Nature. 390, 401-404 (1997).

12. Medbo A., Melbye H., Rudebeck C.E. 'I did not intend to stop. I just could not stand cigarettes any more.' A qualitative interview study of smoking cessation among the elderly. BMC Fam Pract. 12, 42 (2011).

13. Hughes J.R., Keely J., Naud S. Shape of the relapse curve and long-term abstinence among untreated smokers. Addiction. 99, 29-38 (2004).

14. Shahab L., Jarvis M.J., Britton J., West R. Prevalence, diagnosis and relation to tobacco dependence of chronic obstructive pulmonary disease in a nationally representative population sample. Thorax. 61, 1043-1047 (2006).

15. Tønnesen P., Carrozzi L., Fagerstrom K.O., Gratziou C., Jimenez-Ruiz C., Nardini S., et al. Smoking cessation in patients with respiratory diseases: a high priority, integral component of therapy. Eur Respir J. 29, 390-417 (2007).

16. van Eerd E.A., van Rossem C.R., Spigt M.G., Wesseling G., van Schayck O.C., Kotz D. Do we need tailored smoking cessation interventions for smokers with COPD? A comparative study of smokers with and without COPD regarding factors associated with tobacco smoking. Respiration. 90, 211-219 (2015).

17. van Eerd E.A., Risor M.B., van Rossem C.R., van Schayck O.C., Kotz D. Experiences of tobacco smoking and quitting in smokers with and without chronic obstructive pulmonary disease-a qualitative analysis. BMC Fam Pract. 16, (2015).

18. Dieterich A. The modern patient - threat or promise? Physicians' perspectives on patients' changing attributes. Patient Educ Couns. 67, 279-285 (2007). 
19. Butler C.C., Pill R., Stott N.C. Qualitative study of patients' perceptions of doctors' advice to quit smoking: implications for opportunistic health promotion. BMJ. 316, 1878-1881 (1998).

20. George J., Kong D.C., Thoman R., Stewart K. Factors associated with medication nonadherence in patients with COPD. Chest. 128, 3198-3204 (2005).

21. Coleman T., Wilson A. Anti-smoking advice from general practitioners: is a populationbased approach to advice-giving feasible? Br J Gen Pract. 50, 1001-1004 (2000).

22. Rijksoverheid. Kennis Nederlanders over gevaren (mee)roken laag. www.rijksoverheid.nl/. Accessed 10 January 2017.

23. Bethea J., Murtagh B., Wallace S.E. 'I don't mind damaging my own body' a qualitative study of the factors that motivate smokers to quit. BMC Public Health. 15, 4 (2015).

24. Cummings K.M., Hyland A., Giovino G.A., Hastrup J.L., Bauer J.E., Bansal M.A. Are smokers adequately informed about the health risks of smoking and medicinal nicotine? Nicotine Tob Res. 6 Suppl 3, S333-340 (2004).

25. Willems R.A., Willemsen M.C., Smit E.S., Nagelhout G.E., Janssen E., de Vries H. Which smoking cessation aids are proven effective according to smokers who want to quit smoking? A report from the Netherlands. Tob Control. 23, 525-526 (2014).

26. Kotz D., Wesseling G., Huibers M.J., van Schayck O.C. Efficacy of confronting smokers with airflow limitation for smoking cessation. Eur Respir J. 33, 754-762 (2009).

27. US Department of Health and Human Services. Public Health Service. Clinical practice guideline. Treating tobacco use and dependence: 2008 update. www.ncbi.nlm.nih.gov/books/NBK63952/. Accessed 17 November 2015.

28. Aveyard P., West R. Managing smoking cessation. BMJ. 335, 37-41 (2007).

29. Coleman T., Wilson A. Anti-smoking advice in general practice consultations: general practitioners' attitudes, reported practice and perceived problems. Br J Gen Pract. 46, 87-91 (1996).

30. Stead M., Angus K., Holme I., Cohen D., Tait G. Factors influencing European GPs' engagement in smoking cessation: a multi-country literature review. Br J Gen Pract. 59, 682-690 (2009).

31. Vogt F., Hall S., Marteau T.M. General practitioners' and family physicians' negative beliefs and attitudes towards discussing smoking cessation with patients: a systematic review. Addiction. 100, 1423-1431 (2005).

32. Coleman T., Wynn A., Barrett S., Wilson A. Discussion of NRT and other antismoking interventions in UK general practitioners' routine consultations. Nicotine Tob Res. 5, 163-168 (2003).

33. Ellerbeck E.F., Ahluwalia J.S., Jolicoeur D.G., Gladden J., Mosier M.C. Direct observation of smoking cessation activities in primary care practice. J Fam Pract. 50, 688-693 (2001).

34. Brown-Johnson C.G., Cataldo J.K., Orozco N., Lisha N.E., Hickman N.J., 3rd, Prochaska J.J. Validity and reliability of the Internalized Stigma of Smoking Inventory: An exploration of shame, isolation, and discrimination in smokers with mental health diagnoses. Am J Addict. 24, 410-418 (2015).

35. Raty L.K., Gustafsson B. The influence of confirming and disconfirming healthcare encounters on the self-relation and quality of life of persons with epilepsy. $J$ Neurosci Nurs. 34, 261-272 (2002).

36. Raty L., Gustafsson B. Emotions in relation to healthcare encounters affecting selfesteem. J Neurosci Nurs. 38, 42-50 (2006). 
37. Levy D.T., Graham A.L., Mabry P.L., Abrams D.B., Orleans C.T. Modeling the impact of smoking-cessation treatment policies on quit rates. Am J Prev Med. 38, S364-372 (2010).

38. Levy D.T., Chaloupka F., Gitchell J. The effects of tobacco control policies on smoking rates: a tobacco control scorecard. J Public Health Manag Pract. 10, 338-353 (2004).

39. Nagelhout G.E., Willemsen M.C., van den Putte B., de Vries H., Willems R.A., Segaar D. Effectiveness of a national reimbursement policy and accompanying media attention on use of cessation treatment and on smoking cessation: a real-world study in the Netherlands. Tob Control. 0, 1-7 (2014).

40. Verbiest M.E., Chavannes N.H., Crone M.R., Nielen M.M., Segaar D., Korevaar J.C., et al. An increase in primary care prescriptions of stop-smoking medication as a result of health insurance coverage in the Netherlands: population based study. Addiction. 108, 2183-2192 (2013).

41. Willemsen M.C., Segaar D., van Schayck O.C. Population impact of reimbursement for smoking cessation: a natural experiment in The Netherlands. Addiction. 108, 602-604 (2013)

42. U.S. National Cancer Institute and World Health Organization. The Economics of Tobacco and Tobacco Control. National Cancer Institute Tobacco Control Monograph 21. Bethesda, MD: U.S. Department of Health and Human Services, National Institutes of Health, National Cancer Institute; and Geneva, CH: World Health Organization, 2016.

43. Risor M.B., Spigt M., Iversen R., Godycki-Cwirko M., Francis N., Altiner A., et al. The complexity of managing COPD exacerbations: a grounded theory study of European general practice. BMJ Open. 3, (2013).

44. Berger B.E., Kapella M.C., Larson J.L. The experience of stigma in chronic obstructive pulmonary disease. West J Nurs Res. 33, 916-932 (2011).

45. Sheridan N., Kenealy T., Salmon E., Rea H., Raphael D., Schmidt-Busby J. Helplessness, self blame and faith may impact on self management in COPD: a qualitative study. Prim Care Respir J. 20, 307-314, 301 p following 314 (2011).

46. Halding A.G., Heggdal K., Wahl A. Experiences of self-blame and stigmatisation for selfinfliction among individuals living with COPD. Scand J Caring Sci. 25, 100-107 (2011).

47. Noar S.M., Benac C.N., Harris M.S. Does tailoring matter? Meta-analytic review of tailored print health behavior change interventions. Psychol Bull. 133, 673-693 (2007).

48. DiClemente C.C., Prochaska J.O., Fairhurst S.K., Velicer W.F., Velasquez M.M., Rossi J.S. The process of smoking cessation: an analysis of precontemplation, contemplation, and preparation stages of change. J Consult Clin Psychol. 59, 295-304 (1991).

49. West R., Sohal T. 'Catastrophic' pathways to smoking cessation: findings from national survey. BMJ. 332, 458-460 (2006).

50. Farkas A.J., Pierce J.P., Zhu S.H., Rosbrook B., Gilpin E.A., Berry C., et al. Addiction versus stages of change models in predicting smoking cessation. Addiction. 91, 12711280; discussion 1281-1292 (1996).

51. Johansson R., Sjoberg E., Sjogren M., Johnsson E., Carlbring P., Andersson T., et al. Tailored vs. standardized internet-based cognitive behavior therapy for depression and comorbid symptoms: a randomized controlled trial. PLoS One. 7, e36905 (2012).

52. Silfvernagel K., Carlbring P., Kabo J., Edstrom S., Eriksson J., Manson L., et al. Individually tailored internet-based treatment for young adults and adults with panic attacks: randomized controlled trial. J Med Internet Res. 14, e65 (2012).

53. Carlbring P., Maurin L., Torngren C., Linna E., Eriksson T., Sparthan E., et al. Individuallytailored, Internet-based treatment for anxiety disorders: A randomized controlled trial. Behav Res Ther. 49, 18-24 (2011). 
54. Makoul G., Clayman M.L. An integrative model of shared decision making in medical encounters. Patient Educ Couns. 60, 301-312 (2006).

55. Stewart M.A. Effective physician-patient communication and health outcomes: a review. Can Med Assoc J. 152, 1423-1433 (1995). 

Summary

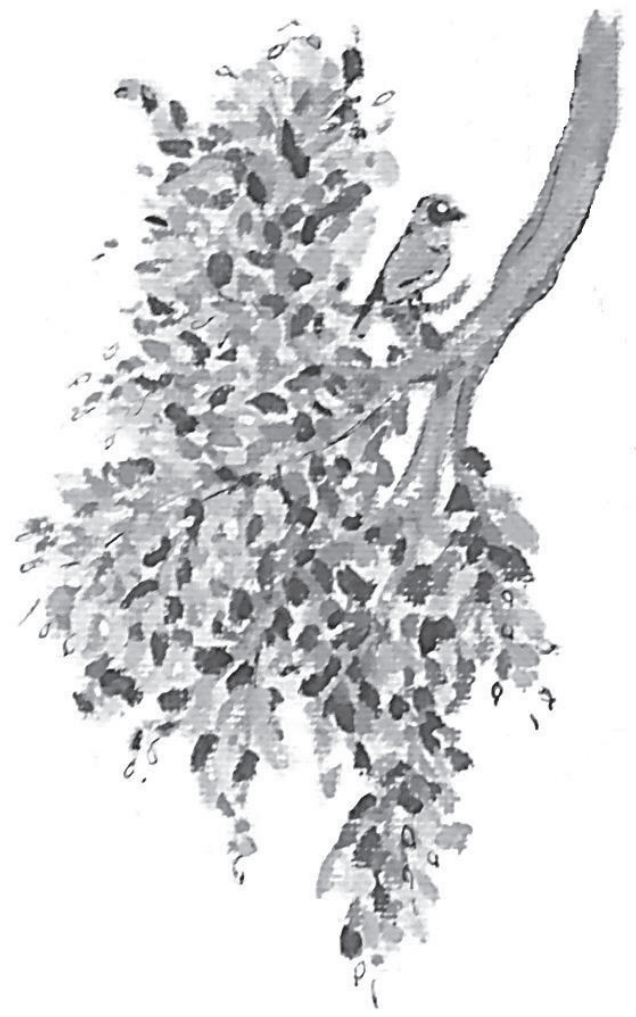





\section{Summary}

Tobacco-smoking is the most important risk factor for developing COPD in high-income countries. In the Netherlands, $85 \%$ of new COPD cases is attributed to smoking. Besides, smoking has a detrimental effect on the course of this disease; it increases the accelerated decline in lung function. Quitting smoking is, therefore, the only evidencebased intervention that reduces the risk of developing COPD and slows down the progression of the disease.

Several smoking cessation interventions have been developed to support smokers when quitting. Despite the availability of these evidence-based interventions, the prevalence of smoking in patients with COPD is still high and exceeds the rate of smoking in the general population. There is only limited evidence that patients get motivated to quit on receiving a diagnosis of COPD. Many still continue smoking, and do not use evidence-based smoking cessation interventions.

Smoking cessation interventions are currently not tailored specifically to the needs of COPD patients. There are suggestions from the literature that COPD patients face specific problems and have different needs regarding smoking cessation. Furthermore, physicians seem to experience difficulties in providing qualitatively good care to their COPD patients, including smoking cessation treatments. In order to stimulate smoking cessation and the use of smoking cessation interventions in this particular group of patients it is important to understand patient- and physician-related concerns and needs regarding smoking cessation treatments. In this dissertation we tried to gain more clarity hereon. If we address these needs in tailored smoking cessation interventions for patients with COPD, the effectiveness of these interventions is likely to increase, and more patients with COPD will successfully quit smoking.

We started (Chapter 2 ) by systematically reviewing the literature on which smoking cessation interventions are currently available and effective for smokers with COPD. In the general smoking population a combination of behavioural treatment and pharmacotherapy is most effective, but little is known about the effectiveness of different smoking cessation interventions for the particular group of smokers with COPD. Therefore, we assessed the effectiveness of behavioural or pharmacological interventions, or both, in this particular group of smokers. We only included studies that reported how many participants had stopped smoking after at least six months of 
follow-up. This resulted in 16 included studies (involving a total of 13,123 participants). In four of these studies (1,540 participants) we found high-quality evidence for the effectiveness of pharmacotherapy plus high-intensity behavioural treatment compared with placebo plus high-intensity behavioural treatment (relative risk (RR) 2.53, 95\% confidence interval (Cl) 1.83 to 3.50). Furthermore, we concluded that there is no convincing evidence for preferring any particular form of behavioural or pharmacological treatment. In addition, we did not find COPD-specific smoking cessation interventions, and it remained unclear whether smokers with COPD are different from smokers without COPD with regard to which treatments work best to help them stop smoking.

In Chapter 3 and 4 we, therefore, tried to gain more insight in possible smoking-related differences between smokers with and without COPD. In Chapter 3 we show the results of a cross-sectional study, comparing smokers with and without COPD on factors associated with smoking and quitting. We conducted a questionnaire survey in all smoking patients with a recorded diagnosis of COPD from a large Dutch primary health care network. The smokers with COPD were compared with twice as many age-, sex-, and health care centre-matched smokers without COPD. We collected data from 107 smokers with COPD and 86 smokers without COPD. The number of attempts to quit was similar in both groups, but more smokers with COPD had ever used pharmacological, behavioural and alternative smoking cessation treatments. Furthermore, smokers with COPD more often received triggers to quit from their environment and from their general practitioner, and they were more concerned about, and aware of, the health risks of smoking. Importantly, smokers with COPD reported higher levels of depression and cigarette dependence and a lower selfefficacy to refrain from smoking than smokers without COPD. We concluded that smokers with COPD differed from smokers without COPD on several factors which are associated with tobacco smoking and quitting. When providing behavioural counselling health care providers should pay extra attention to depressive symptoms, high nicotine dependence and low self-efficacy in patients with COPD. This should have an impact on reducing smoking in this patient population in the future.

In Chapter 4 we tried to gain more insight into underlying reasons for the differences found in Chapter 3. We aimed to explore which justifications for tobacco smoking and experiences of quitting were commonly shared in smokers with and without COPD, and 
which, if any, were specific to smokers with COPD. In 10 smokers with and 10 smokers without COPD, who responded to the questionnaire survey, we conducted semistructured, in-depth interviews. We generated three themes from these interviews. In theme 1, 'balancing the impact on health of smoking', we found that all participants trivialized health consequences of smoking but those with COPD seemed to be less knowledgeable about smoking and health. In theme 2, 'challenging of autonomy by social interference', we showed that both groups of smokers found autonomy very important; the participants felt they needed freedom to decide to do as they wished. Also, smokers with COPD were indignant about a perceived lack of empathy in their communication with doctors. In theme 3, 'prerequisites for quitting', we saw that smokers with COPD in particular had little faith in the efficacy of smoking cessation aids. Besides, we found that motivation for quitting was subject to fluctuations by varying intrinsic and extrinsic influences. Furthermore, smokers with COPD specifically maintained that their vision of life was linked with quitting. We concluded that participants showed many similarities in their reasoning about smoking and quitting. These corresponding themes argue for a less paternalistic regime in the communication with smokers with attention required for the motivational stage and room made for smokers' own views, and with clear information and education. Furthermore, addressing social interactions, health perceptions and moral agendas in the communication with smokers with COPD may help to make smoking cessation interventions more suitable for them.

Our final patient-centred study on COPD-specific factors influencing smoking cessation, was a prediction study. Chapter 5 shows the results of a secondary analysis wherein we identified predictors of long-term abstinence in patients with COPD who participated in a randomised controlled smoking cessation trial. A total of 296 smokers with previously undetected mild-moderate COPD were included in this analysis. For the prediction model we selected measurements which were clinically relevant or, according to the literature, were candidate predictors of prolonged abstinence (5-52 weeks after the target quit date). We used manual backward elimination to determine the best-fit model with significant predictors. Three baseline characteristics predicted successful quitting. The odds of abstinence were 3.23 times higher in smokers with high level of education than in smokers with low level of education (95\% Cl 1.03-10.15); 1.03 times higher per point increase in general health perception (scale 1-100, 95\% Cl 1.01-1.06); and 3.89 times higher in smokers not having a partner compared with smokers having 
a partner that smoked $(95 \% \mathrm{Cl} 1.23-12.31)$. These predictors are similar to predictors in the general smoking population. When supporting smokers with COPD with quitting, health care providers should take into account the patients' health perceptions and social environment in order to increase their chance of successful quitting.

In Chapter 6 we looked at physician-related difficulties in smoking cessation treatment for smokers with COPD. For this secondary analysis we used focus group discussions about exacerbation management in patients with COPD. We assessed physicians' experienced difficulties and potential solutions regarding the smoking of their COPD patients and the effectiveness of smoking cessation treatments. In total, 21 focus group discussions were held with general practitioners and pulmonologists in seven different countries in Europe and Asia. We generated three themes from these discussions, whereby some of the issues concerned smokers in general. First theme: 'physicians' frustration with COPD patients who smoke'; these frustrations interfered with the provision of evidence-based treatment and could result in this group of patients being treated unequally. Second theme: 'physicians' limited knowledge of, and negative beliefs about, smoking cessation treatment'; this hindered treating smokers effectively. Third theme: 'healthcare organisational factors that influence the use of smoking cessation treatments'; lack of time and financial reimbursement, as well as the failure to regard smoking as an addictive disease, influenced how physicians engaged in smoking cessation treatment. Our results indicated that there was a number of physician-related barriers to the provision of effective smoking cessation treatment to patients with COPD and smokers in general. We suggested that introducing an informative smoking cessation program, including communication skills and ethical issues, in the vocational and postgraduate medical training may help to address these barriers and increase engagement with smoking cessation treatment.

In this dissertation we wanted to gain a better understanding of patient- and physicianrelated problems and needs regarding smoking cessation treatments for patients with COPD. In the general discussion (Chapter 7) we discuss that there appeared to be a lot of common non-specific issues and attitudes from both smokers with and without COPD, and physicians. Therefore, we would suggest to follow existing smoking cessation interventions for patients with COPD and add COPD patient-specific factors to them. If we address their specific needs (e.g. attention for depressive symptoms, self-efficacy and social interactions) in such tailored smoking cessation interventions, 
the effectiveness of these interventions might increase and more patients with COPD will successfully quit smoking. Tailored messages are more likely to be read, understood, recalled, rated highly, and perceived as credible, and it is therefore advisable to adjust the advice to what occupies the patients' mind at that moment. This will help physicians to gain a common understanding and trust from the patient, so information and education will possibly be appreciated more and absorbed better by the patient. For example, for smokers with COPD, we advised to pay special attention to discuss depressive symptoms, nicotine dependence and self-efficacy, as these factors might be COPD-specific barriers to quitting. In the end patients with other chronic conditions might benefit of this as well, as they are also more likely to develop, e.g., depressive symptoms. Furthermore, physicians should, in their communication with smokers with COPD, take more time to explore social interactions, health perceptions and moral agendas that influence thoughts, feelings and what makes sense concerning smoking and quitting. To help physicians' engage with these recommendations for smoking cessation support, we advised introducing an informative smoking cessation program, including communication and ethic, into the vocational training and postgraduate medical training. The attachment of stigma should be considered in this training and how this interferes with giving professional smoking cessation support. In addition, evidence-based smoking cessation treatment should be taught and communication should be practiced. 

Samenvatting

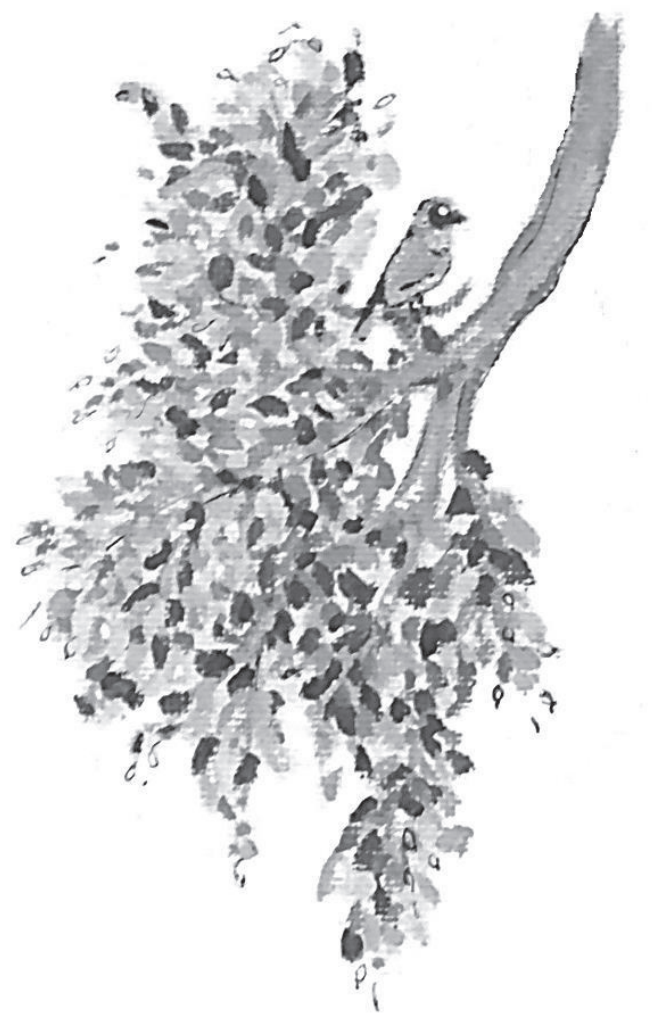





\section{Samenvatting}

In de Westerse wereld is roken de belangrijkste oorzaak voor het ontwikkelen van COPD. In Nederland wordt ongeveer 85\% van de nieuwe COPD gevallen veroorzaakt door roken. Roken heeft ook een nadelig effect op het beloop van deze ziekte; het zorgt namelijk voor een nog snellere achteruitgang van de longfunctie. Stoppen met roken is dan ook de enige evidence-based interventie die het risico op het krijgen van COPD vermindert en de progressie van de ziekte vertraagt.

Verscheidene stop-roken-interventies zijn ontwikkeld om rokers te ondersteunen bij hun stoppoging. Desondanks zijn er nog veel COPD patiënten die roken, dit aantal overstijgt zelfs het aantal rokers in de algehele populatie. Het krijgen van de diagnose COPD leidt in veel gevallen dus niet tot definitief stoppen met roken. Velen gaan door met roken en maken geen gebruik van evidence-based stop-roken-interventies.

Op dit moment zijn er geen stop-roken-behandelingen specifiek voor patiënten met COPD. Echter, vanuit de literatuur wordt gesuggereerd dat COPD patiënten specifieke behoeftes en problemen hebben rondom het stoppen-met-roken. Daarnaast blijkt dat ook artsen vaak belemmeringen ervaren bij het begeleiden van hun COPD patiënten, zo ook bij stop-roken-begeleiding. Het is daarom van belang dat we meer inzicht krijgen in deze COPD-specifieke behoeftes en problemen van zowel patiënten als artsen rondom het stoppen met roken. In dit proefschrift beschrijven we verscheidene studies die ons hier meer inzicht in geven. Het uiteindelijke doel is om de informatie die hieruit voortkomt, toe te passen op bestaande stop-roken-behandelingen en daarmee de effectiviteit ervan, specifiek voor COPD patiënten, te vergroten. Dit zou ertoe moeten leiden dat meer patiënten met COPD wél gebruik maken van effectieve stop-rokenbehandelingen en uiteindelijk succesvol kunnen stoppen met roken.

We begonnen dit proefschrift (Hoofdstuk 2) met het systematisch doorzoeken van de literatuur naar welke stop-roken-interventies momenteel beschikbaar zijn en effectief blijken voor rokers met COPD. Voor rokers in het algemeen geldt dat een combinatie van een gedragsmatige interventie en medicatie het meest effectief is. Er is weinig bekend over de effectiviteit van de verschillende beschikbare interventies voor de specifieke groep rokers met COPD. We hebben daarom de effectiviteit van gedragsmatige en farmacologische interventies voor deze specifieke groep onderzocht. We includeerden hiervoor alleen studies die rapporteerden hoeveel deelnemers er na 
minimaal zes maanden follow-up gestopt waren met roken. Dit resulteerde in 16 geïncludeerde studies (met in totaal 13.123 deelnemers). In vier van deze studies (1.540 deelnemers) vonden we bewijs van hoge kwaliteit dat medicatie samen met een intensieve gedragsmatige interventie effectiever is dan placebo samen met een intensieve gedragsmatige interventie (relatieve risico (RR) 2.53, 95\% betrouwbaarheidsinterval (BI) 1.83 tot 3.50, risk difference (RD) 0.10, 95\% BI 0.07 tot 0.14). Daarnaast concludeerden we dat er geen overtuigend bewijs is voor het prefereren van een bepaalde vorm van gedragsmatige of medicamenteuze behandeling. Tot slot vonden we geen COPD-specifieke interventies en bleef het vooralsnog onduidelijk of rokers mét en zonder COPD verschillen aangaande welke behandeling het beste voor hen is ter ondersteuning bij het stoppen met roken.

In Hoofdstuk 3 en 4 wilden we daarom meer inzicht verkrijgen in mogelijke verschillen tussen rokers mét en zonder COPD wat betreft roken en stoppen met roken. In Hoofdstuk 3 laten we de resultaten zien van een cross-sectionele studie, waarin we rokers mét en zonder COPD met elkaar vergeleken. We hebben vragenlijsten afgenomen bij alle rokers met een COPD diagnose die patiënt waren bij één van de 10 gezondheidscentra van Stichting Gezondheidscentra Eindhoven. Deze rokers met COPD wilden we vergelijken met twee keer zoveel rokers zonder COPD van gelijke leeftijd, geslacht en afkomstig uit hetzelfde gezondheidscentrum. Uiteindelijk verkregen we de volledige gegevens van 107 rokers mét COPD en 86 rokers zonder COPD. Het aantal pogingen om te stoppen met roken was vergelijkbaar in beide groepen, maar meer rokers mét COPD hadden ooit gebruik gemaakt van medicatie of gedragsmatige en/of alternatieve stop-roken-behandelingen. Rokers mét COPD kregen tevens vaker advies om te stoppen met roken vanuit hun omgeving en van hun huisarts. Ook waren ze meer bezorgd over, en zich bewust van de gezondheidsrisico's van roken. Tot slot viel het op dat rokers mét COPD meer depressieve symptomen rapporteerden, een hogere mate van nicotine afhankelijkheid hadden en een lagere zelfredzaamheid aangaven om te kunnen stoppen met roken. We concludeerden dat rokers mét COPD verschilden van rokers zonder COPD wat betreft factoren die geassocieerd zijn met roken en stoppen met roken. Wij adviseren zorgverleners daarom bij rokers met COPD extra aandacht te besteden aan de aanwezigheid van depressieve symptomen, een hogere nicotine afhankelijkheid en een lagere zelfredzaamheid om te stoppen met roken. In de toekomst zal dit, naar verwachting, van invloed zijn op het verminderen van het aantal rokers in deze patiëntenpopulatie. 
In Hoofdstuk 4 hebben we geprobeerd om meer inzicht te krijgen in de onderliggende redenen voor de verschillen die we in Hoofdstuk 3 tussen rokers mét en zonder COPD vonden. Daarom hebben we gekeken welke ervaringen en behoeftes omtrent roken en stoppen met roken vaak naar voren kwamen bij zowel rokers mét als zonder COPD. Daarnaast keken we of er specifieke ervaringen en behoeftes waren bij de groep rokers mét COPD. We hebben semigestructureerde diepte-interviews gehouden met 10 rokers mét en 10 rokers zonder COPD, die de vragenlijst (Hoofdstuk 3) hadden ingevuld. Aan de hand van deze interviews konden we drie thema's identificeren. In thema 1 , 'het tegen elkaar afwegen van de impact van roken op de gezondheid', zagen we dat alle deelnemers de gevolgen van roken op de gezondheid bagatelliseerden, maar patiënten met COPD leken zich nog minder bewust van de gezondheidseffecten van roken. In thema 2, 'het uitdagen van de autonomie door sociale inmenging', konden we zien dat beide groepen rokers autonomie zeer belangrijk vonden; de deelnemers vonden dat ze de vrijheid moesten krijgen om hun eigen beslissingen te nemen. Rokers mét COPD gaven daarnaast aan verontwaardigd te zijn over een vermeend gebrek aan empathie van hun artsen. In thema 3, 'voorwaarden om te stoppen', zagen we dat rokers mét COPD in het bijzonder weinig vertrouwen hadden in de effectiviteit van stop-roken-hulpmiddelen. Bovendien viel het op dat de motivatie om te stoppen kon veranderen onder invloed van intrinsieke en extrinsieke factoren. Daarnaast kwam naar voren dat rokers met COPD aangaven dat hun levensvisie direct verbonden was aan het al dan niet stoppen met roken. Uiteindelijk concludeerden we dat de deelnemers veel overeenkomsten vertoonden in hun redeneringen omtrent roken en stoppen met roken. Deze overeenkomstige thema's pleiten voor een minder paternalistische communicatie met rokers met aandacht voor de motivatie en standpunten van de roker. Daarnaast is het van belang duidelijke informatie en educatie te geven. Tot slot is het belangrijk aandacht te besteden aan sociale interacties, gezondheidspercepties en morele agenda's in de communicatie met rokers met COPD. Hierdoor zullen stop-roken-interventies beter aansluiten aan de behoeftes van deze specifieke groep rokers.

De laatste patiëntgerichte studie keek naar COPD-specifieke factoren die van invloed zijn op het succesvol stoppen met roken. Hoofdstuk 5 toont de resultaten van een secundaire analyse waarbij we voorspellers wilden identificeren voor succesvol stoppen met roken bij patiënten met COPD. Deze patiënten namen aanvankelijk deel aan een gerandomiseerd stop-roken-onderzoek. In totaal werden 296 rokers met 
eerder onopgemerkt milde tot matige COPD meegenomen in deze analyse. Om tot een model te komen dat succesvol (abstinentie van week 5-52 na de beoogde stopdatum) stoppen met roken zou voorspellen, selecteerden we kandidaat voorspellers aan de hand van literatuur en praktijkervaring. We kwamen tot een finaal model door de voorspellers één voor één, handmatig, uit het model te elimineren. Drie patiëntgerelateerde kenmerken voorspelden succesvol stoppen met roken: de kans om succesvol te stoppen was 3,23 keer hoger bij rokers met een hoog opleidingsniveau dan bij rokers met een laag opleidingsniveau (95\% Cl 1,03-10,15); 1,03 keer hoger per punt stijging van de algemene gezondheidsbeleving (schaal 1-100, 95\% Cl 1,01-1,06); en 3,89 keer hoger bij rokers die geen partner hadden in vergelijking met rokers die een partner hadden die rookte ( $95 \%$ BI 1,23-12,31). Bij het ondersteunen van rokers met COPD bij het stoppen met roken, is het daarom raadzaam voor zorgverleners rekening te houden met de gezondheidspercepties van de patiënt en de invloed van hun sociale omgeving, zodat de kans om succesvol te stoppen wordt vergroot.

Tot slot, hebben we in Hoofdstuk 6 gekeken naar waar artsen tegenaan lopen bij het ondersteunen van rokers met COPD in de stop-roken-behandeling. Voor deze secundaire analyse gebruikten we focusgroep discussies die oorspronkelijk tot doel hadden om de behandeling omtrent exacerbaties bij patiënten met COPD in kaart te brengen. We filterden hieruit de verschillende visies van artsen omtrent ondersteuning bij het stoppen met roken, en de effectiviteit van stop-roken-behandelingen. In totaal werden 21 focusgroep discussies gevoerd met huisartsen en longartsen in zeven verschillende landen in Europa en Azië. We destilleerden hieruit drie thema's, waarbij sommige thema's ook van toepassing waren op rokers in het algemeen. Het eerste thema: 'frustratie bij artsen over COPD-patiënten die roken'; deze frustraties hadden invloed op de kwaliteit van het uitvoeren van evidence-based stop-rokenbehandelingen, en kon ertoe leiden dat rokers met COPD kwalitatief minder goed werden behandeld. Het tweede thema: 'beperkte kennis van artsen, en negatieve overtuigingen, over stop-roken-behandelingen'; dit bemoeilijkte de effectieve behandeling van rokers in het algemeen. Het derde en laatste thema: 'organisatorische factoren in de gezondheidszorg die het gebruik van stop-roken-behandelingen beïnvloeden'; gebrek aan tijd en financiële vergoeding, alsmede roken niet als verslavingsziekte beschouwen, beïnvloedde hoe artsen bezig waren met stop-rokenbehandelingen. Onze resultaten laten zien dat er een aantal arts-gerelateerde belemmeringen is bij het effectief ondersteunen van patiënten met COPD en rokers in 
het algemeen, bij het stoppen met roken. We adviseren om een informatief stoproken-onderwijsprogramma in te voeren, waarbij communicatieve vaardigheden en ethische kwesties behandeld worden. Als dit ingevoerd wordt in de geneeskunde- en vervolgopleidingen zal dit bijdragen belemmeringen bij artsen te verkleinen en daarmee de ondersteuning bij stop-roken-behandelingen te verbeteren.

Door middel van dit proefschrift wilden we patiënt- en arts-gerelateerde problemen en behoeftes inzake stop-roken-behandelingen voor patiënten met COPD in kaart brengen. In de algemene discussie (Hoofdstuk 7) bespreken we dat er veel algemene roken-gerelateerde knelpunten en attitudes zijn bij zowel rokers mét en zonder COPD, als artsen. Daarom stellen wij voor om bestaande stop-roken-interventies ook voor COPD patiënten na te volgen en daar COPD-patiënt-specifieke factoren aan toe te voegen. Als we aandacht besteden aan hun specifieke behoeftes (bijvoorbeeld aandacht voor depressieve symptomen, eigen-effectiviteit en sociale interacties) zal de effectiviteit van deze interventies waarschijnlijk vergroten en zullen mogelijk meer patiënten met COPD succesvol kunnen stoppen met roken. Gepersonaliseerde informatie wordt namelijk vaker gelezen, begrepen, onthouden, hoog gewaardeerd en gezien als geloofwaardig, en het is daarom raadzaam om advies aan te passen aan de situatie waarin de patiënt zich op dat moment bevindt. Bijvoorbeeld, voor rokers met COPD adviseren we om specifiek aandacht te besteden aan depressieve symptomen, mate van nicotineverslaving en eigen-effectiviteit om te stoppen met roken. Deze factoren kunnen namelijk bij een COPD-patiënt het stoppen met roken belemmeren. Uiteindelijk zullen ook patiënten met andere chronische aandoeningen kunnen profiteren van een dergelijke gepersonaliseerde stop-roken-behandeling, omdat ook zij bijvoorbeeld meer kans hebben om depressieve symptomen te ontwikkelen. Daarnaast is het belangrijk dat artsen in hun communicatie met rokers met COPD meer aandacht besteden aan sociale interacties, gezondheidspercepties en morele agenda's omtrent roken en stoppen met roken. Om artsen daarin te ondersteunen, adviseren wij om een informatief stop-roken-onderwijsprogramma, inclusief communicatie en ethiek, te implementeren in de geneeskunde- en vervolgopleidingen. Ook stigmatisatie en hoe dit interfereert met het geven van professionele stop-roken-ondersteuning zou in deze training aan bod moeten komen. Daarnaast zouden evidence-based stop-rokenbehandelingen moeten worden besproken en specifieke communicatievaardigheden worden geoefend. 

Valorisation

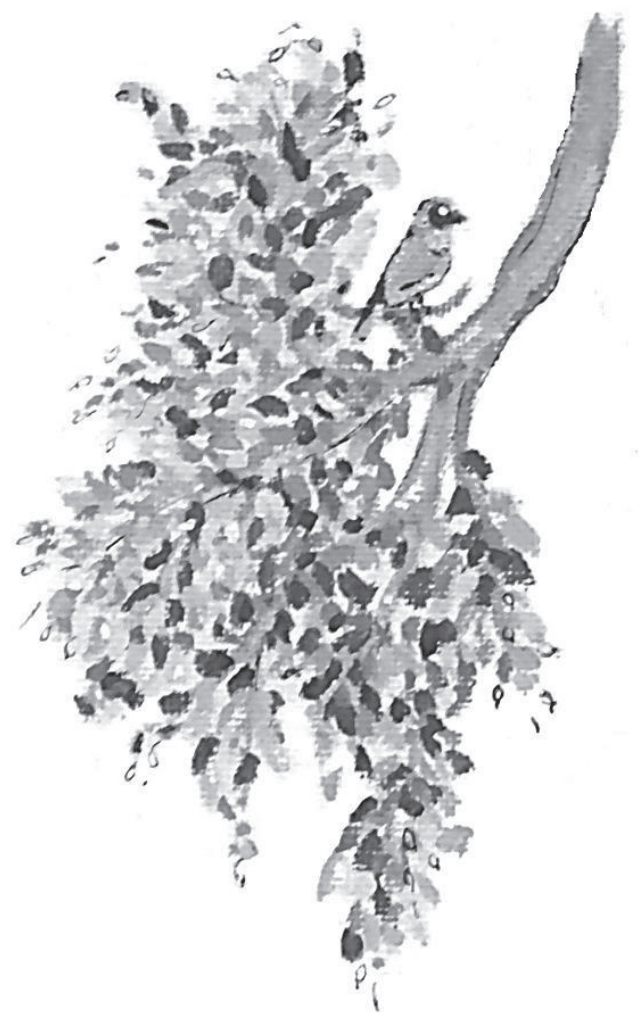





\section{Valorisation}

Valorisation is the process of creating value out of knowledge. It is about translating scientific knowledge into practice. The societal value of the different studies in this dissertation is already discussed in the individual chapters. We now summarise the implications of the major findings of this dissertation. We will discuss this in three parts: societal relevance, target groups, products and innovation, and realisation.

\section{Societal relevance}

As described previously in this dissertation, COPD is a major public and individual health problem. In the Netherlands, around 607,000 people had COPD in $2015^{1}$. Due to exacerbations and comorbidities a lot of these patients end up in hospital every now and then. Besides, approximately 6,400 people died in the Netherlands in 2015 with COPD as the primary cause ${ }^{1}$. Due to sick leave and premature disability or death this results in a huge economic burden; in the Netherlands, smoking-related health care costs amount around 3 billion euro ${ }^{1}$, while costs for COPD and asthma care amount more than 1.5 billion euro ${ }^{1}$. Giving up smoking is the most effective way to prevent the disease from worsening and, therefore, delay premature disability and death ${ }^{2,3}$. However, in the general discussion (Chapter 7) we described that many smokers are not able to quit due to psychological and social factors. Thus, it is of utmost importance for patients with COPD to be supported in their attempts to quit smoking. We will discuss how this support can be effectively offered.

\section{Target groups, products and innovation}

\section{Physicians and other health care providers}

The first health care contact with smokers is often with the general practitioner. Therefore, general practitioners are a significant target group to discuss smoking behaviour with patients and support them with quitting. In the Netherlands, practice nurses expand their activities increasingly and most practices also facilitate nurses for support. These nurses are often the right persons to offer smoking cessation support to the patients. Most of the chronic care, including COPD care, is delivered by practice nurses as well, which makes them the designated person to provide smoking cessation treatment to smokers with COPD. For smoking cessation support in general practice the smoking cessation guideline from the Dutch College of General Practitioners is 
most often used ${ }^{4}$. Unfortunately, a lot of physicians do not seem to comply with these guidelines.

In Chapter 4 and 6 we gained further insight into the quality of the smoking cessation support from physicians. We found that autonomy was very important for smokers in general and patients with COPD in particular requested a less paternalistic doctorpatient communication. They also indicated they would appreciate receiving some personal attention from their physicians, with exploration of social interactions, health perceptions, feelings and concerns. Physicians, on the other hand, indicated they needed tools and guidance in how to support smokers with quitting. Therefore, we would recommend introducing an informative smoking cessation program with teaching of evidence-based smoking cessation treatments and communication, into the vocational training and postgraduate medical training. Because, if doctors are not well-informed and motivated, then how can patients be?

\section{Guideline developers}

The previously mentioned smoking cessation guidelines, used in general practices, discuss general smoking cessation issues and attitudes. We would suggest to add patient-specific advices to these general guidelines, such as paying special attention to discuss depressive symptoms, nicotine dependence and self-efficacy, as these factors might be COPD-specific barriers to quitting. This might also be useful for other specific groups of patients. Therefore, it would be useful to further map out which specific patients need what kind of specific attention.

\section{Services}

In the introduction of this chapter we already mentioned that smoking cessation treatments that are provided are not often used, and we know from this dissertation that lack of time and experience (Chapter 6) are often mentioned as barriers for providing smoking cessation advice. It might therefore be interesting to look into the effectiveness of smoking cessation support services. At the moment the United Kingdom (UK) offers the world's most comprehensive support for smokers to quit ${ }^{5}$. Stop Smoking Services have been established throughout the UK. Some are under local authority control, others remain as part of the National Health Services. These services offer practical support and pharmaceutical treatments on prescription to help smokers to give up at no or very low cost ${ }^{5}$. These services show great promise. In the 
Netherlands, we do not have such large-scale services. The ones that we have are rather hard to find and not free of cost. It is interesting to notice that we do have clinics with multidisciplinary treatment of eating disorders or other drug addictions. Unfortunately, for nicotine addiction there are no such facilities and on the basis of the results of this dissertation we would argue in favour of such service facilities.

\section{Government}

Governments have the obligation to care for the health of the residents. Governmental actions such as raising taxes are extremely cost-effective interventions to reduce tobacco use and prevent COPD ${ }^{6}$. The tobacco industry contradicts this information, but their arguments are not evidence-based. They state that raising taxes will lead to more illicit trade and smuggling. The only evidence that does exist is that increase in cigarette taxes and the passage of comprehensive clean air laws are the cornerstone of strategies that have been successful in reducing smoking rates ${ }^{6}$. These tax revenues could then be used for tobacco control, health promotion and other public health interventions. Mass media campaigns and cessation policies also play an important role in reducing the smoking rates ${ }^{6}$. In the Netherlands, we saw that a national reimbursement policy accompanied by media attention was followed by an increase in quit attempts and quit rates ${ }^{7}$. An increased use of cessation treatments was one of the reasons for this ${ }^{8,9}$. Furthermore, as previously mentioned, in the Netherlands, commercial cessation methods are widely promoted and people lack knowledge of evidence-based smoking cessation treatments ${ }^{10}$. Therefore, it is highly recommended that evidence-based smoking cessation methods are promoted and alternative, nonevidence-based treatments, are not advocated. Campaigns on the health consequences of smoking are very important too.

\section{Realization}

We will discuss the main findings from this dissertation with the vocational training institute with the recommendation of introducing an informative smoking cessation program. We can assist in the development of such a training program. Furthermore, we will advise the Dutch College of General Practitioners guideline panel to consider adding COPD-specific elements to the next update of the smoking cessation guideline. We advise researchers to further map out which additional information is needed in the guideline for other specific patient groups. 


\section{References}

1. Volksgezondheidenzorg.info. www.volksgezondheidenzorg.info. RIVM: Bilthoven. Accessed 3 April 2017.

2. From the Global Strategy for the Diagnosis, Management and Prevention of COPD, Global Initiative for Chronic Obstructive Lung Disease (GOLD) 2015. http://goldcopd.org. Accessed 17 November 2015.

3. Anthonisen N.R., Connett J.E., Murray R.P. Smoking and lung function of Lung Health Study participants after 11 years. Am J Respir Crit Care Med. 166, 675-679 (2002).

4. Chavannes N.H., Kaper J., Frijling B.D., Van der Laan J., Jansen P., Guerrouj S., et al. NHG-Standaard Stoppen met roken. Huisarts Wet. 50, 306-314 (2007).

5. Lifestyles Statistics Team H.a.S.C.I.C. Statistics on NHS Stop Smoking Services in England. 2015.

6. Levy D.T., Chaloupka F., Gitchell J. The effects of tobacco control policies on smoking rates: a tobacco control scorecard. J Public Health Manag Pract. 10, 338-353 (2004).

7. Nagelhout G.E., Willemsen M.C., van den Putte B., de Vries H., Willems R.A., Segaar D. Effectiveness of a national reimbursement policy and accompanying media attention on use of cessation treatment and on smoking cessation: a real-world study in the Netherlands. Tob Control. 0, 1-7 (2014).

8. Verbiest M.E., Chavannes N.H., Crone M.R., Nielen M.M., Segaar D., Korevaar J.C., et al. An increase in primary care prescriptions of stop-smoking medication as a result of health insurance coverage in the Netherlands: population based study. Addiction. 108, 2183-2192 (2013).

9. Willemsen M.C., Segaar D., van Schayck O.C. Population impact of reimbursement for smoking cessation: a natural experiment in The Netherlands. Addiction. 108, 602-604 (2013).

10. Willems R.A., Willemsen M.C., Smit E.S., Nagelhout G.E., Janssen E., de Vries H. Which smoking cessation aids are proven effective according to smokers who want to quit smoking? A report from the Netherlands. Tob Control. 23, 525-526 (2014). 
Dankwoord

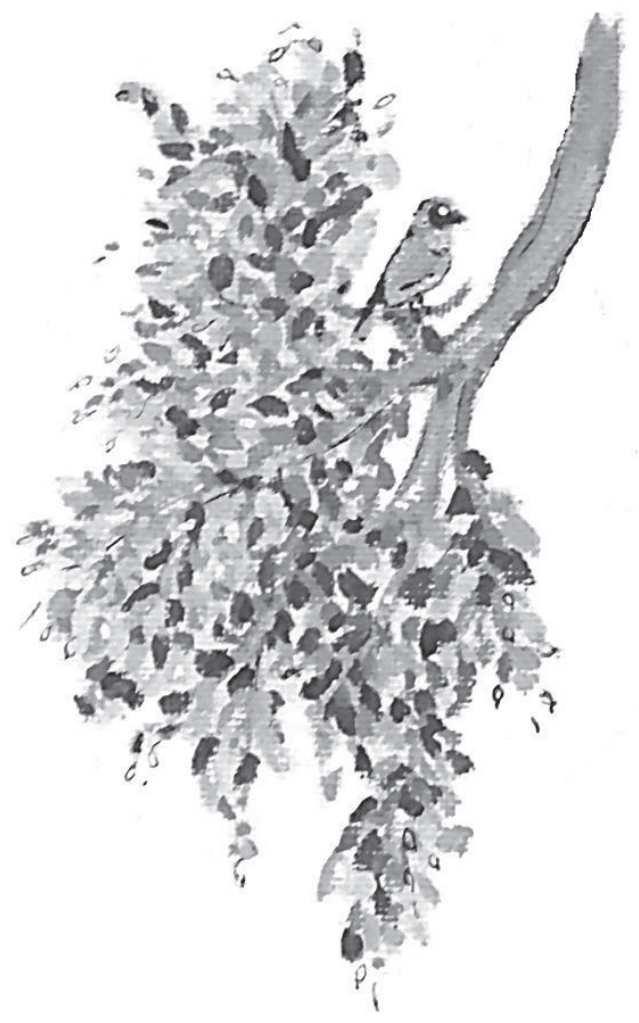





\section{Dankwoord}

Het begon allemaal Down Under in het Lyell McEwan Hospital in Adelaide, waar ik bij de Obstetrie onderzoek deed naar te kleine baby's in de moederbuik. Dat het huisartsenvak me boeide stond als een paal boven water, maar dat onderzoek doen zo leuk kon zijn, overviel me. En dat je dan 6 jaar lang deze twee super leuke banen mag combineren was een geschenk uit de hemel. Dus terwijl de kangoeroes nog om me heen hopten, wist ik het al zeker; ik wil AIOTHO (arts in opleiding tot huisarts en onderzoeker) worden. Alleen al omdat het zo exotisch klinkt. Bij terugkomst in ons koude kikkerlandje ben ik snel naar het zonnige zuiden afgereisd om mijn AIOTHO avontuur te beginnen in het Nederlandse Down Under...

Dankzij Onno. Jij had het al snel gezien (na één gesprek): ik was geschikt voor het onderzoeksproject en als het aan jou lag, kon ik meteen aan de slag. Na onze eerste kennismaking stuurde je me meteen langs de huisartsenopleiding om daar zaken te doen. Het begin was gemaakt. Helaas leverde het onderzoeksproject niet het gewenste promotietraject op, maar het verschafte mij wel inzicht in wat ik wél en niet wilde. Onno, jij hebt ervoor gezorgd dat ik naar Maastricht ben gekomen, waarvoor mijn dank. Ik heb hier de afgelopen jaren zeer waardevolle ervaringen opgedaan. Fijn dat je vertrouwen in me bleef houden ondanks dat ons eerste project tegenviel. Uiteindelijk hebben we onze samenwerking na een jaar pauze voortgezet en heb je me met Daniel in contact gebracht en dat was een schot in de roos.

Daniel. Van jou was oorspronkelijk het idee om te kijken of COPD patiënten anders zijn dan 'gewone' rokers. De SBOH (werkgever voor huisartsen in opleiding) vond dit ook een interessant onderzoek en je mocht hiervoor een geschikte AIOTHO kandidaat zoeken. Dat je mij als die kandidaat zag om promovendus te worden op dit project, vereerde me. Over jou had ik niets dan goeds gehoord, dus ik had er vertrouwen in dat dit project zou slagen. Voor mij ben je de perfecte begeleider. Met nadruk op perfectie. Ik kan altijd bij je terecht als ik vragen heb. Je geeft constructief en weloverwogen commentaar en gaf me de vrijheid het project naar eigen inzicht te organiseren. Terugkijkend naar de afgelopen jaren, kan ik me de tegenslagen niet eens meer goed herinneren. Ik weet dat ze er waren, maar het allesoverheersende gevoel is: we did it!

Bij het overdenken van de afgelopen zes jaar, springt ook de samenwerking met Noorwegen eruit als heel mooie ervaring. Mark, jij bracht mij in contact met Mette en 
haalde me vervolgens over om ook eens naar Noorwegen te gaan om haar daadwerkelijk te ontmoeten en de samenwerking te versterken. Dit beviel zo goed van beide kanten dat we de samenwerking hebben voortgezet en ik ondertussen alle seizoenen in Noorwegen heb mogen meemaken: van midzomernacht zon tot bijna totale duisternis, maar mét het Noorderlicht. Het is een bijzonder land met bijzondere mensen en ik ben heel dankbaar dat ik hier kennis mee heb mogen maken. Ons laatste bezoek aan Troms $\varnothing$ zal me nog het langste bijblijven: de grote hoeveelheid orka's die we gezien hebben was indrukwekkend (de goede gesprekken tijdens het avondeten ook!).

Perhaps less impressive than meeting the orcas, but certainly more important was meeting you, Mette. I am really happy I met you. Thank you a lot for explaining qualitative research in 'Jip en Janneke-taal' (easy language). I would have gone lost in the web of qualitative literature without you. You gave me direction when I drowned in all the information and took the time to skype with me to guide me. I really appreciate what you have done for me. Thanks to you I could also use very interesting data from the PEXACO study (a rich database of focus group discussions about COPD care in Europe and Asia), which enriched my dissertation.

Van de totale zes jaar van het AIOTHO-traject ben ik de helft van de tijd bezig geweest met het 'updaten' van de Cochrane review uit Hoofdstuk 2. Dit 'updaten' bleek uiteindelijk het schrijven van een geheel nieuwe Cochrane review. Regina, heel fijn dat ik dit samen met jou kon doen. Het koste ons drie jaar van ons leven maar dan heb je ook wat. Steeds als ik dacht dat het einde in zicht was, moest er weer iets gewijzigd worden of kwam er een nieuwe search update. Ik dacht soms echt dat er nooit meer een einde aan zou komen. Gelukkig had ook jij, Regina, een lange adem en ik ben heel blij met het resultaat. Ik waardeer het bijzonder dat je je vrije tijd hierin wilde steken, want zonder jou had ik niet geweten hoe soms verder te gaan. Nu nog maar even niet denken aan de nieuwe search update die binnenkort weer in mijn inbox zal verschijnen!

Met betrekking tot de PheSmoC studie wil ik nog een aantal mensen bedanken: Carolien, jij had al een mooie voorzet gemaakt voor de opzet van die studie. Je had al nagedacht over de vragenlijsten en interviews en een heleboel contacten gelegd die voor mij van pas zouden komen. In het begin kon ik op je terugvallen en toen ik op 
eigen benen kon staan, heb ik het project verder uitgewerkt. Hilde, dank voor je hulp en interesse, en natuurlijk ook voor de gezelligheid. Geertjan Wesseling, bedankt voor het meedenken in de beginfase van de PheSmoc studie. Karin (Aretz), dankjewel voor de hulp bij het hanteren van SPSS. Natuurlijk gaat ook heel veel dank uit naar Stichting Gezondheidscentra Eindhoven (SGE) alwaar ik alle data verzameld heb. Daarnaast waren de dames op het bedrijfsbureau ontzettend behulpzaam waardoor het versturen en ontvangen van de vragenlijsten, ondanks obstakels, goed is verlopen. En zoals altijd, zonder patiënten geen onderzoek! Dank voor alle medewerking.

Naast al deze mensen die direct betrokken waren bij de onderzoeksprojecten, waren er nog heel veel andere collega's belangrijk voor mij tijdens deze zes jaar. Als ik bij mijn eerste dag op het Deb begin, moet ik aan jou denken, Merijn. Jij was immers mijn eerste kamergenoot. Jij maakte me wegwijs in het Deb leven. Jouw rust en Brabantse gastvrijheid heeft me goed gedaan. Je nam de tijd voor serieuze gespreksonderwerpen maar ik heb ook veel met je kunnen lachen. Ik vond het heel jammer om je te zien gaan. Gelukkig kon de leegte die je achterliet deels opgevuld worden door een nieuwe buddy...Eef! We begonnen samen aan ons promotietraject en herkenden dus elkaars beslommeringen. Ik moest even wennen aan een nieuwe kamergenoot, maar nu kan ik niet meer zonder! Daarom sta je tijdens de promotie ook aan mijn zijde als paranimf. Ik heb heel veel bewondering voor jouw kwaliteiten als onderzoeker maar ook als arts. Er zijn maar weinig vraagstukken waar jij geen oplossing voor vindt. (Zelfs de 'nine dots' puzzel van de mindfulness cursus was niet veilig voor je.) Je bijt je vast in alles wat op je pad komt en daarmee (ben en) ga jij heel ver (ge)komen. Heel leuk vind ik het ook dat ik je op de fiets heb gekregen (althans met die eer strijk ik graag). Ik hoop in ieder geval dat we nog vele fietstochtjes samen gaan maken (op een nieuwe fiets?).

Lieve kamergenoten, Nicole en Krista, het was me een waar genoegen de laatste maanden als AIOTHO met jullie te mogen doorbrengen op één AIOTHO-kamer. We boden elkaar een luisterend oor indien nodig, we hielpen elkaar en konden samen lachen. Soms was het wel een kippenhok als we er met zijn vieren tegelijk waren, maar het voelt écht als thuiskomen in onze kamer en dat is het belangrijkste. Een plek waar we lekker onszelf kunnen zijn, in goede en in slechte tijden. Ik ga jullie missen!

Dan zijn er natuurlijk nog een heleboel collega's die op wat voor manier dan ook hebben bijgedragen aan het werkplezier hier op het Deb: Annerika, Esther, Anneke, 
Angel, Kirsten, Jean-Marie, Anouk, Floor, Maartje, Tineke en Ruud. Bedankt voor de gezellige wandelingen, de luisterende oren en constructieve feedback. Dankjewel Karin (Vaessen), voor de organisatie rondom de laatste fase van mijn promotietraject. En niet te vergeten, Ine, dank voor al je hulp, en voor je kritische blik op (en vaak ook complimentjes over) mijn outfits.

En dan, mijn allerbeste maatje vanaf de basisschool, Lidy! Wat ben ik je ouders dankbaar dat jullie naar Heeswijk-Dinther verhuisden en jij bij mij in de klas kwam. Tijdens mijn promotie sta je ook naast me als paranimf, hoe kan het ook anders. Onafscheidelijk zijn we sinds de middelbare school; naast elkaar zitten in de klas, altijd samen in de pauzes en samen weer naar huis. En alsof dat nog niet genoeg was, gingen we ook na school leuke dingen doen met elkaar of schreven elkaar brieven. Dezelfde kleding en hetzelfde kapsel. Ondanks dat we zo op elkaars lip zaten (en jij mijn schoen vies had gemaakt :P) was en blijf je mijn beste maatje. Na de middelbare school scheidden onze wegen enigszins, maar op één of andere manier maakten we veel dezelfde keuzes en groeiden we niet uit elkaar: we studeerden allebei geneeskunde, hebben vervolgens een tijd gereisd en uiteindelijk werden we allebei AIOTHO! We werden allebei verliefd op een Zuid-Amerikaan en vorig jaar nog hadden we samen een geweldige tijd tijdens het NAPCRG congres in Colorado. Lidy, onze vriendschap is van onschatbare waarde en maakt me heel blij.

Dan nu de allerlaatste dankwoorden en deze zijn gericht aan mijn familie. Allereerst, tante Godelieve. Jij hebt het ontwerp verzorgd van de omslag van mijn boekje. Ter herinnering aan papa, jouw broer, wilde ik graag een symbolische maar ook informatieve kaft. Het was even puzzelen, maar het resultaat mag er wezen. Voor mij betekent het heel veel dat iemand die zo dicht bij mijn vader staat, zo'n mooie bijdrage heeft willen leveren aan mijn proefschrift. Mascha, jou wil ik bedanken voor het bewerken van de kaft zodat het helemaal perfect is geworden.

Michiel, Rutger en Arthur, mijn broers. Jullie vroegen je al af waarvoor ik jullie zou bedanken. En specifiek voor dit proefschrift zou ik dat ook niet weten, maar ik ben heel gelukkig met zo'n leuke, gezellige en grappige broers, waar ik altijd op terug kan vallen. Leuk Michiel dat je tegenwoordig ook in de medische wereld je werkzaamheden verricht en ik soms gebruik kan maken van de apps/websites die jij maakt. Rutger, fantastisch dat we je op de fiets hebben gekregen (wederom even strijken met de eer) 
en dat je vorig jaar voor het eerst een rondje Limburg mee hebt gepeddeld. Ik hoop dat er nog vele volgen! Arthur (en Marieke), speciaal bedankt dat jullie Tristan op de wereld hebben gezet; want tante zijn van zo'n leukerd is echt een verrijking.

Eric, liefde van mijn leven. Hoe ik een Surinaamse blije vogel in Maastricht heb gevonden, is me nog steeds een raadsel, maar het was een zeer waardevolle vondst. Samen met jou is het leven nóg leuker. De laatste tijd bevonden we ons in een rollercoaster van fantastische gebeurtenissen; we kochten samen een nieuwbouwhuis dat onlangs werd opgeleverd, ik rondde mijn opleiding af en startte mijn eerste baan als huisarts. Ik rondde mijn proefschrift af en als klap op de vuurpijl zijn we op 6 februari ook nog man en vrouw geworden! Niets van dit alles had ik willen missen, maar ik kijk erg uit naar wat rust na mijn promotie zodat we ook daadwerkelijk van ons mooie huis kunnen genieten. Het AIOTHO traject bleef voor jou nog vaak een mysterie, maar dat weerhield je er echter niet van mij te ondersteunen waar je kon: je luisterde naar mijn overwegingen en twijfels en je steunde me als ik nerveus of onzeker was. Mattie, ik wil je nooit meer kwijt. Lobi you, mi gudu.

Lieve mama, jou wil ik bedanken voor je bijdrage aan mijn kennis; jij leest alles wat los en vast zit en filtert daaruit altijd alle relevante informatie voor mij. Als ik thuis kom wacht mij weer een stapel 'wetenschaps-journalistiek'. Jij zorgde er dus voor dat ik upto-date bleef op mijn onderzoeksgebied en met betrekking tot het huisartsen-vak. Mama, jij hebt me van begin af aan gesteund, letterlijk en figuurlijk. Eerst zie ik ons nog thuis rondspringen van geluk toen ik hoorde dat ik nageplaatst was voor de geneeskunde opleiding. Later vertrok ik naar Australië, wat je in het begin niet gemakkelijk vond, maar deze kans werd mede dankzij jou mogelijk gemaakt. Hier ben ik je nog altijd dankbaar voor. Mede dankzij jouw steun en het voorbeeld dat jij mij gaf om door te zetten als dingen tegen zitten, heb ik mijn AIOTHO traject zo succesvol doorlopen.

Tot slot, papa, wat vind ik het verdrietig dat je er niet bij kunt zijn nu er zoveel indrukwekkende gebeurtenissen plaatsvinden in mijn leven. Altijd ben ik nieuwsgierig geweest naar hoe jij tegen belangrijke gebeurtenissen aan zou kijken en ik denk dat ik heel veel van je had kunnen leren. Ooit schreef je zelf een boekje dat je opdroeg aan Arthur en mij. Het leek me dus vanzelfsprekend dat ik mijn boekje aan jou zou opdragen. 

Curriculum vitae

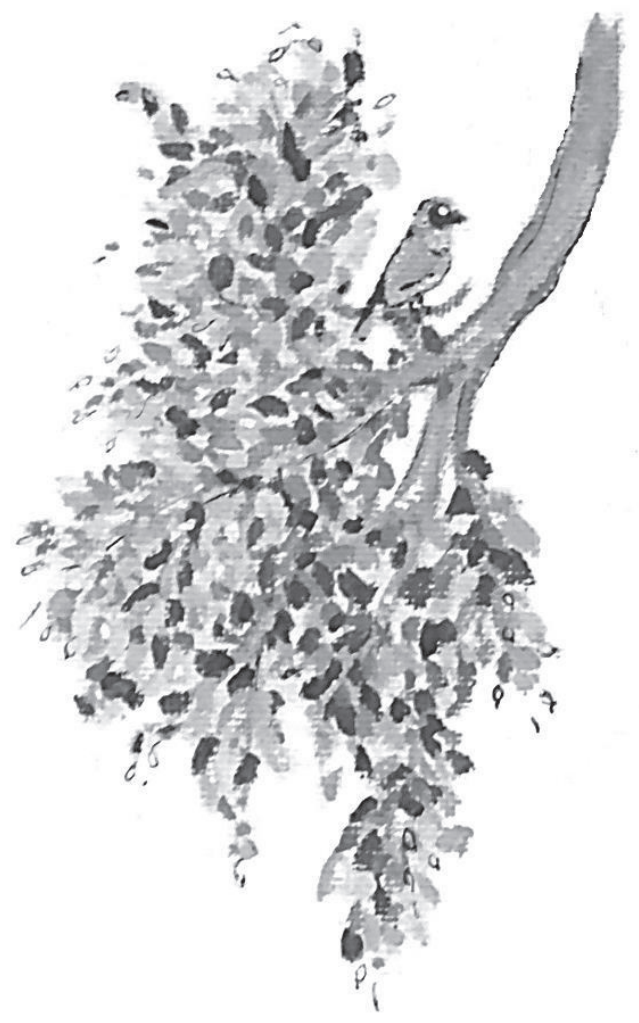





\title{
Curriculum vitae
}

\author{
Er was eens een meisje in Dinther \\ Dat werd geboren in het hartje van de winter \\ Juist toen de Elfstedentochters over de finish gleden \\ Zei haar moeder 'Och heden' \\ Volgens mij komt het kind er
}

John van Eerd

Eva van Eerd was born in Heeswijk-Dinther, the Netherlands, on February 21, 1985. She was de youngest of four and the only girl in the family. In her birth town in Brabant she attended primary school and also got her high school certificate from Gymnasium Bernrode, in 2003. After high school she was given a place to study medicine at the Free University of Amsterdam, were she was also living at that time. During her studies she was collaborating on scientific research in plastic surgery and child psychiatry. She qualified as a medical doctor in 2009 and started living in Adelaide, Australia for one year. She participated in research at the

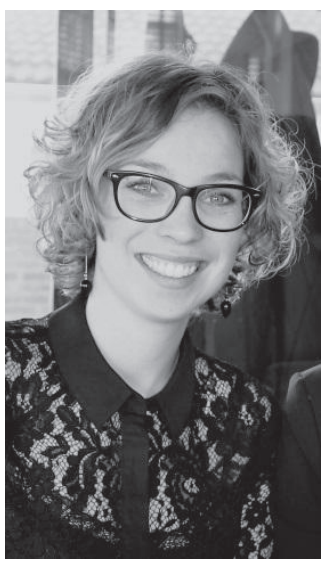
Gynaecology and Obstetrics department of the Lyell McEwan Hospital for six months. The following six months she spend traveling around Australia and New Zealand.

Back in the Netherlands, in 2011, she started a research project at Maastricht University on COPD patients' self-management. Later that year she also began her Family Medicine Specialty Training. Simultaneous to this traineeship she started a PhD trajectory at Maastricht University in 2012. During this trajectory she collaborated with researchers from The Arctic University of Troms $\varnothing$ in Norway. Eva started working as a Family doctor in Eijsden in April this year.

From 2011 onwards Eva is biking through life (and the beautiful landscape of Limburg) with her soulmate Eric. 

Publications

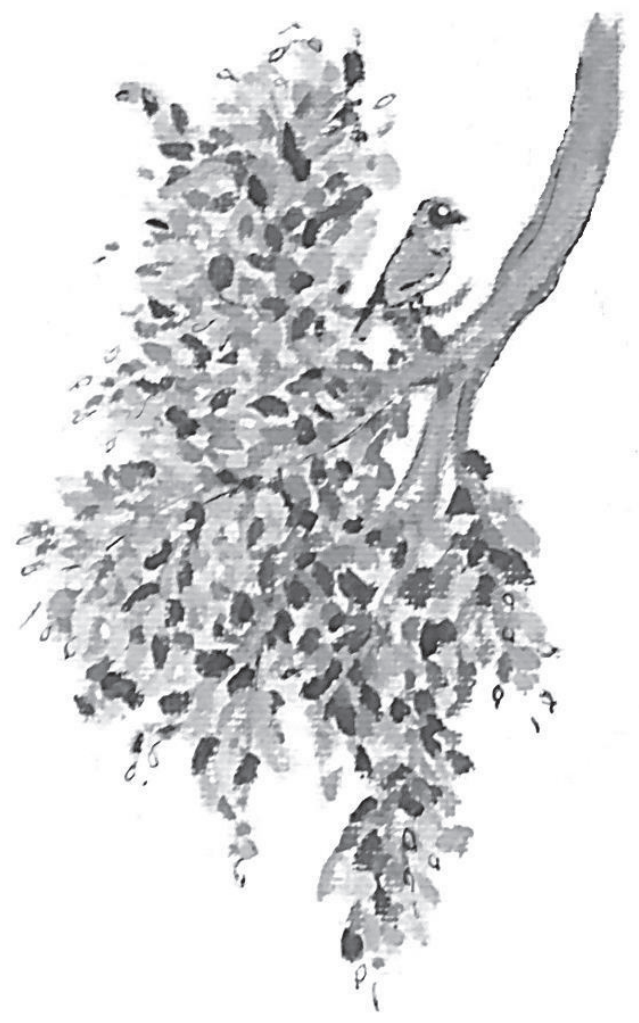




\section{Publications}

1. Eva van Eerd. Zuurstoftherapie kan verademing zijn. Huisarts Wet. 60, 6 (2017)

2. van Eerd EAM, van Schayck OCP, Wesseling G, Kotz D. Predictors of long-term smoking cessation in patients with COPD: results from a randomised controlled trial. Eur Respir J. (2017) Accepted.

3. van Eerd EAM, Bech-Ris $\varnothing r$ M, Spigt M, Godycki-Cwirko M, Andreeva E, Francis N, Wollny A, Melbye $\mathrm{H}$, van Schayck OCP, Kotz D. Why do physicians lack engagement with smoking cessation treatment in their COPD patients? A multinational qualitative study. npj Prim Care Respir Med. (2017) Accepted.

4. Eva van Eerd, Daniel Kotz. Mobiele telefoon effectief bij stoppen met roken. Huisarts Wet. 59, 12 (2016).

5. van Eerd EAM, van der Meer RM, van Schayck OCP, Kotz D. Smoking cessation for people with chronic obstructive pulmonary disease (Review). Cochrane Database Syst Rev. 8, CD010744 (2016).

6. Emmylou Beekman, Ilse Mesters, Mark Spigt, Eva van Eerd, Rik Gosselink, Rob de Bie and Onno van Schayck. Phenotypic variation in patients with chronic obstructive pulmonary disease in primary care. BioMed Res Int. 2016, 8108717 (2016).

7. van Eerd EAM, Bech-Risør M, van Rossem CR, van Schayck OCP, Kotz D. Experiences of tobacco smoking and quitting in smokers with and without chronic obstructive pulmonary disease - a qualitative analysis. BMC Fam Pract. 16, (2015).

8. van Eerd EAM, van Rossem CR, Spigt M, Wesseling G, van Schayck OCP, Kotz D. Do we need tailored smoking cessation interventions for smokers with COPD? A comparative study of smokers with and without COPD regarding factors associated with tobacco smoking. Respiration. 90, 211-219 (2015).

9. van Eerd EAM, Kotz D. Stop-roken interventies op maat voor rokers met COPD? CAHAG, COPD \& Astma Huisartsen Advies Groep. COPD \& Astma bulletin huisartsgeneeskunde. 2, (2015). 
10. van Eerd EAM, van der Meer RM, Reda AA, van Schayck OCP, Kotz D. Smoking cessation in smokers with chronic obstructive pulmonary disease (Protocol). Cochrane Database Syst Rev. 9, CD010744 (2013).

11. van Eerd EAM, Roex AJ, Nikpoor P, Dekker GA. Adverse perinatal outcome and maternal risk factors in population versus customized defined SGA babies. J Matern Fetal Neona. 25, 369-373 (2012).

12. Roex AJ, Nikpoor P, van Eerd EAM, Hodyl N, Dekker GA. Serial plotting on customised fundal height charts results in doubling of the antenatal detection of small for gestational age fetuses in nulliparous women. Aust N Z J Obstet Gynaecol. 52, 78-82 (2012).

13. van Eerd EAM, van Schayck OCP, Chavannes NH, van der Molen T. Self-management programs for Chronic Obstructive Pulmonary Disease. US Respir Dis. 8, 17-22 (2012). 
